\title{
Site-specific PEGylation of interleukin-2 enhances immunosuppression via the sustained activation of regulatory T cells
}

\author{
Bo Zhang ${ }^{1,2,8}$, Jiaqi Sun ${ }^{2,8}$, Yan Wang ${ }^{2,8}$, Dezhong Ji ${ }^{2,8}$, Yeshuang Yuan ${ }^{3,4,8}$, Shengjie Li ${ }^{1}$, Yeting Sun ${ }^{1,5}$, \\ Yingqin $\mathrm{Hou}^{6}$, Pengchong Li ${ }^{1,5}$, Lidan Zhao, ${ }^{1,5}$, Fei Yu², Wenxiao Ma ${ }^{2}{ }^{2}$, Boyang Cheng ${ }^{2}$, Ling Wu ${ }^{2}$, \\ Jin $\mathrm{Hu}^{1}$, Min Wang ${ }^{3,4}$, Wei Song ${ }^{1}$, Xiaogang Li', Hao Li ${ }^{7}$, Yunyun Fei ${ }^{1,5}$, Hua Chen ${ }^{1,5}$, Lihe Zhang ${ }^{2}$, \\ George C. Tsokos ${ }^{7 凶}$, Demin Zhou ${ }^{2 凶}$ and Xuan Zhang ${ }^{4 凶}$
}

The preferential activation of regulatory $T\left(T_{\text {reg}}\right)$ cells by interleukin-2 (IL-2), which selectively binds to the trimeric IL-2 receptor (IL-2R) on $\mathbf{T}_{\text {reg }}$ cells, makes this cytokine a promising therapeutic for the treatment of autoimmune diseases. However, IL-2 has a narrow therapeutic window and a short half-life. Here, we show that the pharmacokinetics and half-life of IL-2 can be substantially improved by orthogonally conjugating the cytokine to poly(ethylene glycol) (PEG) moieties via a copper-free click reaction through the incorporation of azide-bearing amino acids at defined sites. Subcutaneous injection of a PEGylated IL-2 that optimally induced sustained $\mathbf{T}_{\text {reg }}$-cell activation and expansion over a wide range of doses through highly selective binding to trimeric IL-2R led to enhanced therapeutic efficacy in mouse models of lupus, collagen-induced arthritis and graft-versus-host disease without compromising the immune defences of the host against viral infection. Site-specific PEGylation could be used more generally to engineer cytokines with improved therapeutic performance for the treatment of autoimmune diseases.

A utoimmune diseases (ADs), such as systemic lupus erythematosus (SLE) and rheumatoid arthritis (RA), are characterized by a loss of immune tolerance accompanied by a decrease in $\mathrm{T}_{\text {reg }}$-cell function and uncontrolled effector $\mathrm{T}\left(\mathrm{T}_{\text {eff }}\right)$-cell expansion due to a dysregulated IL-2 response ${ }^{1,2}$. It has been well established that IL-2 binds to its trimeric receptor (IL-2R; comprising IL-2R $\alpha$, IL-2R $\beta$ and IL-2R $\gamma$ ) with high affinity and to dimeric IL-2R (comprising IL-2R $\beta$ and IL-2R $\gamma$ ) with moderate affinity. Trimeric IL-2Rs are typically expressed at high levels on $\mathrm{T}_{\text {reg }}$ cells, activated effector $\mathrm{T}$ cells and innate lymphoid cells ${ }^{2}$, whereas the dimeric form of IL-2R is expressed mostly on resting natural killer (NK) cells and $\mathrm{CD}^{+} \mathrm{T}$ cells, which renders $\mathrm{T}_{\text {reg }}$ cells highly sensitive to IL-2 (refs. ${ }^{2,3}$ ). This sensitivity leads to preferential activation and subsequent expansion of $\mathrm{T}_{\text {reg }}$ cells in response to treatment with a low dose of IL-2 (refs. ${ }^{1,2}$ ).

Given this essential role of IL-2 in $\mathrm{T}_{\text {reg }}$ homeostasis and immune regulation, low-dose IL-2 treatment has been evaluated in clinical trials for numerous ADs, including SLE, RA, type I diabetes (T1D) and graft-versus-host disease (GvHD) ${ }^{4-12}$. Although low-dose IL-2 treatment preferentially activates $\mathrm{T}_{\text {reg }}$ cells and might be therapeutically beneficial in ADs, high-dose IL-2 treatment paradoxically activates cytotoxic lymphocytes, which may exacerbate $\mathrm{ADs}^{2,12}$. Moreover, IL-2 is cleared very rapidly from the body due to its low molecular mass $(\sim 15 \mathrm{kDa})^{13}$. Thus, to preferentially activate $\mathrm{T}_{\text {reg }}$ cells over $\mathrm{T}_{\text {eff }}$ cells, low-dose IL-2 must be administered daily to maintain low but adequate serum levels, which are technically difficult to achieve $^{1}$. The development of new and feasible strategies that ensure the IL-2-mediated selective activation of $\mathrm{T}_{\text {reg }}$ cells is therefore critical to achieve a favourable treatment response in patients with ADs.

Numerous approaches that exploit the differential expression patterns of IL-2Rs on functionally distinct T-cell subsets have been developed in an effort to address this problem ${ }^{14-27}$. On the basis of the quaternary structure of IL-2 assembled to its trimeric receptor, a series of IL-2 muteins with variable affinity to IL-2R $\alpha^{21,22}$ or IL-2 $\beta \gamma^{15,16,23,24}$ have been developed. IL-2-anti-IL-2 immunocomplexes have also been designed to redirect IL-2 towards functionally distinct T-cell subsets and to increase the half-life of IL-2. For example, mouse monoclonal antibodies (JES6-1 and S4B6) that sterically block mouse IL-2 (mIL-2) binding to the $\beta$ and $\alpha$ subunits-therefore endowing mIL-2-antibody complexes with the ability to selectively activate $\mathrm{T}_{\text {reg }}$ and $\mathrm{T}_{\text {eff }}$ cells, respectively ${ }^{14,28}$ - have been developed. It has also been reported that the generation of anti-human IL-2 antibodies that formed IL-2-antibody complexes were able to stimulate $\mathrm{CD} 8^{+} \mathrm{T}_{\text {eff }}$ cells in mice ${ }^{26,27}$ or $\mathrm{T}_{\text {reg }}$ cells in mice $^{20}$ and non-human primates ${ }^{25}$ in vivo, consequently enhancing their effectiveness in the treatment of cancer or ADs. However, the

'State Key Laboratory of Complex Severe and Rare Diseases, Peking Union Medical College Hospital, Chinese Academy of Medical Sciences and Peking Union Medical College, Beijing, China. ${ }^{2}$ State Key Laboratory of Natural and Biomimetic Drugs, School of Pharmaceutical Sciences, Peking University, Beijing, China. ${ }^{3}$ Graduate School of Peking Union Medical College, Chinese Academy of Medical Sciences and Peking Union Medical College, Beijing, China. ${ }^{4}$ Department of Rheumatology, Beijing Hospital, National Center of Gerontology, Institute of Geriatric Medicine, Clinical Immunology Center, Graduate School of Peking Union Medical College, Chinese Academy of Medical Sciences and Peking Union Medical College, Beijing, China. ${ }^{5}$ The Ministry of Education Key Laboratory, Department of Rheumatology and Clinical Immunology, Peking Union Medical College Hospital, Chinese Academy of Medical Sciences and Peking Union Medical College, Beijing, China. ${ }^{6}$ Beijing National Laboratory for Molecular Sciences, Center for Soft Matter Science and Engineering, Peking University, Beijing, China. 'Division of Rheumatology and Clinical Immunology, Beth Israel Deaconess Medical Center, Harvard Medical School, Boston, MA, USA. ${ }^{8}$ These authors contributed equally: Bo Zhang, Jiaqi Sun, Yan Wang, Dezhong Ji, Yeshuang Yuan. 凶e-mail: gtsokos@bidmc.harvard.edu; deminzhou@bjmu.edu.cn; zxpumch2003@sina.com 
stability of IL-2-antibody complexes in the circulation remains an important issue in clinical application ${ }^{19,29}$. An alternative initiative involving IL-2 fused to antibodies or IL-2R $\alpha$ directly ${ }^{17,19,30}$ or permanently grafted IL-2 to the binding groove of an anti-human-IL-2 monoclonal antibod ${ }^{29}$ has been considered to overcome the limitations of cytokine-antibody complexes.

PEGylation is a chemical process through which inert PEG moieties are conjugated covalently to a protein molecule through interactions with constituent amino acids, including lysine, histidine and cysteine $^{31}$. PEGylation provides further advantages over antibodies and fusion approaches because it not only slows the rapid renal clearance of IL-2 by increasing its hydrodynamic volume but it also has the potential to substantially alter the binding of IL-2 to individual IL-2R subunits if designed appropriately to block specific binding areas. NKTR-214, which is a non-site-specific PEGylated IL-2 variant with up to six randomly conjugated releasable PEG moieties that increase the molecular mass of IL-2 and reduce its renal clearance, increased the preferential activation of $\mathrm{CD}^{+} \mathrm{T}$ cells over $\mathrm{T}_{\text {reg }}$ cells ${ }^{32}$. The difficulties with PEGylation lie in the abundance of reactive amino acids, which usually results in heterogeneous conjugates with an uncontrolled number and random distribution of PEG moieties, making it a challenge to fine-tune IL-2-for example, by blocking the $\beta$ over $\alpha$ subunits - for the selective activation of $\mathrm{T}_{\text {reg }}$ cells.

A facile approach for the site-specific PEGylation of proteins of interest was recently developed by our group and by other groups ${ }^{33-36}$. Steps in this method include the genetic-code-expansion-guided incorporation of azide-bearing amino acids and the subsequent orthogonal conjugation of PEG moieties through a copper-free click reaction $^{33-38}$. Using this approach, we generated site-specific and receptor-biased PEGylated IL-2 variants carrying PEG moieties of different sizes at one or more predefined sites. These receptor-biased PEGylated IL-2 variants, particularly one with dual $20 \mathrm{kDa}$ PEG moieties at the Tyr 31 and Thr 51 sites of IL-2 (dual-31/51-20K), preferentially bind to the IL-2R $\alpha$ subunit over the $\beta$ subunit and sustainably activate $\mathrm{T}_{\text {reg }}$ cells. Compared with unmodified IL-2, dual-31/51-20K exhibited excellent treatment effects with minimal side effects across a wide range of treatment doses in mouse models of various ADs, including SLE, RA and GvHD. We conclude that $\mathrm{T}_{\mathrm{reg}}$-cell-biased IL-2 engineered through site-specific PEGylation is a promising and reliable therapeutic strategy for ADs. Ultimately, our research may lead to new pharmacologic strategies involving precision PEGylation to engineer cytokines that elicit favourable treatment responses in ADs and other diseases.

\section{Results}

Precision PEGylation of IL-2 carrying PEG moieties of different sizes at defined sites. To design an IL-2 PEGylate with reduced binding to the beta subunit of IL-2R, we first sought to identify the key residues that are involved in this binding. On the basis of the crystal structure of the IL-2-IL-2R complex ${ }^{39,40}$, a series of constitutive residues in IL-2 that are responsible for its binding to the $\beta$ subunit-including solvent-exposed Asp 20, Thr 51,
Ala 73, Lys 76 and His 79 in helix A; the BC loop; the C terminus of helix C; and the CD loop (Fig. 1a)-were selected for site-specific PEGylation. Additional residues distant from the predicted binding sites, including Tyr 31 within the $\mathrm{AB}$ loop, were also selected due to their potentially milder effects on the bioactivities of IL-2. PEGylation of each residue was performed as previously reported ${ }^{34,35}$ (Fig. 1b). In brief, the triplet codon in the IL-2 gene was mutated to an amber stop codon, and the resulting plasmid was then transformed into the Origami B(DE3) strain containing pSURAR-YAV for the site-specific incorporation of an azide-bearing amino acid $\left(N^{\varepsilon}\right.$-2-azideoethyloxycarbonyl-L-lysine (NAEK)) into IL-2. Finally, the resulting protein was conjugated in parallel with $5 \mathrm{kDa}, 10 \mathrm{kDa}$, $20 \mathrm{kDa}$ and $30 \mathrm{kDa}$ PEG moieties through a copper-free click reaction (Fig. 1b,c). The success of the site-specific incorporation of NAEK and subsequent site-specific conjugation was validated in parallel by mass spectrometry of the PEGylates (Supplementary Fig. 1a,b) and by coupling with a fluorescent probe, dibenzocycloocytyne-Cy3, to mitigate the potential disturbance from the dispersity of PEG moieties (Supplementary Fig. 1c). The results revealed that the conjugation efficiency decreased following an increase in the PEG moiety size, as demonstrated by $\sim 95 \%$ and $~ 20 \%$ coupling yields for PEG moieties of $20 \mathrm{kDa}$ and $30 \mathrm{kDa}$, respectively, but almost undetectable for $40 \mathrm{kDa}$ PEGylates even at $48 \mathrm{~h}$ of reaction (Supplementary Fig. 2). Dual- or tri-PEGylated IL-2 variants were generated using the same procedure, with the exception that two or three TAG codons encoding NAEK were simultaneously introduced at specific sites. Using this approach, numerous PEGylated IL-2 variants carrying PEG moieties of different sizes at defined sites were developed and purified as single homogenous products (Fig. 1c).

Evaluating the preferential binding capacity of PEGylated IL-2 variants to different IL-2Rs. We next sought to determine which of the above-mentioned PEGylated variants exhibited a reduced binding affinity for the $\beta$ subunit of IL-2R and would therefore selectively activate $T_{\text {reg }}$ cells. We used biolayer interferometry (BLI) with biosensors bearing the $\alpha$ or $\beta$ subunit of human IL-2R to evaluate the binding affinity of each PEGylated variant (Fig. 1d and Supplementary Table 1). Compared with IL-2, mono-D20-20K, a variant that is PEGylated at Asp 20, exhibited complete abrogation of the binding affinity for the $\beta$ subunit and mildly to moderately decreased affinity for the $\alpha$ subunit. By contrast, variants that were mono-PEGylated at sites Ala 73, Lys 76 and His 79 exhibited reduced affinity for the $\beta$ subunit but to a much lower degree than mono-D20-20K; thus, these variants showed markedly lower selectivity compared with mono-D20-20K. Furthermore, variants with mono-PEGylation at the sites Tyr 31 and Thr 51 exhibited the least-selective binding among these mono-PEGylates due to the spatial distance from the PEGylated sites to the binding sites for both subunits. Notably, dual31/51-20K, a PEGylated variant with dual $20 \mathrm{kDa}$ PEG moieties at Tyr 31 and Thr51, exhibited a markedly reduced binding affinity for the $\beta$ subunit ( $\sim 80$-fold decrease) but only a mildly reduced binding affinity for the $\alpha$ subunit. The overall preferential binding

Fig. 1 | Site-specific PEGylation of human IL-2 mediated by amber codon suppression and screening of resultant PEGylated variants with differential binding to the $\alpha$ or $\beta$ subunit of IL-2R for identification of receptor-biased IL-2 ligands showing the highest level of selectivity to trimeric IL-2Rs. a, Schematic of the well-established quaternary structure of IL-2 associated with the trimeric receptor, comprising $\alpha, \beta$ and $\gamma$ subunits (Protein Data Bank (PDB): 2ERJ); the critical and constitutive residues are highlighted. The higher affinity of IL-2 for the trimeric receptor, which is typically expressed at high levels on $T_{\text {reg }}$ cells, compared with its affinity for dimeric IL-2R, which comprises the $\beta$ and $\gamma$ subunits and is expressed mostly on effector cells with moderate affinity, renders $T_{\text {reg }}$ cells highly sensitive to IL-2. $\mathbf{b}$, Schematic of the amber codon suppression-mediated incorporation of NAEK into the desired positions of IL-2 and subsequent modification with 4-dibenzocyclooctynol (DIBO)-PEG polymers. c, Verification of the precision PEGylation of IL-2 carrying PEG moieties of different sizes at defined sites by Coomassie blue staining of SDS-polyacrylamide gel electrophoresis (PAGE) gels. Left, PEGylation with PEG sizes of $5 \mathrm{kDa}, 10 \mathrm{kDa}, 20 \mathrm{kDa}$ and $30 \mathrm{kDa}$ at the Tyr 31 and Thr 51 sites. Right, mono-, di- and tri-PEGylated IL-2 variants at the defined sites. The SDS-PAGE images are representative of at least three biologically independent experiments. $\mathbf{d}$, Screening of the PEGylated variants for binding to the extracellular domains of the $\alpha$ or $\beta$ subunit of IL-2R, assessed by BLI (left), and for comparisons of their binding affinities ( $K_{\mathrm{D}}$, right). NA, not available. A list of all of the kinetic parameters is provided in Supplementary Table 1. 
of dual-31/51-20K to the $\alpha$ subunit relative to the $\beta$ subunit might be ascribed to the steric location of Tyr 31 and Thr 51 in different helix domains in opposite directions (Fig. 1a). Moreover, similar to
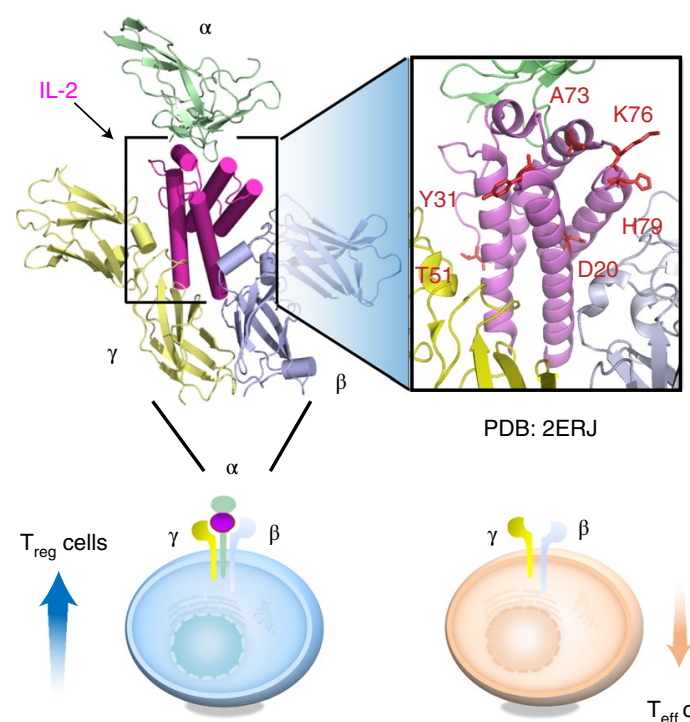

c

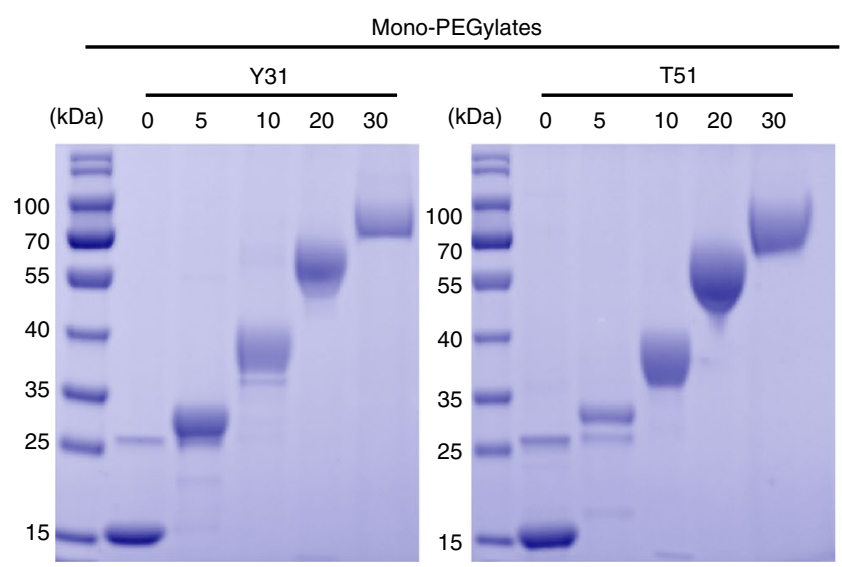

b

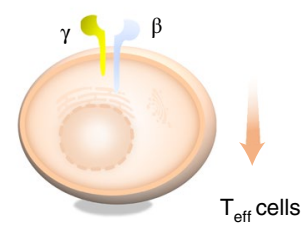

mono-D20-20K, a variant with tri-PEGylation at Tyr 31, Thr 51 and Asp 20 did not bind to the $\beta$ subunit but retained marginal binding affinity for the $\alpha$ subunit (Supplementary Table 1 ).
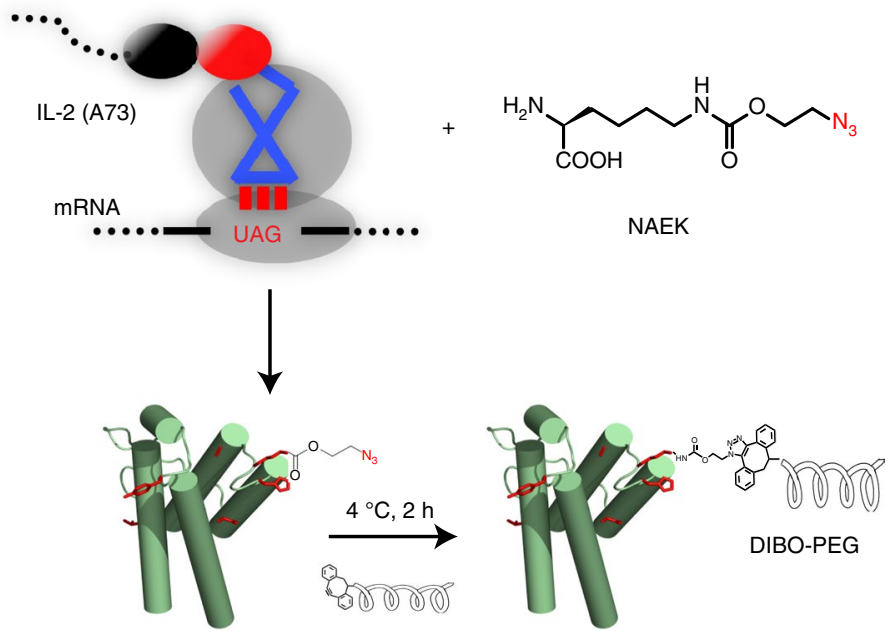

IL-2

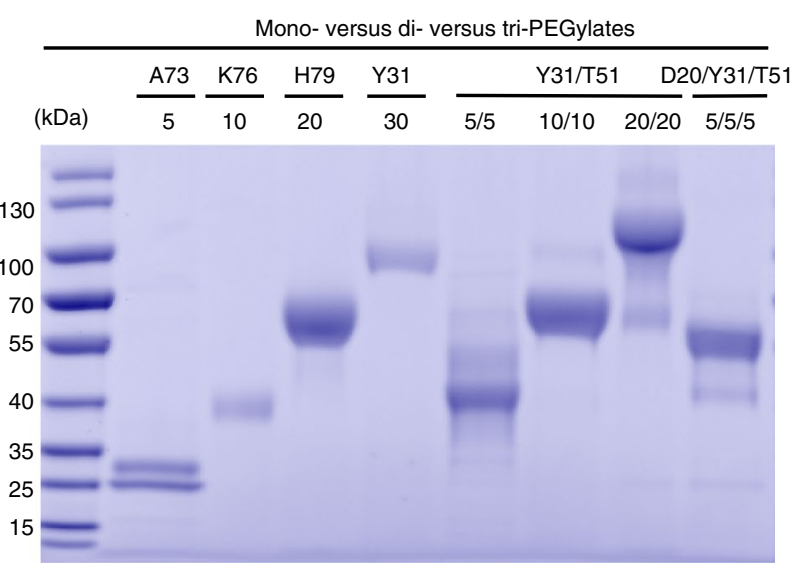

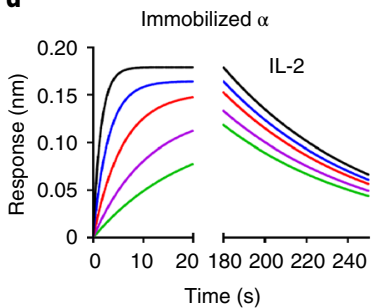
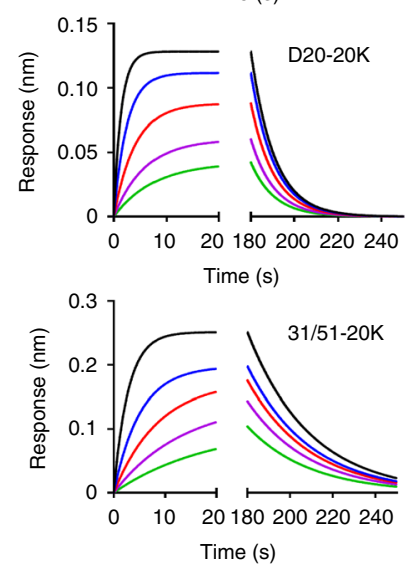
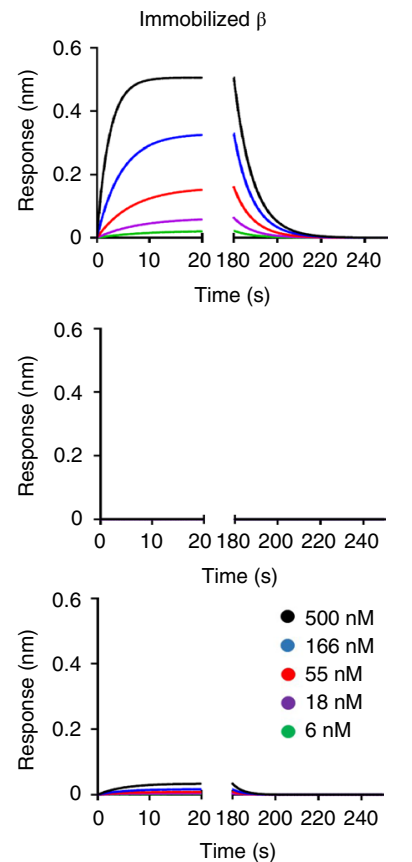

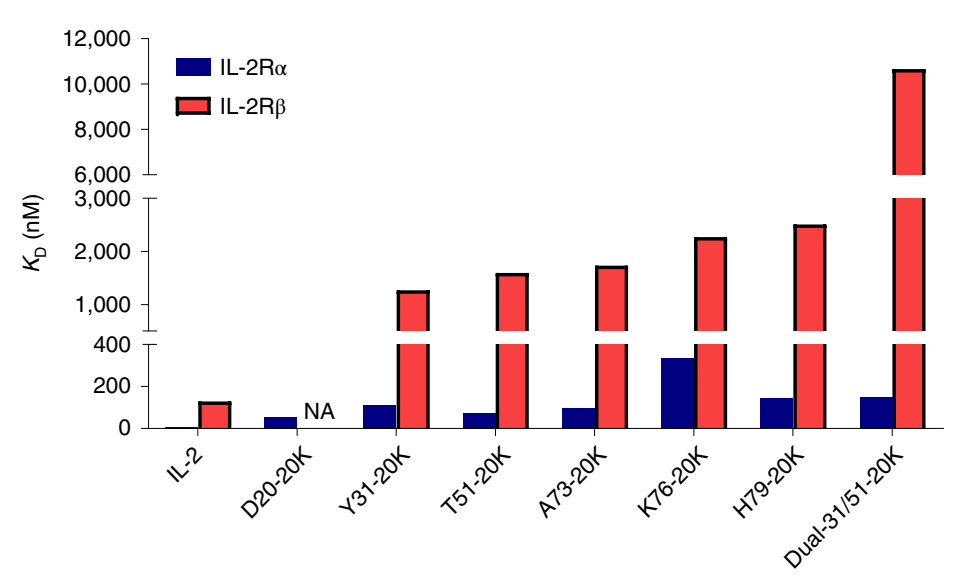


We subsequently evaluated the binding affinity of the PEGylated variants for the trimeric and dimeric IL-2R complexes using Fc-tagged extracellular domains of IL-2R subunits $\alpha, \beta$ and $\gamma$ immobilized separately on CM5 sensor chips. As expected, unmodified IL-2 exhibited a higher binding affinity for trimeric IL-2R compared with dimeric IL-2R (Extended Data Fig. 1). However, mono-D20$20 \mathrm{~K}$ showed almost undetectable affinity for dimeric IL-2R and moderate affinity for trimeric IL-2R, indicating the shielding effect of the PEG moiety on the $\beta$ subunit. Mono-PEGylation at other sites, including Tyr 31 or Thr51, also considerably reduced the binding affinity to dimeric IL-2R, albeit to a lesser degree compared with that obtained with mono-D20-20K. Interestingly, the above-mentioned decrease in binding to dimeric IL-2R was further intensified by additional PEGylation at the Thr 51 site (dual-31/5120K) (Extended Data Fig. 1 and Supplementary Table 2). These data collectively suggest that the site-specific PEGylation of IL-2 at both Tyr 31 and Thr 51 (dual-31/51-20K) or at Asp 20 alone (mono-D20$20 \mathrm{~K}$ ) selectively reduces its binding affinity for IL-2R $\beta$ compared with that of unmodified IL-2 and biases the binding of IL-2 towards trimeric IL-2R.

Selective activation of $\mathrm{T}_{\text {reg }}$ cells versus $\mathrm{CD8}^{+} \mathrm{T}$ cells by receptor-biased IL-2 PEGylates in vitro. We next sought to determine whether receptor-biased PEGylates preferentially activate $\mathrm{T}_{\text {reg }}$ cells over $\mathrm{CD}^{+} \mathrm{T}$ cells by measuring the level of phosphorylated STAT5 (pSTAT5), which is a critical downstream mediator of IL-2R signalling ${ }^{3}$, in bulk human peripheral blood mononuclear cells (hPBMCs) as previously reported ${ }^{41}$. We found that these receptor-biased PEGylated variants preferentially activated $\mathrm{T}_{\text {reg }}$ cells $\left(\mathrm{CD} 3^{+} \mathrm{CD} 4^{+} \mathrm{CD} 8^{-} \mathrm{CD} 25^{\text {high }} \mathrm{CD} 127^{\text {low }}\right)$ compared with $\mathrm{T}_{\text {eff }}$ cells $\left(\mathrm{CD}^{+}{ }^{+} \mathrm{CD} 4^{-} \mathrm{CD}^{+}\right.$; Supplementary Fig. 3), as demonstrated by the $50 \%$ effective concentration $\left(\mathrm{EC}_{50}\right)$ values derived from the dose-dependent activation curves (Fig. 2a,b and Supplementary Table 3). Note that this increase in selectivity occurred at the expense of IL-2 activity because the targeting/disruption of the interaction of IL- 2 with IL2R- $\beta$ led to an intrinsic reduction in IL-2 bioactivity because the IL-2R chain drives the ensuing activation. Furthermore, the preferential activation of $\mathrm{T}_{\text {reg }}$ cells over $\mathrm{T}_{\text {eff }}$ cells became more obvious as the size of the PEG moieties increased up to $30 \mathrm{kDa}$, and a further increase in the moiety size was associated with a marked reduction in STAT5 phosphorylation for both $\mathrm{T}_{\text {eff }}$ cells and $\mathrm{T}_{\text {reg }}$ cells, even with poor detection of $\mathrm{T}_{\text {reg }}$-cell activation (Fig. $2 \mathrm{~b}$ and Supplementary Table 3). Notably, dual-31/51-20K exhibited almost complete abrogation of the baseline bioactivities for $\mathrm{CD}^{+} \mathrm{T}$ cells but showed a substantially lower decrease in activity for $\mathrm{T}_{\text {reg }}$ cells, which resulted in highly skewed $\mathrm{T}_{\text {reg }}$-cell-selective activation. However, the aforementioned mono-D20-PEGylates and tri-20/31/51-5K exhibited only $5-20 \%$ of the baseline $\mathrm{T}_{\text {reg }}$ stimulatory activity, even though they exhibited no detectable binding to the $\beta$ subunit (Fig. $2 \mathrm{~b}$ and Supplementary Fig. 4).

To exclude potential confounding factors due to intercellular interactions, the selective activation of $\mathrm{T}_{\mathrm{reg}}$ cells by receptor-biased
PEGylated IL-2 variants was re-evaluated in various subsets of immune cells isolated from healthy donors. IL-2 stimulated $\mathrm{T}_{\text {reg }}$ cells, naive $\mathrm{CD} 4^{+}$cells, memory $\mathrm{CD} 4^{+}$cells, naive $\mathrm{CD} 8^{+}$cells, memory $\mathrm{CD}^{+}$cells and NK cells at all tested doses, whereas dual-31/51$20 \mathrm{~K}$ preferentially induced phosphorylation of STAT5 in $\mathrm{T}_{\text {reg }}$ cells but not in the other cell subsets (Fig. 2c). This finding was consistent with the expression levels of CD25 and FoxP3 on $\mathrm{T}_{\text {reg }}$ cells and of CD25 and CD49d on CD8 ${ }^{+} \mathrm{T}$ cells (Supplementary Fig. 5). As expected, mono-D20-20K showed markedly reduced activation of both CD8 ${ }^{+} \mathrm{T}$ cells and $\mathrm{T}_{\text {reg }}$ cells compared with IL-2. Taken together, these data suggest that site-specific PEGylation of IL-2, particularly PEGylation resulting in dual-31/51-20K, endows IL-2 with sustainable ability to preferentially stimulate $\mathrm{T}_{\text {reg }}$ cells over $\mathrm{T}_{\text {eff }}$ cells by selectively reducing the binding affinity for the $\beta$ subunit of IL-2R.

Evaluation of the pharmacokinetic properties of precision-PEGylated IL-2 variants in mouse models. After we constructed these site-specific IL-2 PEGylates and identified those that can preferentially activate $T_{\text {reg }}$ cells, we sought to determine whether these site-specific IL-2 PEGylates would be suitable for use in vivo by assessing their persistence in the circulation. To test whether the size of the PEG moieties and the site of PEGylation affected the stability of these PEGylates in vivo, we subcutaneously injected these individual IL-2 PEGylates into mice and assessed their pharmacokinetic properties. All PEGylated variants were present in the circulation, with an increased clearance half-life $\left(T_{1 / 2}, \sim 1.5\right.$-fold to 16-fold) and enhanced maintenance of the blood concentration (area under drug concentration versus time curve (AUC), 1.5-fold to 30-fold) compared with IL-2, and this effect was dependent on the size of the PEG moieties (Fig. 3a and Table 1). The mean residence time (MRT), which is similar to the clearance half-life, increased and was dependent on the size of the PEG moieties (Fig. 3b), with peak times of fourfold to sixteenfold longer than those of IL-2, indicating a substantial reduction in the clearance rate. We evaluated the impact of the PEGylation site on the pharmacokinetics and found that, among all mono-PEGylated variants, mono-D20-20K had the longest MRT, which was 12.4-fold longer compared with that of IL-2. The dual- and tri-PEGylated variants had even slower clearance rates, as exemplified by dual-31/51-20K, which could be detected $3 \mathrm{~d}$ after a single-dose injection. The MRT of this variant was superior to those of the mono-PEGylated variants, which were eliminated from the body within $2 \mathrm{~d}$ (Fig. 3a,b). Moreover, we performed differential scanning fluorimetry (DSF) to assess the stability of IL-2 after PEGylation. The apparent melting temperature $\left(T_{\mathrm{m}}\right)$ of unmodified IL-2 was determined to be $63^{\circ} \mathrm{C}$, whereas the stability of PEGylated IL-2 was markedly increased, as demonstrated by the finding that the intrinsic fluorimetry measurements of all PEGylated IL-2 variants did not show any notable change, even when the temperature reached $95^{\circ} \mathrm{C}$ (Fig. 3c).

We also evaluated the effect of PEGylation on the endocytosis of IL-2, which is a step that determines the fate of IL-2 after binding to its receptors, through an assay using CD25-expressing

Fig. 2 | Profiling of the receptor-biased IL-2 PEGylates in terms of selective activation of $\mathbf{T}_{\text {reg }}$ cells versus $\mathrm{CD}^{+} \mathbf{T}$ cells in vitro. $\mathbf{a}, \mathbf{b}$, Dose-dependent assessment of IL-2 variants containing $20 \mathrm{kDa}$ PEG at different sites (a), different sizes of PEGs or multiple PEGs (b) in the activation of $\mathrm{T}_{\text {reg }}$ cells over CD8 ${ }^{+}$ T cells by the pSTAT5 assay for comparisons of their selectivity in hPBMCs. The EC $\mathrm{C}_{50}$ and selectivity $\left(\mathrm{EC}_{50}\right.$ ratio of $\mathrm{CD} 8^{+} \mathrm{T}_{\text {cells }}$ to $\mathrm{T}_{\text {reg }}$ cells) of the above responses for $\mathrm{CD}^{+} \mathrm{T}$ and $\mathrm{T}_{\text {reg }}$ cells were calculated and are provided in Supplementary Table 3. Data are mean \pm s.e.m. $n=4$ biologically independent samples from individual donors, and representative results from one of three experiments are shown. Statistical analysis was performed using two-tailed unpaired Student's $t$-tests; $T_{\text {reg }}$-cell group versus CD8 ${ }^{+}$T-cell group, ${ }^{\star \star \star} P \leq 0.001,{ }^{\star \star \star \star} P \leq 0.0001$. c, Profiling of IL-2 and its receptor-biased PEGylates on isolated cell subsets. The purified naive CD4 ${ }^{+}$cells, memory-type CD4+ (MP-CD4) cells, naive CD8 ${ }^{+}$cells, memory-type CD8 ${ }^{+}$(MP-CD8) cells and NK cells were isolated by magnetic separation and analysed fresh. $T_{\text {reg }}$ cells were isolated using fluorescence-activated cell sorting (FACS) and expanded with CD3/CD28 beads and IL-2 ex vivo for $9 \mathrm{~d}$ before the assay. hPBMCs from healthy donors were stimulated by IL-2 or its PEGylates in a series of fivefold dilutions and then stained for quantitative flow analyses. Data are mean \pm s.e.m. $n=4$ biologically independent samples from different individual donors, and representative results from one of two experiments are shown. The concentrations of PEGylated IL-2 reflect the molecular mass of IL-2 without the attached PEG. 
YT cells versus their parental YT cell line. The results showed that PEGylated IL-2-including D20-20K and dual-31/51-20K, which were labelled with pHrodo-Red as previously reported ${ }^{42}$ - exhibited a longer half-life on the cell surface and underwent less endocytosis compared with unmodified IL-2 (Fig. 3d). IL-2 showed substantial endocytosis after incubation with CD25-expressing YT cells but not YT cells, verifying the previously reported critical role of CD2539,43 (Supplementary Fig. 6). The remarkable improvement in the pharmacokinetic properties of IL-2 was further verified by independent fluorescence confocal analysis, which showed that PEGylated IL-2
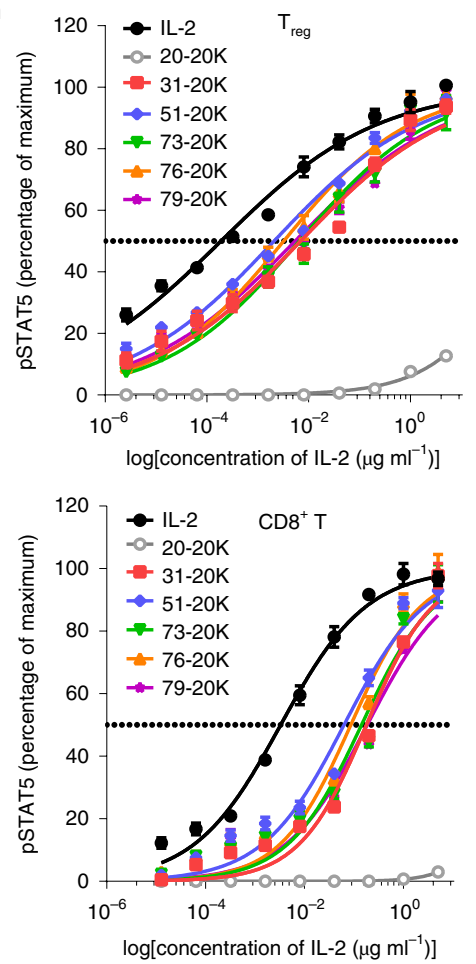

b
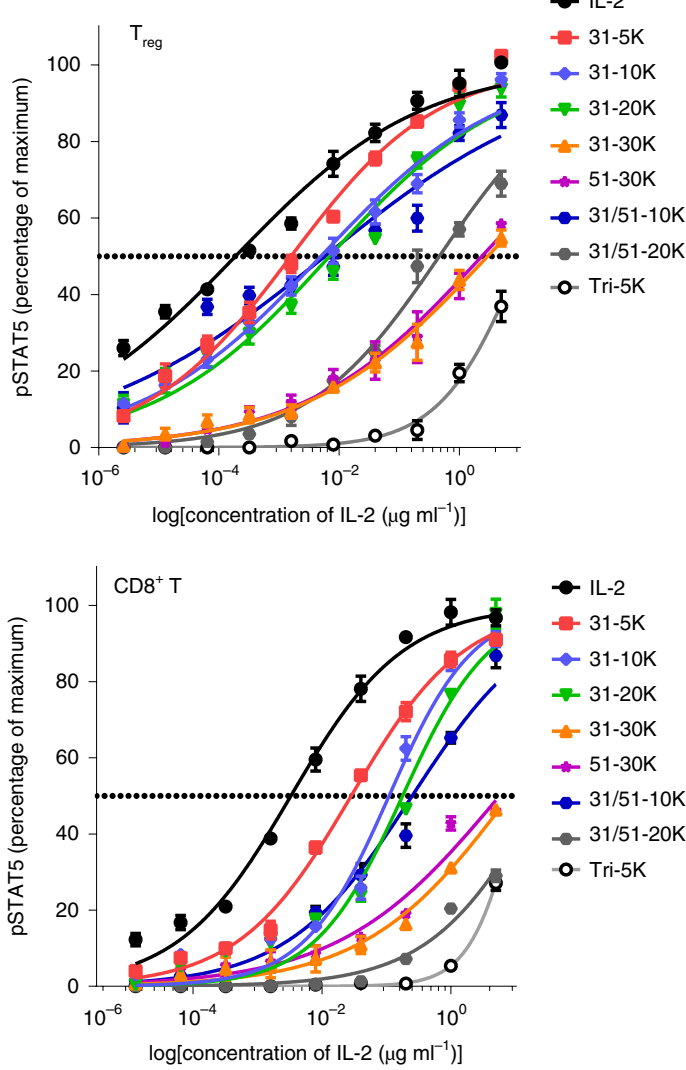

$\rightarrow$ IL-2

$-31-5 K$

$\rightarrow 31-10 K$

$\rightarrow 31-20 K$

$\pm 31-30 K$

$\rightarrow 51-30 \mathrm{~K}$

$\rightarrow 31 / 51-10 \mathrm{~K}$

$\rightarrow 31 / 51-20 \mathrm{~K}$

o- Tri-5K
$0.0016 \mu \mathrm{g} \mathrm{ml}^{-1}$
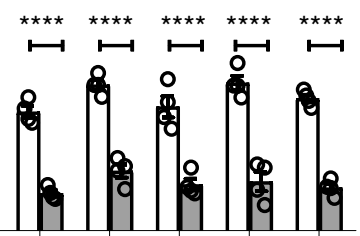

$v^{2} 2^{2^{2 t}} 3^{2^{2 t}} 5^{2^{2 t}} 1^{3^{2 t}} 1^{0^{2 t}} 1^{0^{2 t}}$
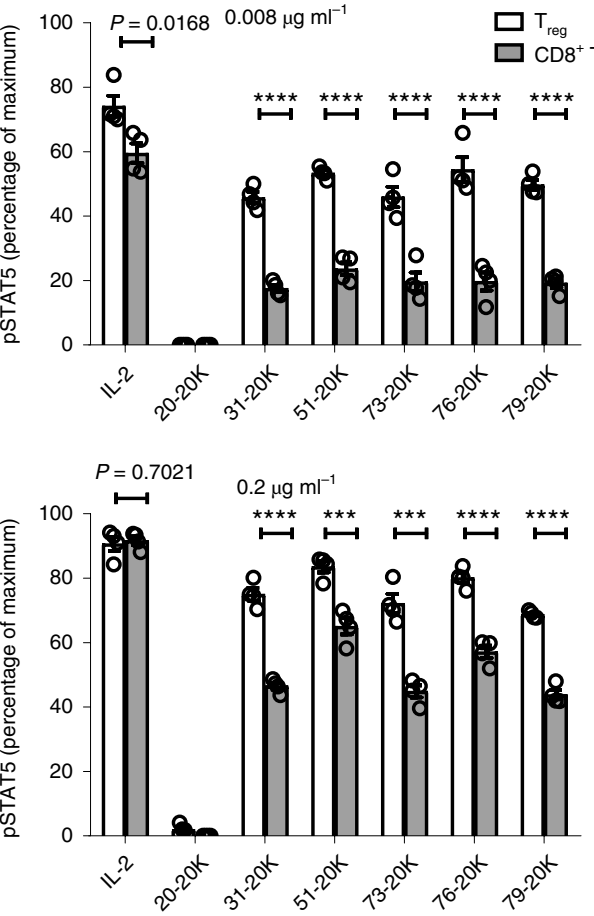

Concentration of IL-2 $\left(\mu \mathrm{g} \mathrm{ml}^{-1}\right)$
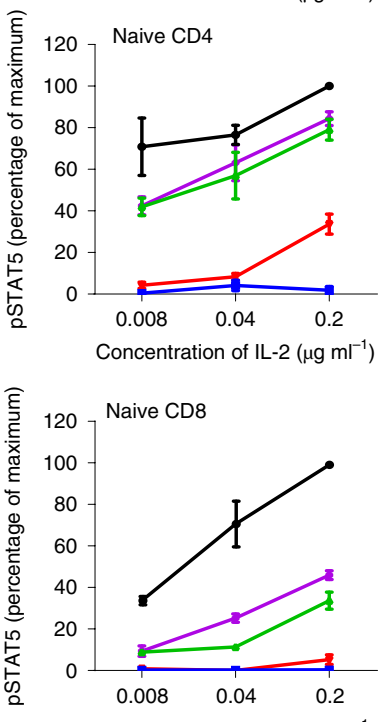

Concentration of IL-2 $\left(\mu \mathrm{g} \mathrm{ml}^{-1}\right)$

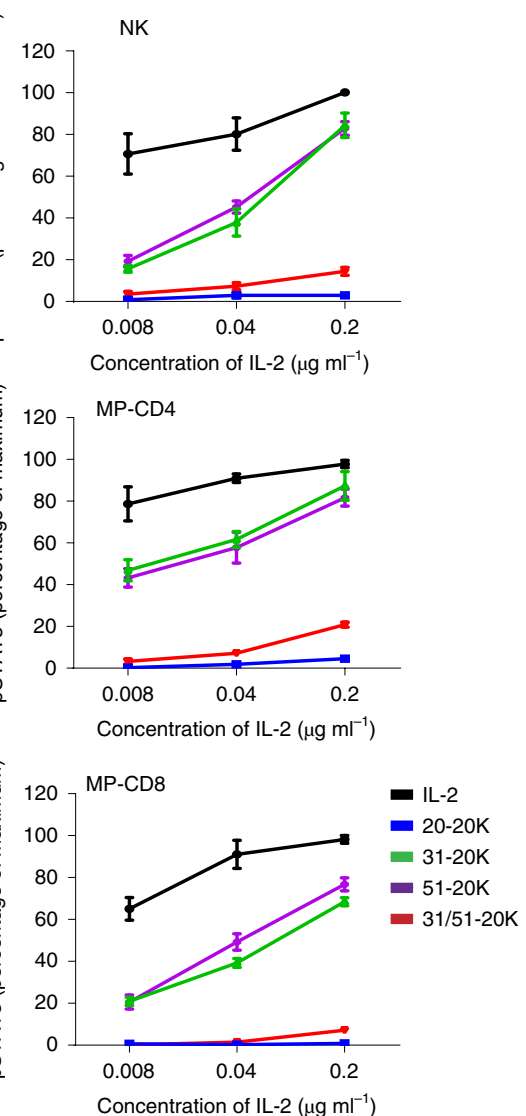


was retained for a markedly longer time on the cell surface, even up to $24 \mathrm{~h}$, compared with its parental form (Fig. $3 \mathrm{~d}$ ).

Dual-31/51-20K-mediated prevention of disease aggravation in GvHD mice through selective $T_{\text {reg }}$-cell proliferation and activation. Next, we sought to determine whether the receptor-biased IL-2 PEGylates, including dual-31/51-20K, mono-Y31-20K and mono-D20-20K as representatives, selectively stimulate human lymphocytes in a humanized mouse model, which was established by the intravenous administration of anti-CD3/CD28-antibody-activated hPBMCs into immunodeficient non-obese diabetic SCID gamma (NSG) mice as previously reported ${ }^{20}$, In brief, NSG mice (aged around 9 weeks; three in each group) were injected intravenously with $5 \times 10^{6} \mathrm{hPBMCs}$ and then administered subcutaneously with $0.4 \mu \mathrm{g}, 2 \mu \mathrm{g}$ or $10 \mu \mathrm{g}$ of IL-2 daily for five consecutive days or an equal dose of PEGylated IL-2 variants once every other day for a total of three times. A mobilization analysis of splenocytes (including human $\mathrm{T}_{\text {reg }}$ cells, $\mathrm{CD}^{+} \mathrm{T}$ cells and conventional $\mathrm{T}\left(\mathrm{T}_{\text {conv }}\right)$ cells), which were harvested $5 \mathrm{~d}$ after the last injection, indicated that dual31/51-20K PEGylates induced the most preferential and sustained expansion of $\mathrm{T}_{\text {reg }}$ cells at all three doses, followed by the mono-Y31$20 \mathrm{~K}$ group, as demonstrated by elevated $\mathrm{T}_{\text {reg }} / \mathrm{CD}^{+} \mathrm{T}$ and $\mathrm{T}_{\text {reg }} / \mathrm{T}_{\text {conv }}$ cell ratios that lasted for $5 \mathrm{~d}$ after the final treatment (Fig. $4 \mathrm{a}, \mathrm{b}$ and Supplementary Fig. 7). Consistent with this, the biomarkers CD25 and FoxP3 were also upregulated on $\mathrm{T}_{\text {reg }}$ cells but not on $\mathrm{CD}^{+} \mathrm{T}$ cells by the PEGylated IL-2 variants compared with the results obtained with the negative (PBS) and positive (IL-2) groups, and the greatest effect was obtained with the dual-31/51-20K group (Extended Data Fig. 2). Intriguingly, the D20-20K group exhibited a further reduction in $\mathrm{T}_{\text {reg }}$-cell proliferation, as well as in the $\mathrm{T}_{\mathrm{reg}} / \mathrm{CD}^{+} \mathrm{T}$ and $\mathrm{T}_{\text {reg }} / \mathrm{T}_{\text {conv }}$ cell ratios compared with the PBS group. A mechanistic examination indicated that IL-2-induced STAT5 phosphorylation was inhibited by D20-20K in CD25-expressing YT cells but not in native YT cells (Supplementary Fig. 8). This finding further verified that the PEGylation of IL-2 at Asp 20 completely abrogates the binding to the IL-2R $\beta$ subunit with mild effects on IL-2R $\alpha$; the persistent presence of D20-20K competes with endogenous IL-2 in binding to IL-2R $\alpha$ with a resultant reduction in $\mathrm{T}_{\text {reg }}$-cell activation.

Given the critical role of $\mathrm{T}_{\text {reg }}$ cells in maintaining self-antigen tolerance and preventing $\mathrm{GvHD}^{12,44}$, we evaluated the potential effect of PEGylated IL-2 in xeno-GvHD mice. A lethal dose $\left(3 \times 10^{7}\right)$ of activated hPBMCs from healthy donors was injected into NSG mice. The mice were then administered with $0.03 \mu \mathrm{g}, 0.1 \mu \mathrm{g}$ or $0.5 \mu \mathrm{g}$ of IL-2 daily for five consecutive days or an equal dose of PEGylated IL-2 variants once every other day for a total of three times, and this regimen was repeated the following week. We found that dual$31 / 51-20 \mathrm{~K}$ treatment significantly alleviated disease severity, as evidenced by attenuated weight loss and increased survival rates, and this protection lasted for an additional 6 weeks, which was superior to the effects of IL-2 treatment (Fig. 4c). Notably, the dual$31 / 51-20 \mathrm{~K}$ doses of $0.1 \mu \mathrm{g}$ and $0.5 \mu \mathrm{g}$ exhibited the most impressive therapeutic effects, and the lower doses showed even better protection with respect to the body weight. Although only moderate protection was observed with the IL-2 treatment dose of $0.1 \mu \mathrm{g}$, higher or lower doses had a lower therapeutic benefit. All data indicated that dual-31/51-20K can clearly protect GvHD mice against disease aggravation through the induction of $\mathrm{T}_{\mathrm{reg}}$-cell proliferation and activation, and its effect was further improved after optimization of the administered dose.

Dual-31/51-20K-mediated preferential activation of $T_{\text {reg }}$ cells from patients with SLE and mitigation of disease activity and severity in MRL/lpr SLE-prone mice. We subsequently investigated the therapeutic potential of IL-2 versus its PEGylated variants towards SLE. To this end, we first evaluated the cross-reactivity and selective effects of human IL-2 on murine immune cells in healthy C57BL/6 mice. The subcutaneous injection of PEGylated human IL-2 variants, particularly dual-31/51-20K, led to increases in the percentage and number of murine $\mathrm{T}_{\text {reg }}$ cells, whereas the numbers of $\mathrm{CD}^{+} \mathrm{T}$ and $\mathrm{T}_{\text {conv }}$ cells were reduced (Fig. $5 \mathrm{a}$ and Supplementary Fig. 9a). These effects correlated with increased splenic $\mathrm{T}_{\text {reg }} /$ $\mathrm{CD}^{+} \mathrm{T}$ and $\mathrm{T}_{\text {reg }} / \mathrm{T}_{\text {conv }}$ cell ratios (Supplementary Fig. 9b) as well as upregulated activation markers on $\mathrm{T}_{\text {reg }}$ cells but not $\mathrm{CD}^{+} \mathrm{T}$ cells (Supplementary Fig. 9c). Furthermore, we evaluated different schedules of administration and found that a one-time injection of an overall dose of $2 \mu \mathrm{g}$ of dual-31/51-20K led to a markedly higher degree of $\mathrm{T}_{\text {reg }}$-cell-selective activation but a sharp decrease over the following days. This finding is considerably different from the results obtained with the injection of $0.5 \mu \mathrm{g}$ of dual-31/51-20K every other day for four times, which induced $\mathrm{T}_{\mathrm{reg}}$-cell-selective activation in a persistent and steady manner (Supplementary Fig. 10a,b). Thus, unless otherwise noted, a regimen consisting of injections every other day was used for PEGylated IL-2 variants in various mouse models instead of a regimen consisting of a daily injection of IL-2. Collectively, these results suggest that PEGylated human IL-2 variants, particularly dual-31/51-20K, can cross-react with murine immune cells and exert selective effects on both murine and human $\mathrm{T}_{\text {reg }}$ cells.

Given the superiority of dual-31/51-20K to other PEGylated variants, we next used MRL/lpr mice to test the effectiveness of this variant in alleviating SLE disease activity. In brief, female MRL/lpr mice (aged 9 weeks) were subcutaneously injected with unmodified IL-2 daily for five consecutive days or with an equal dose of dual-31/51-20K once every other day for a total of three times, and this regimen was repeated every week for two weeks. To examine the changes in lymphocytes in response to treatment, we euthanized half of the mice treated with $0.5 \mu \mathrm{g}$ after $3 \mathrm{~d}$ of treatment and excised the spleens for flow cytometry analysis. As expected, dual$31 / 51-20 \mathrm{~K}$ treatment significantly increased the number of $\mathrm{T}_{\mathrm{reg}}$ cells but not $\mathrm{CD}^{+} \mathrm{T}$ cells or $\mathrm{T}_{\text {conv }}$ cells in the spleen compared with IL-2 treatment (Supplementary Fig. 11a). Furthermore, treatment with dual-31/51-20K induced a greater reduction in splenic $\mathrm{T}$ follicular

Fig. 3 | Evaluation of the effects of PEGylation on the pharmacokinetic properties of IL-2. a, The effect of PEG size (left) and site (right) on the persistence of circulating IL-2 in mouse models. IL-2 and PEGylated IL-2 variants at a dose of $5 \mu$ ger mouse were subcutaneously administered to $\mathrm{BALB} / \mathrm{c}$ mice, and blood was collected at the indicated time points for quantification by ELISA. b, Comparisons of the persistence of IL-2 versus its PEGylated variants in the circulation according to the MRT. The pharmacokinetic properties were modelled and calculated using Kinetica 5.1, and all of the pharmacokinetic parameters are shown in Table 1. Data are mean \pm s.e.m. $n=3$ biologically independent mice per group. Statistical analysis was performed using two-tailed Student's $t$-tests, comparing the 20 -20K-treated versus the IL-2- or 31-20K-treated group; ${ }^{\star \star \star} P=0.0003,{ }^{\star \star \star \star} P \leq 0.0001$. c, Assessment of the thermal stability of IL-2 versus its PEGylated variants by performing DSF. Data are representative of three independent experiments. $\mathbf{d}$, The effect of PEGylation on the fate of IL-2 after binding to the receptors using CD25-expressing YT cells versus the parental YT cell line as the endocytic model. YT cells expressing CD25-eGFP (YT-CD25) were incubated at $37^{\circ} \mathrm{C}$ in the presence of saturating IL-2 or its PEGylates. The acidic compartments were stained with LysoTracker Blue BND-22 (blue), and the surface and endocytosed IL-2 were stained with anti-His-AF647 (purple) and pHrodo-Red (red), respectively, for quantification at the defined incubation times: $16 \mathrm{~h}$ (represented by bar graphs; left) and $24 \mathrm{~h}$ (reflected by the immunofluorescence images; right). Scale bar, $20 \mu \mathrm{m}$. Data are mean \pm s.e.m. $n=3$ biologically independent samples per group. Statistical analysis was performed using two-tailed Student's t-tests. Representative results from one of two experiments are shown. 
helper $\left(\mathrm{T}_{\mathrm{fh}}\right)$ cells than IL-2 (Supplementary Fig. 11b). Six weeks after the final dose, dual-31/51-20K-treated mice exhibited further significant reductions in disease activity and severity, as demonstrated by reduced levels of serum anti-double-stranded-DNA antibodies, anti-nuclear antibodies (ANA) and proteinuria (Fig. 5b), compared with those treated with IL-2 or PBS. Moreover, further significant

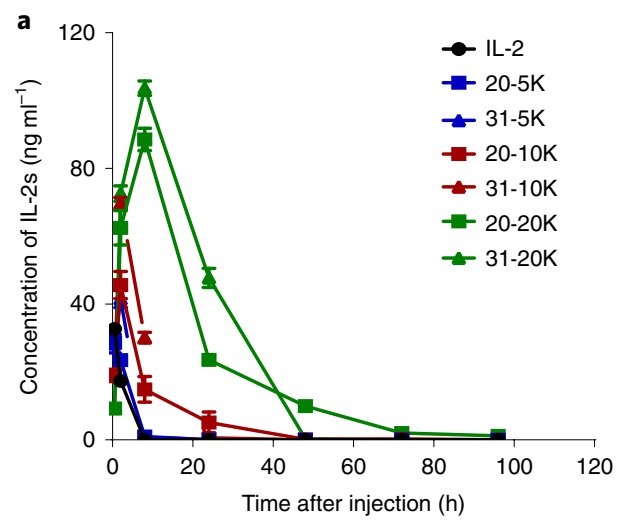

b

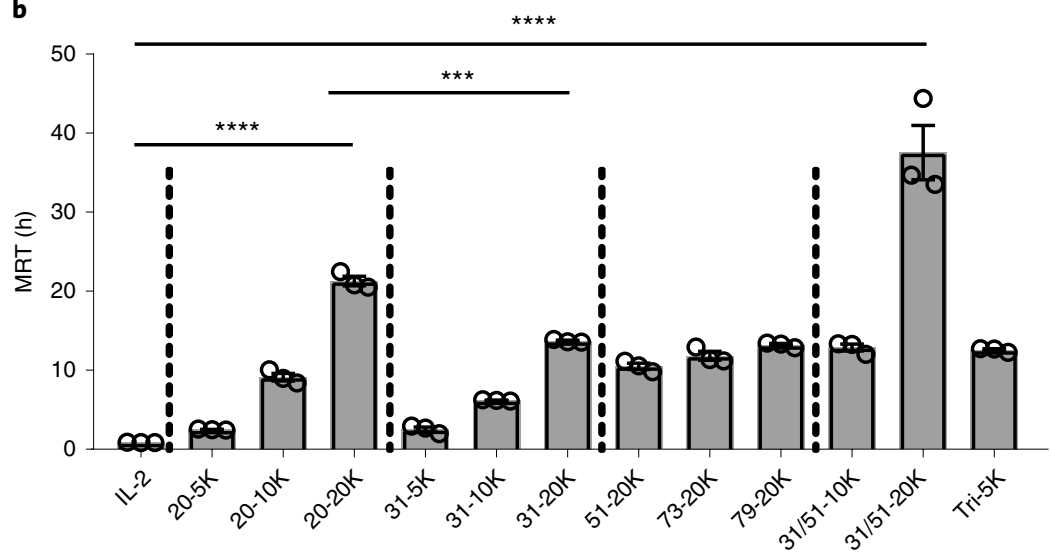

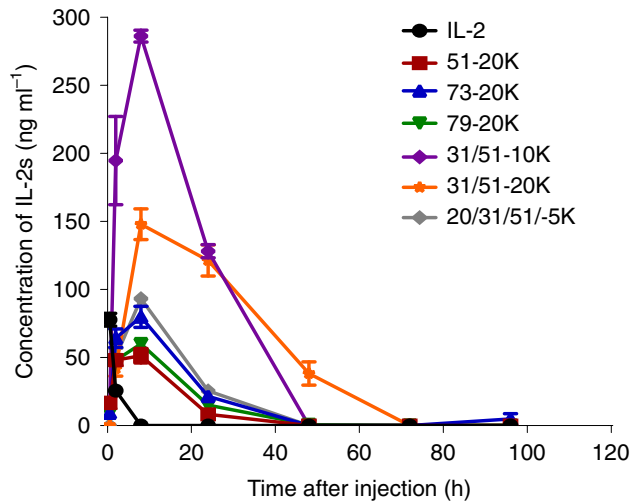

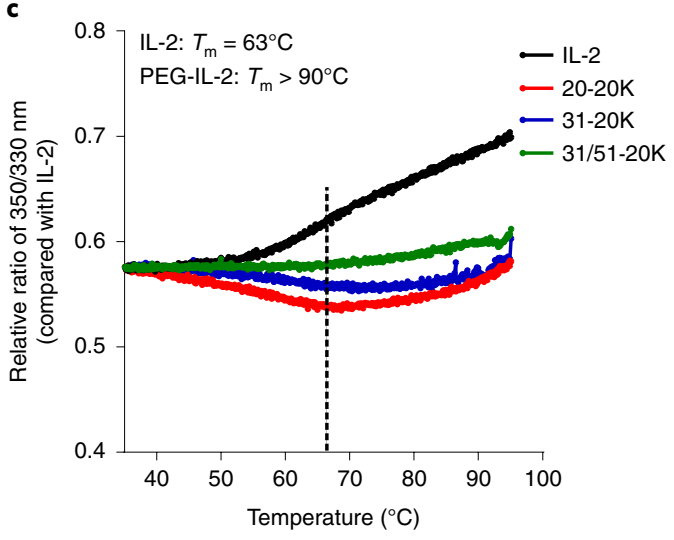

d
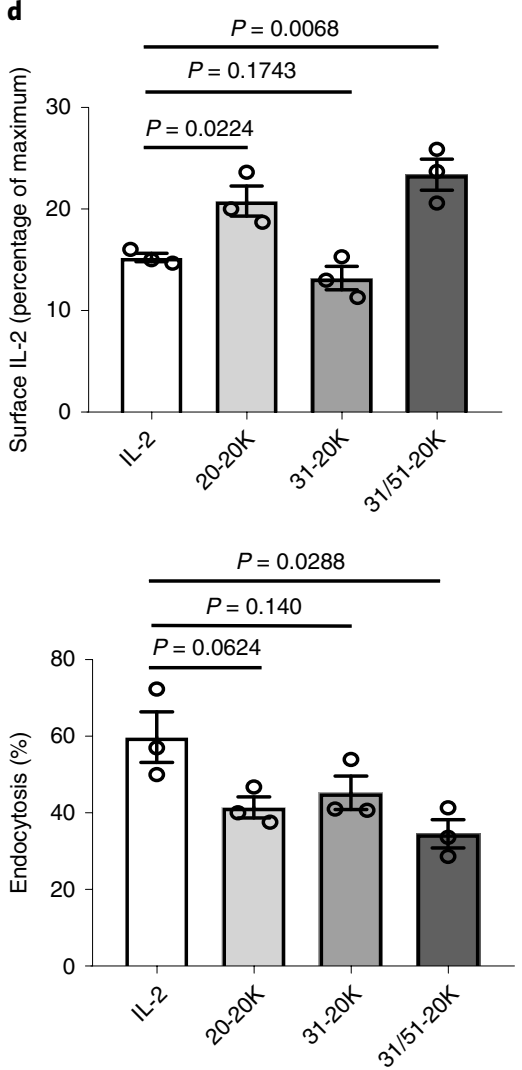

CD25-YT
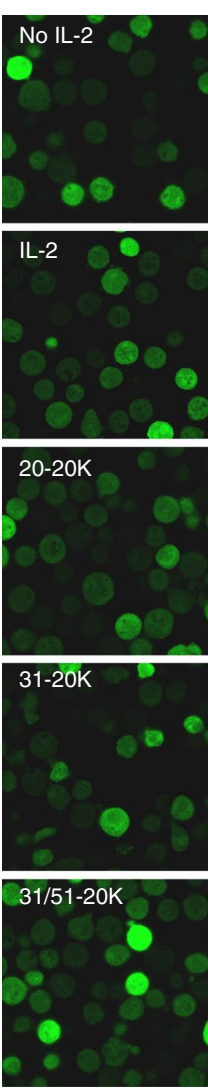

Surface
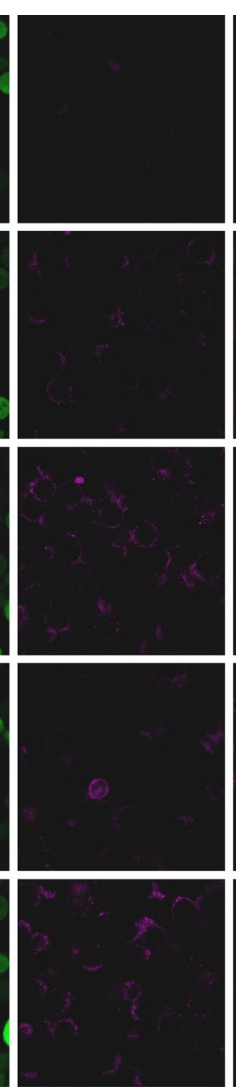

Endocytic

IL-2
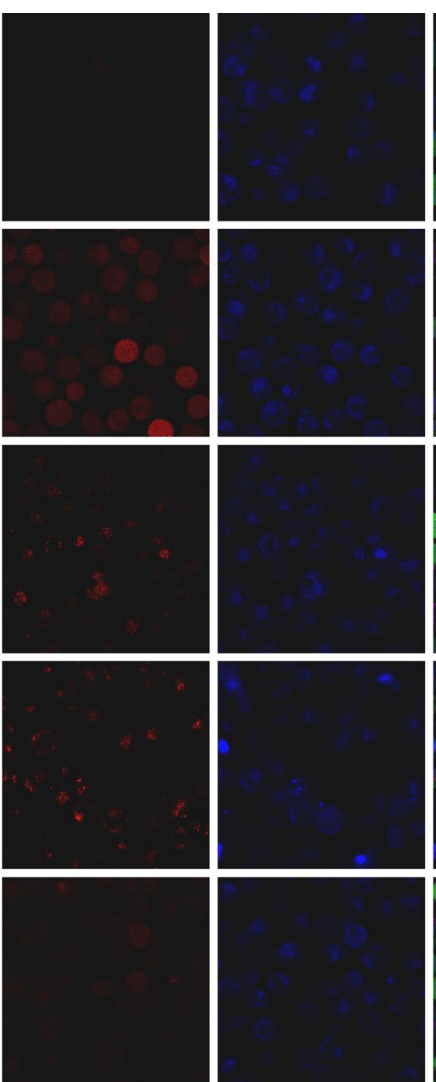

Merge
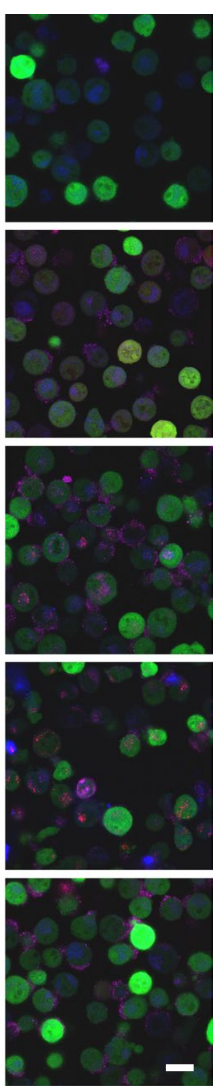
Table 1 | Pharmacokinetic parameters of IL-2 and its PEGylates

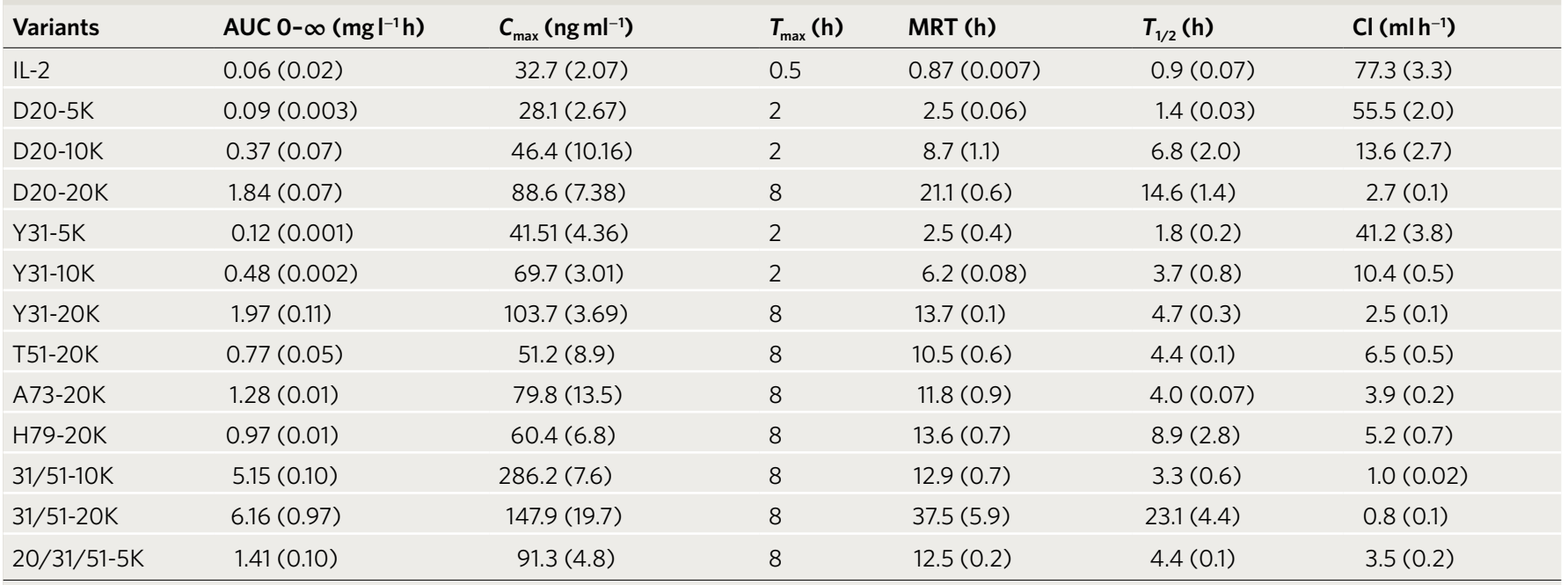

$C_{\max }$, maximal drug concentration; $T_{\max }$ time of maximal drug concentration; $\mathrm{Cl}$, apparent total plasma clearance. Data are mean (s.d.), $n=3$ biologically independent mice per group.

amelioration of kidney lesions and deposition of C3 and IgG as well as spleen inflammation, as demonstrated by histopathological and immunohistochemical examinations, were achieved by dual-31/5120K treatment (Fig. 5c and Extended Data Fig. 3). Notably, given the superiority of the low-dose treatment compared with high-dose treatment on the improvement of SLE activity and progression, the $0.5 \mu \mathrm{g}$ dual-31/51-20K treatment exhibited even better therapeutic benefit compared with the treatment with $0.1 \mu \mathrm{g}$ of unmodified IL-2, further highlighting the therapeutic potential of dual-31/51$20 \mathrm{~K}$ and suggesting that dose optimization may further improve the therapeutic effect (Fig. 5b,c and Extended Data Fig. 3).

Moreover, we evaluated the effect of dual-31/51-20K on restoring the immune homeostasis of hPBMCs isolated from treatment-naive patients with SLE. Compared with PBS or IL-2 treatment, the application of dual-31/51-20K resulted in a significantly increased proportion of $\mathrm{T}_{\text {reg }}$ cells and decreased proportions of $\mathrm{T}$ helper $1\left(\mathrm{~T}_{\mathrm{H}} 1\right)$ and $\mathrm{T}_{\mathrm{H}} 17$ cells but had minimal effects on the numbers of $\mathrm{CD} 8^{+} \mathrm{T}$, NK and $T_{\text {fh }}$ cells (Supplementary Fig. 12a). This finding correlated well with the notable induction of STAT5 phosphorylation in $\mathrm{T}_{\mathrm{reg}}$ cells but not in $\mathrm{CD}^{+} \mathrm{T}$ cells or NK cells at a wide range of doses $\left(0.008-0.2 \mu \mathrm{g} \mathrm{ml}^{-1}\right)$ of dual-31/51-20K isolated from patients with SLE (Supplementary Fig. 12b). $\mathrm{T}_{\text {reg }}$-cell homeostasis and immune regulation by dual-31/51-20K were also observed in hPBMCs from healthy individuals tested in a parallel experiment (Supplementary Fig. 13). This result contrasted with the results obtained with IL-2, which, at high doses, induced considerable STAT5 phosphorylation not only in $\mathrm{T}_{\text {reg }}$ cells but also in $\mathrm{CD}^{+} \mathrm{T}$ cells and NK cells. Collectively, these data demonstrate the superiority of dual-31/51$20 \mathrm{~K}$ in effectively ameliorating the disease severity of SLE.

Dual-31/51-20K-mediated amelioration of CIA. We subsequently evaluated the therapeutic efficacy of dual-31/51-20K in a collagen-induced arthritis (CIA) mouse model generated by intradermal challenge with collagen as previously reported ${ }^{45}$. In brief, collagen-treated mice were subcutaneously injected with $0.5 \mu \mathrm{g}$ of IL-2 once every other day for a total of three injections or with $1.5 \mu \mathrm{g}$ of dual-31/51-20K on the day after the second challenge, and signs of joint inflammation were examined every other day. The mice treated with dual-31/51-20K showed significantly reduced arthritis scores and diminished histopathological inflammation and joint destruction; these therapeutic effects were sustained for at least two additional weeks beyond the effects obtained with the placebo (Fig. 6a).
Intriguingly, treatment with an equivalent dose of IL-2 led to more severe arthritis than the placebo control. Furthermore, compared with the PBS and IL-2 treatments, dual-31/51-20K treatment selectively increased markers of $\mathrm{T}_{\text {reg }}$-cell proliferation and activation, including upregulation of CD25, CTLA- 4 and Foxp3, reduced the proportion of $\mathrm{T}_{\mathrm{H}} 17$ cells, and increased the $\mathrm{T}_{\text {reg }} / \mathrm{CD} 8^{+} \mathrm{T}, \mathrm{T}_{\text {reg }} / \mathrm{T}_{\text {conv }}$ and $\mathrm{T}_{\text {reg }} / \mathrm{T}_{\mathrm{H}} 17$ cell ratios in the spleen, blood and lymph nodes (Fig. $6 \mathrm{~b}, \mathrm{c}$ and Supplementary Fig. 14a,b). We also assessed the prophylactic potential of PEGylated IL-2 on the basis of the subcutaneous administration of IL-2 or dual-31/51-20K one week before the second challenge with bovine type-II collagen (COII). Mice that were pretreated with dual-31/51-20K exhibited a lower incidence of arthritis and lower arthritis scores compared with mice that were pretreated with IL-2 (Fig. 6d,e). Subsequently, the effects of dual31/51-20K on hPBMCs isolated from patients with RA were evaluated, and the results were similar to those observed with hPBMCs from patients with SLE (Supplementary Fig. 15a,b). Collectively, our data supported the finding that the administration of dual-31/51$20 \mathrm{~K}$ before or after the onset of disease considerably decreases the incidence and severity of arthritis.

Immunogenicity of dual-31/51-20K and its impact on host defence against viral infection. As immunogenicity is a critical concern in the development of therapeutic proteins, we tested whether the incorporation of NAEK and subsequent PEG chains through a dibenzocyclooctyne-functionalized click reaction induces an immune response. In brief, $\mathrm{C} 57 \mathrm{BL} / 6$ mice were subcutaneously injected with $0.5 \mu \mathrm{g}$ of human IL-2 daily for five consecutive days or an equal dose of dual-31/51-20K every other day; this treatment lasted for four weeks (Supplementary Fig. 16a). Antibodies against both IL-2 and PEG moieties were detected by directed enzyme-linked immunosorbent assay (ELISA) after the final administration at weeks 2 and 4 . No significant antibodies, including IgG and IgG1 subtypes, were detected for either unmodified IL-2 or dual-31/51-20K (Supplementary Fig. 16b, c). The lack of an immune response was probably due to the fact that the IL-2 sequence is similar between humans and mice; the structural mimics of NAEK to the natural amino acid Lys and the subsequent precise PEGylation led to a single and homogenous conjugate, which was in consistent with a previous report ${ }^{36}$. Moreover, the effect of dual-31/51-20K on pulmonary endothelial cells that may lead to off-target vascular leak syndrome (VLS) was also evaluated. As previously reported, lung 

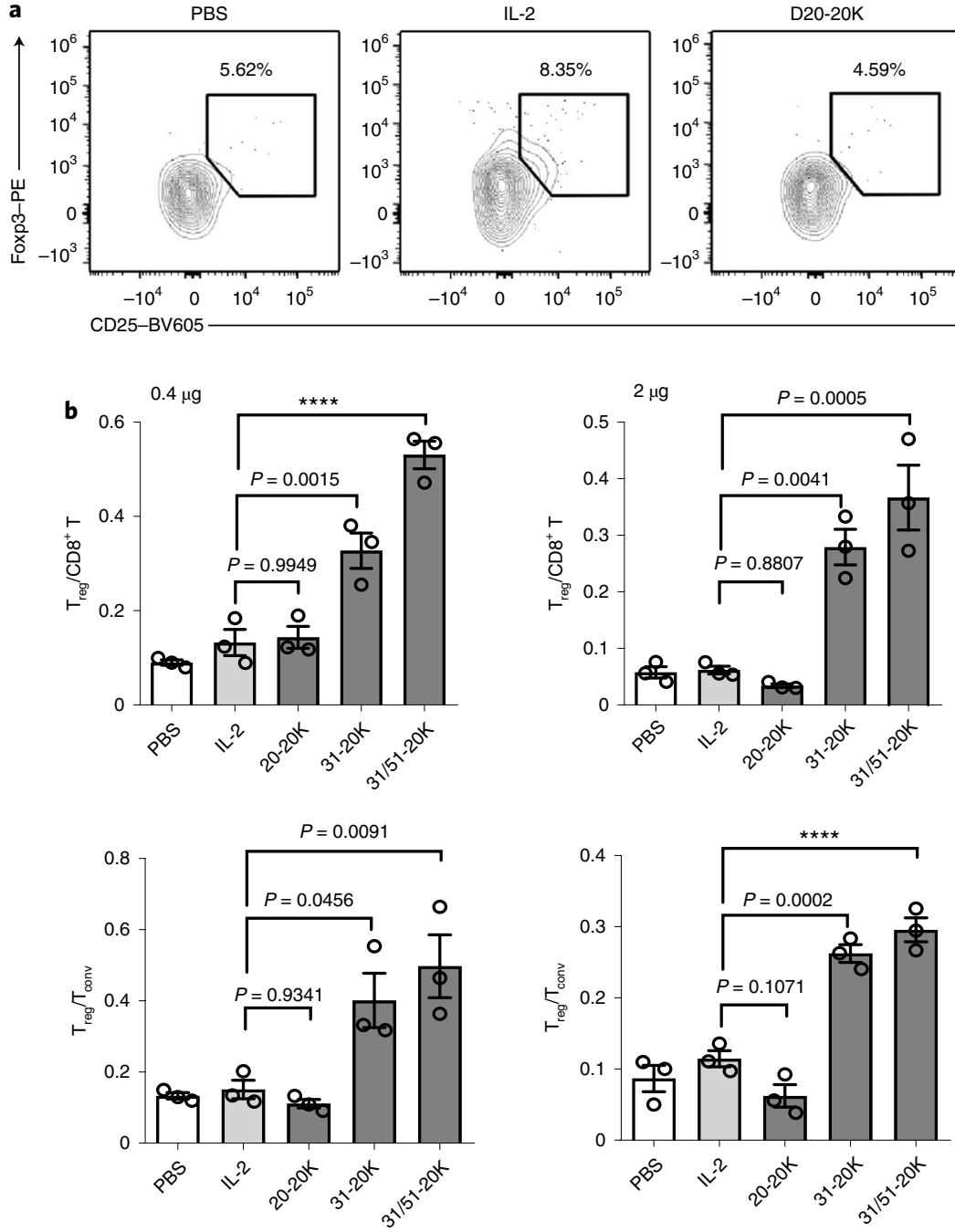

Y31-20K
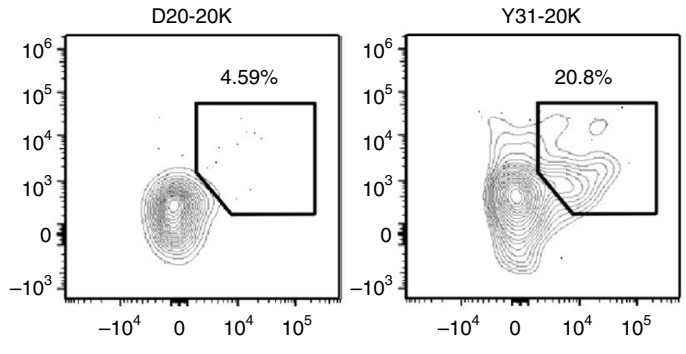

Dual-31/51-20K

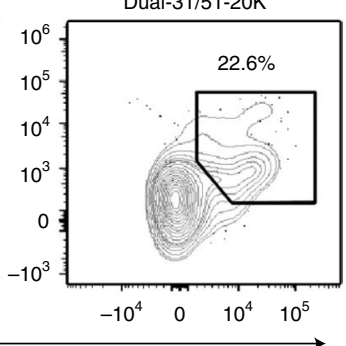

C
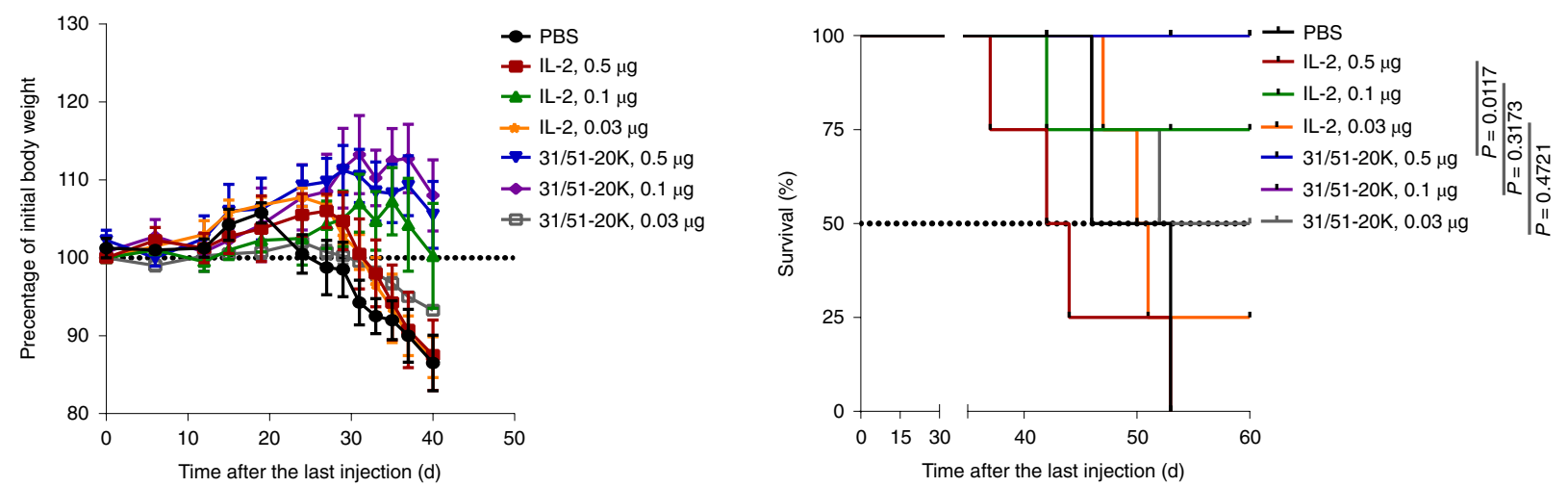

Fig. 4 | Prevention of disease aggravation in GvHD mice by PEGylated IL-2 variants through selective $T_{\text {reg }}$-cell proliferation and activation. $\mathbf{a}, \mathbf{b}$, Validation of $\mathrm{T}_{\text {reg }}$-cell-selective activation, as reflected by increases in the $\mathrm{T}_{\text {reg }} / \mathrm{CD} 8^{+} \mathrm{T}$ and $\mathrm{T}_{\text {reg }} / \mathrm{T}_{\text {conv }}$ cell ratios, by PEGylated IL-2 variants in a xeno-GvHD mouse model. hPBMCs activated by anti-human-CD3/CD28 antibodies overnight were intravenously injected into NSG mice, and then the resultant mice were given the indicated dose of IL-2 daily for five consecutive days or the same dose of PEGylated IL-2 variants three times every other day. Splenocytes were collected $5 \mathrm{~d}$ after the final injection and stained for analyses. Representative results from one of three independent experiments are shown (Extended Data Fig. 2 and Supplementary Fig. 7). a, Representative flow plots reflecting the percentage change in $T_{\text {reg }}$ cells among the total CD4+ $T$ cells after treatment. $\mathbf{b}$, The resultant $\mathrm{T}_{\text {reg }} / C D 8^{+} \mathrm{T}$ and $\mathrm{T}_{\text {reg }} / \mathrm{T}_{\text {conv }}$ cell ratios in response to three doses of the indicated treatment. Data are mean $\pm \mathrm{s}$.e.m. $n=3$ biologically independent mice per group. Statistical analysis was performed using one-way ANOVA with Dunnett's multiple-comparison test, compared with the IL-2-treated group; ${ }^{\star \star \star \star} P \leq 0.0001$. $\mathbf{c}$, The impacts of IL-2 versus its PEGylated variants on xeno-GvHD mice in terms of reduction in the loss of body weight and extended survival, showing disease aggravation. A lethal dose of activated hPBMCs from healthy donors was intravenously injected into NSG mice, followed by subcutaneous administration of PBS or the indicated dose of IL-2 or PEGylated IL-2 variants as described in a, and this regimen was repeated the next week. Data are mean \pm s.e.m. $n=4$ biologically independent mice per group. Statistical analysis was performed using two-tailed log-rank (Mantel-Cox) tests. Representative results from one of two independent experiments are shown. 
cells expressing high levels of CD31, but not other immune cell lineage markers (Lin) were defined as endothelial cells (Ly5.2- ${ }^{-} 220$ $\left.{ }^{-} \mathrm{CD} 3^{-} \mathrm{NK} 1.1^{-} \mathrm{CD} 11 \mathrm{~b}^{-} \mathrm{CD} 11 \mathrm{c}^{-} \mathrm{CD} 31^{+}\right)^{46}$. A mobilization analysis of the lungs from IL-2- versus dual-31/51-20K-treated mice indicated that dual-31/51-20K selectively increased the count numbers and the percentage of $\mathrm{T}_{\text {reg }}$ cells in the lungs but affected the numbers of pulmonary endothelial cells to a markedly lower degree compared with IL-2 or PBS (Supplementary Fig. 17a,b). This finding indicates that dual-31/51-20K preferentially binds to $\mathrm{T}_{\mathrm{reg}}$ cells rather than endothelial cells and other effector cells and therefore minimizes the potential toxicity of IL-2, as shown by VLS.

Given the preferential activation of $\mathrm{T}_{\text {reg }}$ cells in different $\mathrm{AD}$ models, we examined whether the administration of dual-31/51$20 \mathrm{~K}$ compromises the host immune defence against influenza virus. A dosing scheme similar to that implemented in the GvHD and SLE assays was used: the mice received subcutaneous administration of IL-2 ( $0.5 \mu \mathrm{g}$ per mouse) daily for five consecutive days or an equal dose of dual-31/51-20K once every other day for a total of three times and were subsequently infected with a $20 \times$ median lethal dose $\left(\mathrm{LD}_{50}\right)$ dose of influenza $\mathrm{A}$ virus $(\mathrm{A} / \mathrm{WS} / 1933 \mathrm{H} 1 \mathrm{~N} 1$, WSN) four days after the last administration (day 9). Treatment of mice with dual-31/51-20K resulted in a marked reduction in the viral load in the lungs and decreased levels of lymphocyte infiltration and immune injury compared with those found in the IL-2and PBS-treated mice (Fig. 7a). Concomitant with this alleviation of virulence, the dual-31/51-20K-treated mice exhibited milder weight loss and a lower death rate compared with the mice in the other groups (Fig. 7b). Moreover, these mice showed increased proportions and numbers of pulmonary, peripheral and splenic $\mathrm{T}_{\mathrm{reg}}$ cells but not $\mathrm{CD}^{+}$or $\mathrm{CD}^{+}$cells (Fig. $7 \mathrm{c}$ and Supplementary Fig. 18a,b). Importantly, the population of NK cells in the lungs of dual-31/51$20 \mathrm{~K}$-treated mice was significantly increased, and this effect was accompanied by upregulated expression of the markers NKG2D, NKp46 and CD69, in contrast to the findings obtained for the spleen (Fig. $7 \mathrm{c}$ and Extended Data Fig. 4). A summary of the gating strategies that were used for cell sorting in vivo experiments, including SLE, CIA and virus protection, is provided in Supplementary Fig. 19. Thus, the enhanced host defence against viral infection observed in this model was probably due to the dual-31/51-20K-mediated mobilization of NK cells into the infected lung.

\section{Discussion}

Natural $\mathrm{T}_{\text {reg }}$ cells, which comprise $5-10 \%$ of the total peripheral $\mathrm{CD}^{+} \mathrm{T}$ cell population, have a central role in the maintenance of immune tolerance ${ }^{47}$. Reductions in $\mathrm{T}_{\mathrm{reg}}$-cell proliferation and activity have been associated with numerous $\mathrm{ADs}^{44}$. A rational therapeutic strategy involves the use of IL-2 to skew the immune balance between $\mathrm{T}_{\text {reg }}$ cells and $\mathrm{T}_{\text {eff }}$ cells towards $\mathrm{T}_{\text {reg }}$ cells $\mathrm{s}^{2,3}$. However, this strategy is controversial due to the paradoxical effect of IL- 2 because low doses exert immunosuppressive effects through $\mathrm{T}_{\mathrm{reg}}$-cell activation, whereas high doses induce immunostimulatory effects because they can also stimulate $\mathrm{T}_{\text {eff }}$-cell activation ${ }^{2,3,12}$.
To solve this dilemma, we developed an approach using genetic-code-expansion-guided precision PEGylation and constructed a series of PEGylated IL-2 variants with PEG moieties of different sizes at one or more defined sites. By screening these variants, we found that dual-31/51-20K is an ideal receptor-biased agonist that exhibits selectively reduced binding affinity to IL-2R $\beta$ relative to IL-2R $\alpha$; this binding is therefore biased towards trimeric IL-2R. We demonstrated that dual-31/51-20K is able to preferentially activate and expand $\mathrm{T}_{\text {reg }}$ cells compared with $\mathrm{T}_{\text {eff }}$ cells at a wide range of doses, and this effect occurs as early as $3 \mathrm{~d}$ after treatment with either an alternated-day or classical single-dose regimen. This treatment results in the sustainable and selective tipping of the immune balance towards $\mathrm{T}_{\mathrm{reg}}$ cells and considerable alleviation of disease severity in mouse models of GvHD, SLE and RA within a short treatment duration.

Clearly, the persistent skewing of immune homeostasis towards $\mathrm{T}_{\text {reg }}$ cells is needed to suppress AD pathogenesis. These PEGylated IL-2 variants, particularly dual-31/51-20K, exhibited superior pharmacokinetic profiles in kidney clearance and serum half-life and led to a sustained increase in the $\mathrm{T}_{\text {reg }} / \mathrm{T}_{\text {eff }}$ ratio and inhibition of $\mathrm{T}_{\mathrm{H}} 17$ and/or $\mathrm{T}_{\mathrm{fh}}$ cell differentiation. The high-affinity receptor undergoes rapid endocytosis and subsequent dissociation in the endosome after binding with IL-2; IL-2R $\alpha$ can then be recycled back to the plasma membrane, whereas the other subunits of IL-2R undergo degradation with IL-2 (refs. ${ }^{43,48}$ ). Thus, these engineered IL-2 variants with relatively higher affinity for IL-2R $\alpha$ than for the other IL-2R subunits prevent the dissociation of IL-2 from IL-2R $\alpha$ in the endosome and might therefore cause IL-2 to be recycled to the cell surface along with IL-2R $\alpha^{39,40,43}$. This mechanism could also account for the superior pharmacokinetic value of PEGylated IL-2, even though the size of the PEG moieties as well as the site of PEGylation are also important determinants.

Although PEGylation was highly effective in improving pharmacokinetic properties and obtaining IL-2 variants with biased and long-acting activity, this process also compromised the bioactivity of IL-2. Compared with unmodified IL-2, PEGylated IL-2 variants, particularly dual-31/51-20K, exhibited an obvious reduction in the bioactivity of $\mathrm{CD}^{+} \mathrm{T}$ cells compared with $\mathrm{T}_{\text {reg }}$ cells and resulted in highly skewed $\mathrm{T}_{\text {reg- }}$-cell-selective activation. The reduction in activity was observed with an increase in the PEG moiety size up to $30 \mathrm{kDa}$, with the $30 \mathrm{kDa}$ PEGylated variants showing a marked reduction in pSTAT5 responses in both $\mathrm{CD}^{+} \mathrm{T}$ and $\mathrm{T}_{\text {reg }}$ cells, which resulted in decreased $\mathrm{T}_{\text {reg- }}$-cell-selective activation. Notably, we also observed substantially decreased efficiency of PEG coupling when the PEG size increased, as exemplified by sharp decreases in the yield of $30 \mathrm{kDa}$ and $40 \mathrm{kDa}$ PEGylates compared with those of $20 \mathrm{kDa}$ PEGylates. The decrease in the coupling efficiency may be explained by several factors, including the effect of steric hindrance and surface exposure of the PEGylated site(s), which is one of the key issues in subsequent clinical translational research. These results suggest the existence of an upper limit for the PEG size, probably around $20 \mathrm{kDa}$, for

Fig. 5 | Dual-31/51-20K ameliorated SLE in MRL/Ipr mice and ex vitro preferential activation of human $\mathrm{T}_{\text {reg }}$ cells from patients with SLE. a, Validation of cross-reactive and mouse $T_{\text {reg }}$-cell-selective activation by human IL-2 at the indicated doses. The percentages of $T_{\text {reg }}$ cells in CD4 ${ }^{+} T$ cells were determined (Supplementary Fig. 9). b,c, The ability of dual-31/51-20K to reduce signs of disease in MRL/Ipr SLE mice, as reflected by reduced levels of proteinuria, serum anti-double-stranded-DNA (dsDNA) antibodies and anti-nuclear antibodies at the end of the experiment (b), and $\lg G$ and C3 deposition in the kidneys and germinal centre (GC) formation in the spleen examined by immunofluorescence (c). MRL/lpr mice were subcutaneously administered $0.1 \mu \mathrm{g}$ or $0.5 \mu \mathrm{g}$ of IL-2 daily for five consecutive days or an equal dose of dual-31/51-20K every other day three times and repeated once two days later. Cryosections from the kidney or spleen were stained with anti-mouse lgG (red), anti-C3 (green), and anti-B220 (green) + anti-GL7 (red) antibodies. Stained sections were analysed using fluorescence microscopy, and the mean fluorescence intensity (MFI) values of each marker were calculated using ImageJ (Extended Data Fig. 3). Scale bars, $500 \mu \mathrm{m}$ (top and middle) and 1,000 $\mu \mathrm{m}$ (bottom). For a-c, data are mean \pm s.e.m. $n=3$ (a) or $n=4$ (b,c) biologically independent mice per group. For $\mathbf{a}-\mathbf{c}$, statistical analysis was performed using two-tailed Student's $t$-tests, comparing the IL-2- versus the 31/51-20K-treated group at the indicated dose; ${ }^{\star \star \star \star} P \leq 0.0001$. Representative results from one of three (a) and one of two (b,c) experiments are shown. 
the PEGylation of IL-2 because sizes greater than this exerted marked effects on the biological activity of IL-2 and the coupling efficiency of PEG.

a
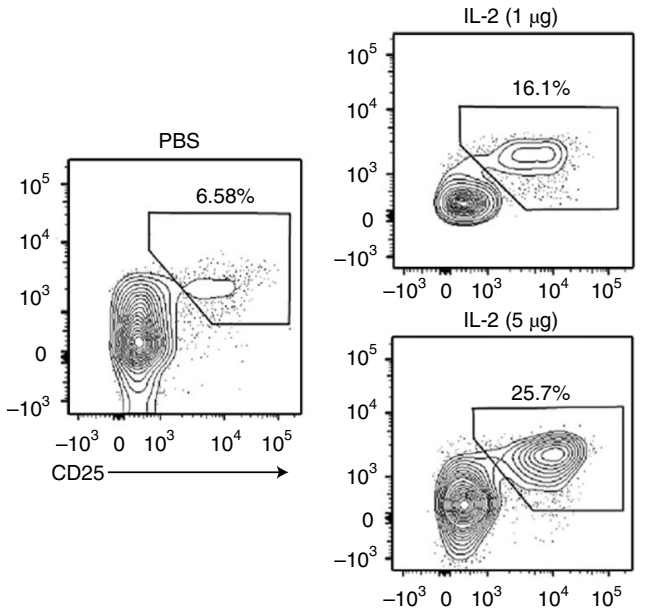

A major side effect of IL-2 treatment is VLS, which is generally believed to be caused by the binding of IL- 2 to $\mathrm{CD} 25^{+}$pulmonary endothelial cells ${ }^{46}$. Here we demonstrated that the effect of dual-31/

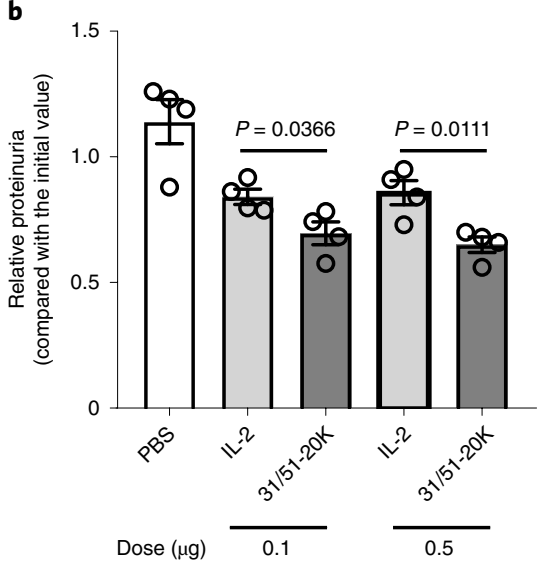

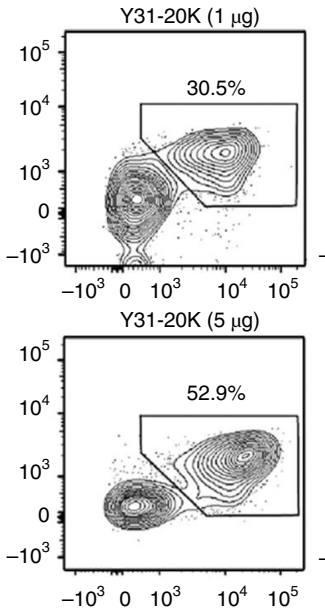

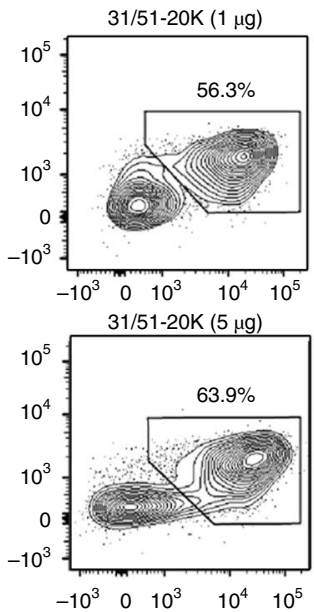

c
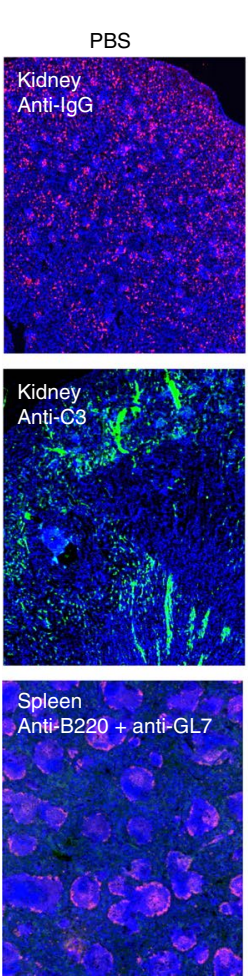
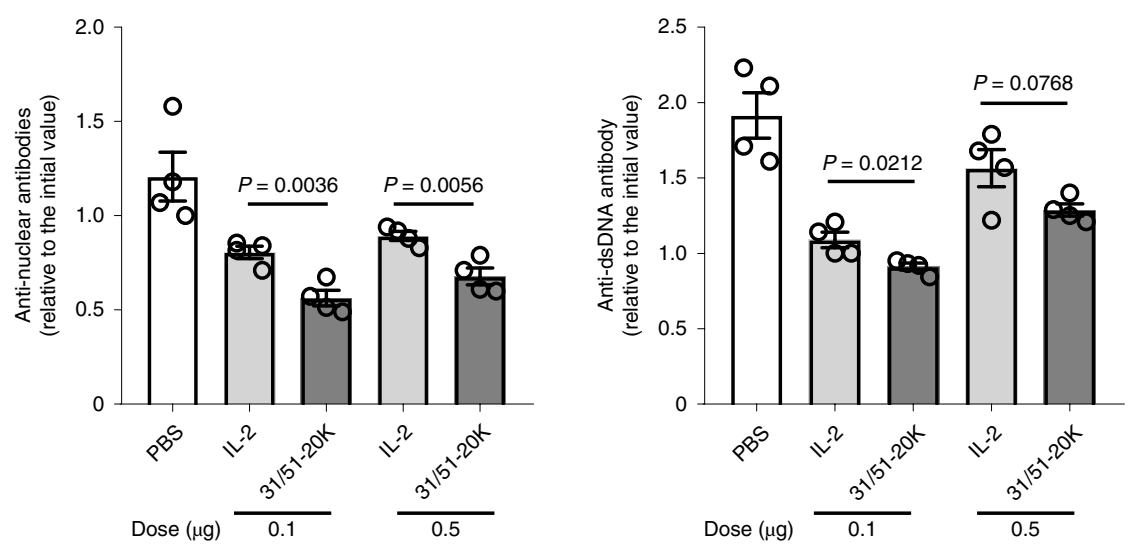

IL-2

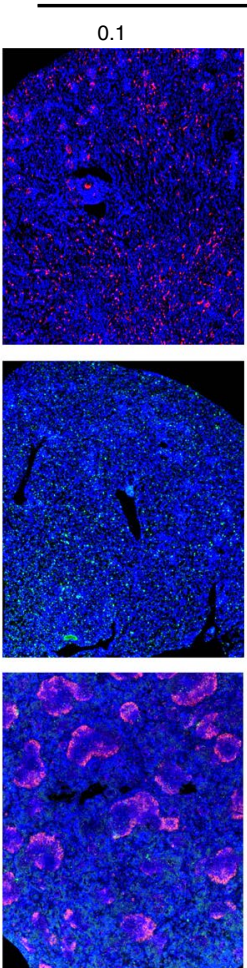

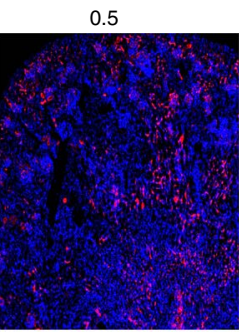
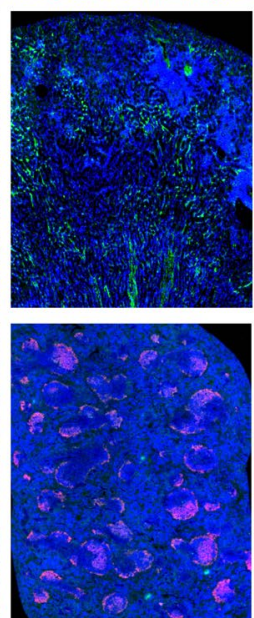

Dual-31/51-20K
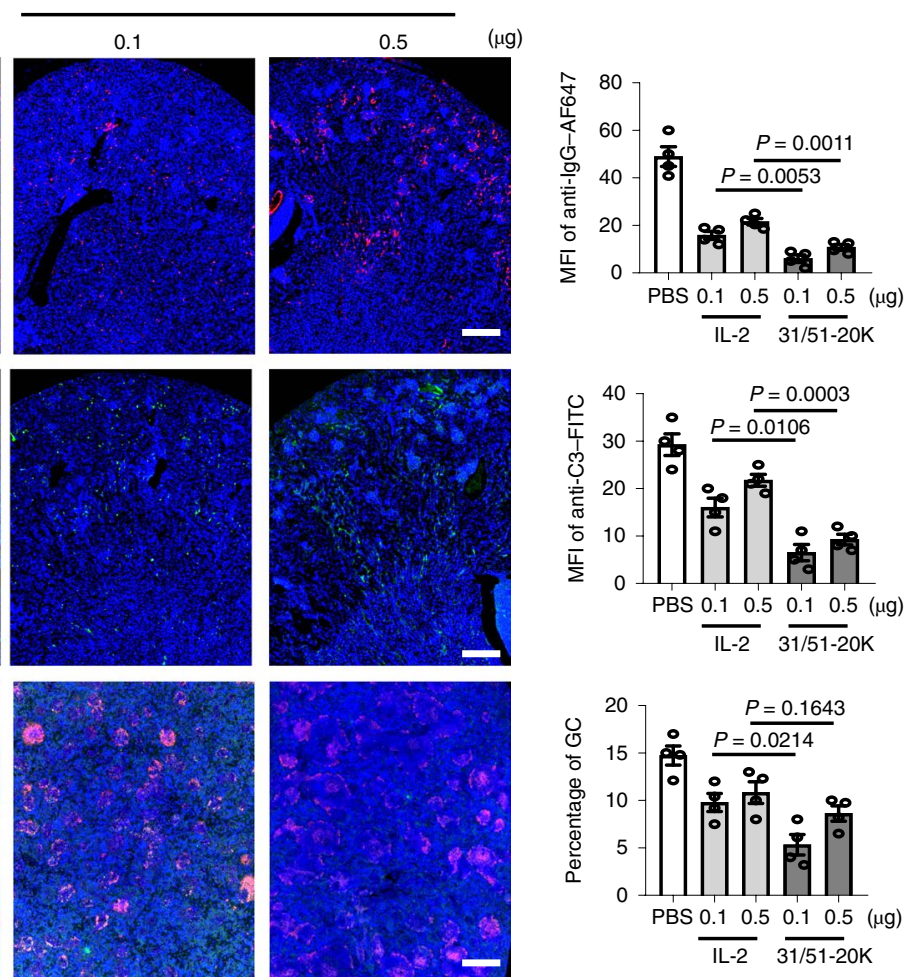

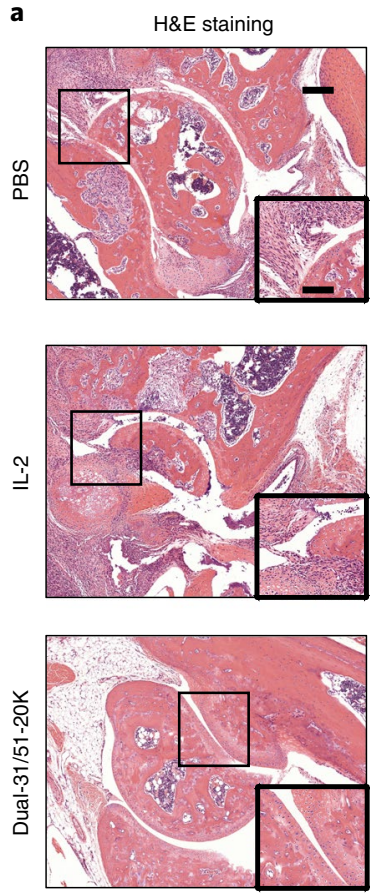
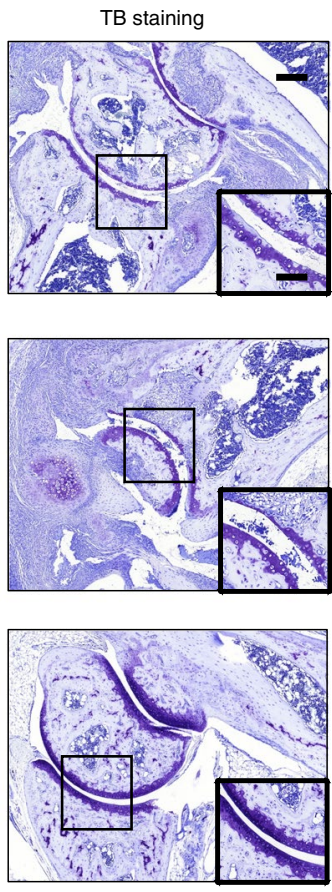
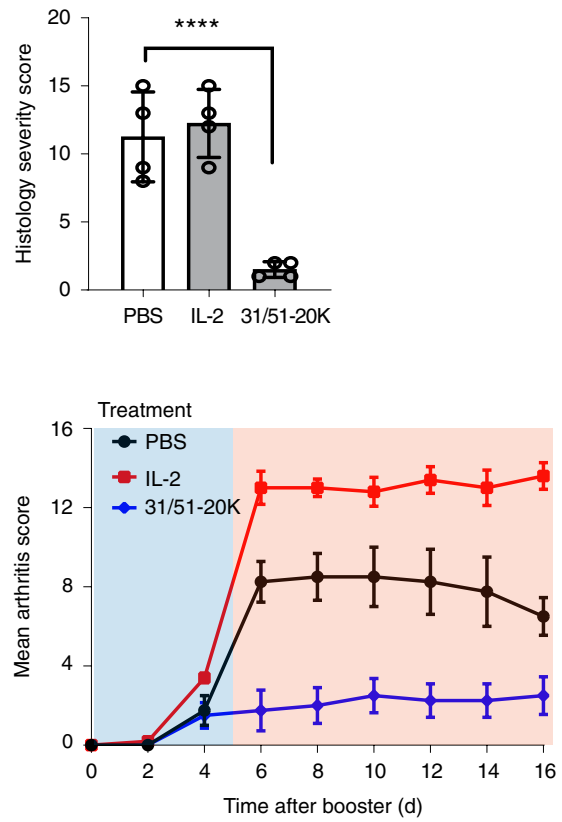

b
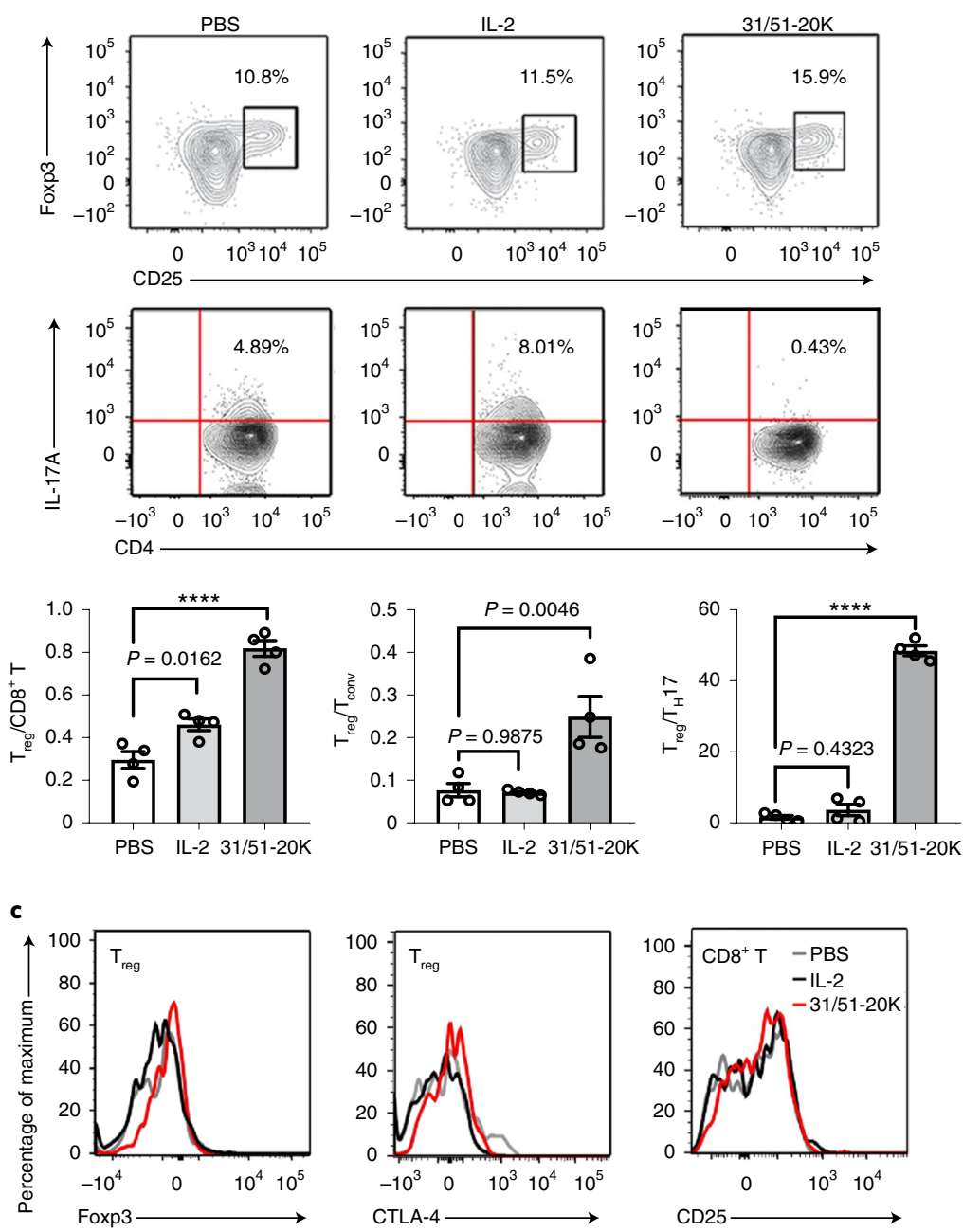

。
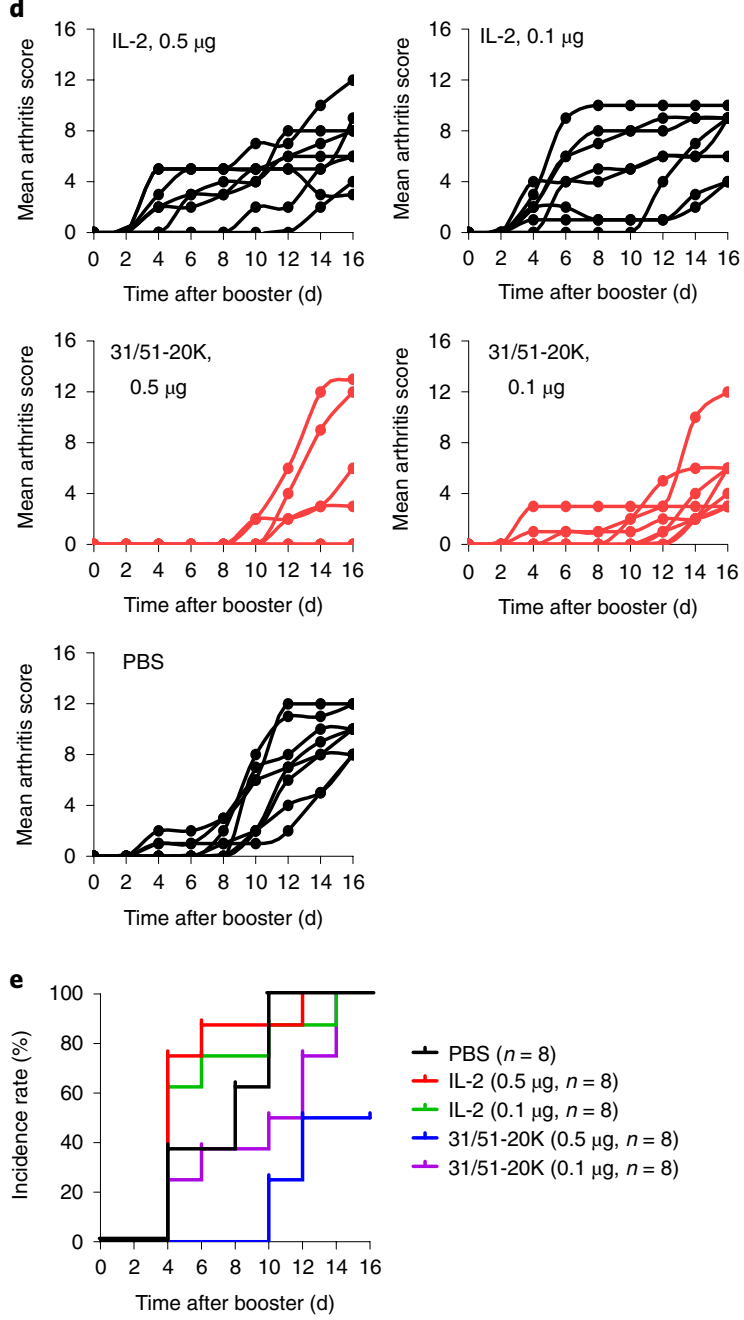

51-20K treatment was superior to that of unmodified IL-2 in not only $\mathrm{T}_{\mathrm{reg}}$-cell-selective activation in the lungs but also on pulmonary endothelial cells. The latter effect may be ascribed to several factors, including the relatively low expression level of trimeric IL-2R on endothelial cells and the reduced binding affinity of $31 / 51-20 \mathrm{~K}$ to IL-2R. Note that $T_{\text {reg }}$ cells have an important role in the protection 
Fig. 6 | Dual-31/51-20K-mediated amelioration of CIA. a, The IL-2- versus dual-31/51-20K-induced change in arthritis severity reflected by the histological severity score and mean arthritis score. DBA/1 mice were immunized with bovine COll from CFA at day 0 and rechallenged $21 \mathrm{~d}$ later. The mice were then given $0.5 \mu \mathrm{g}$ of IL-2 every other day for a total of three times (red) or $1.5 \mu \mathrm{g}$ of dual-31/51-20 $\mathrm{K}$ in a single injection (blue), and scoring was continued without further treatment. The histological severity, determined by haematoxylin and eosin (H\&E) staining, was scored on the basis of a 0-4 scale for each paw, with a cumulative score of 0-16 for each mouse. Scale bars, $200 \mu \mathrm{m}$ and $50 \mu \mathrm{m}$ (insets); the scale bars in the top row apply to the respective images in the middle and bottom rows. TB, toluidine blue. $\mathbf{b}, T_{\text {reg }}$-cell-selective activation in the spleen by dual-31/51-20K versus IL-2, as reflected by an increase in $\mathrm{T}_{\text {reg }} / C D 8^{+} \mathrm{T}, \mathrm{T}_{\text {reg }} / \mathrm{T}_{\text {conv }}$ and $\mathrm{T}_{\text {reg }} / \mathrm{T}_{\mathrm{H}} 17$ cell ratios on day 8 after rechallenge (Supplementary Fig. 14). c, Flow cytometry analysis of induced Foxp3, CTLA-4 and CD25 in $\mathrm{T}_{\text {reg }}$ cells and CD8+ $\mathrm{T}$ cells of the spleen in response to the indicated treatment. d,e, The preventive potential of dual-31/51-20K versus IL-2 tested in CIA models. The COII-preimmunized DBA/1 mice were given the indicated dose of IL-2 every other day three times or an equal dose of dual31/51-20K in a single injection one week before the rechallenge. The mean arthritis scores (d) and CIA incidence (e) after rechallenge were recorded. For $\mathbf{a}-\mathbf{c}$, data are mean \pm s.e.m. $n=4$ biologically independent mice per group. Statistical analysis was performed using one-way ANOVA with Dunnett's multiple-comparison test, compared with the PBS-treated group; ${ }^{\star \star \star \star} P \leq 0.0001$. For a-e, representative results from one of two experiments are shown for all panels.

against IL-2-induced toxicity because VLS could be induced by the administration of low-dose IL-2 in $\mathrm{T}_{\text {reg }}$-cell-depleted mice ${ }^{49}$, which underscores the potential safety of PEGylated IL-2.

Although their affinity for the $\beta$ subunit was abrogated, Asp 20 PEGylates maintained their biological activity, albeit to a lesser degree than that obtained with unmodified IL-2. This finding conflicts slightly with the prevailing view that IL-2R $\beta$ has a crucial and required role in IL-2 signalling and that the $\alpha$ subunit increases the affinity of the IL-2-IL-2R complex but does not participate in IL-2 signalling ${ }^{39}$. Because the precise role of IL-2R $\alpha$ remains elusive ${ }^{39}$, we reasoned that these PEGylated IL-2 variants might have distinct signalling mechanisms, and further structural mechanisms remain to be examined. Furthermore, in the humanized mouse model, mice treated with mono-D20-20K possessed an even lower percentage of $\mathrm{T}_{\text {reg }}$ cells and lower $\mathrm{T}_{\text {reg }} / \mathrm{CD}^{+} \mathrm{T}$ and $\mathrm{T}_{\text {reg }} / \mathrm{T}_{\text {conv }}$ cell ratios compared with mice that were treated with IL-2. This intriguing effect of Asp 20 PEGylates was consistent with recent reports on the development of cytokine partial agonists ${ }^{16}$. Thus, due to the distinct effects caused by site-specific PEGylation, these IL-2 variants could be developed as promising versions of IL-2 therapeutics for uses other than $\mathrm{AD}$ treatment, such as the treatment of solid tumours through the suppression of tumour-infiltrating $\mathrm{T}_{\text {reg }}$ cells ${ }^{50}$.

The results of numerous clinical trials suggest that low-dose IL-2 might be beneficial for treating ADs, but its varying pharmacokinetics across individuals and its rapid clearance from the body make it difficult to achieve sustainable low but sufficient serum IL-2 concentrations $s^{1,4,7,8}$. The therapeutic efficacy of IL-2 is therefore inconsistent, and the requirement of a daily injection hinders its extensive clinical application. Given the heterogeneity and complexity of ADs, the effects of IL-2 at certain administered doses vary across $\mathrm{AD}$ models and even within subsets of mice with the same AD. Indeed, we found that the same low dose of IL-2 exerted therapeutic effects in the GvHD and SLE models but led to aggravation of joint swelling and destruction in the CIA model. This variability of ADs highlights the liability and potential safety issues of using low-dose
IL-2 for the treatment of ADs and underscores the importance of developing $\mathrm{T}_{\text {reg }}$-cell-selective IL-2 drugs. Here we developed such a drug and demonstrated that the effects of treatment with dual$31 / 51-20 \mathrm{~K}$ across a wide range of doses are superior to those of IL-2 in the selective activation of $\mathrm{T}_{\text {reg }}$ cells and the alleviation of disease activity and severity. The combination of its prolonged half-life in the body with its reduced dosing frequency renders dual-31/51$20 \mathrm{~K}$ a promising and more reliable treatment regimen for $\mathrm{ADs}$ that exhibits consistent effects across different doses.

Clinically, the long-term treatment of ADs with immunosuppressants increases the patients' risk of infection ${ }^{51}$. Whether skewing immune homeostasis towards $\mathrm{T}_{\text {reg }}$-cell activation with engineered PEGylated IL-2 impairs host immune defence should therefore be determined. We found that dual-31/51-20K treatment significantly mobilized NK cells to infiltrate the lungs, upregulated NKp46 and NKG2D, and reduced the viral load after challenge with influenza WSN virus, which suggested that dual-31/51-20K does not inhibit but rather enhances the host immune defence against viral infection. This finding is consistent with the results of a clinical study with low-dose IL-2 administration ${ }^{4,8,11}$. Given the superiority of dual$31 / 51-20 \mathrm{~K}$ in enhancing resistance to viral infection and its capacity to reduce an excessive inflammatory response, whether dual-31/51$20 \mathrm{~K}$ as well as other receptor-biased agonists could be applied to reduce the viral load in patients with viral infections such as coronavirus disease 2019 (COVID-19) warrants further investigation.

NKTR-358, which is currently the only known PEGylated IL-2 for ADs, is under investigation in a phase Ib clinical trial (NCT03556007), and its efficacy remains to be determined. Compared with the accessible data ${ }^{52}$, dual-31/51-20K probably acts as a more robust receptor-biased PEGylate and therefore preferentially activates $\mathrm{T}_{\text {reg }}$ cells over $\mathrm{CD}^{+} \mathrm{T}$ cells. This finding can be attributed to the site-specific PEGylation approach adopted in this study, which involves the judicious selection of the PEG size and PEGylation site(s) to optimize the effects on biological and pharmacological properties.

Fig. 7 | Assessment of the impact of IL-2 PEGylation on the immune responses of mice to the influenza virus. C57BL/ 6 mice were treated with $0.5 \mu$ g of IL-2 daily for five consecutive days or an equal dose of dual-31/51-20K every other day for a total of three times; four days after the final injection (day 9), the mice were administered with a $20 \times \mathrm{LD}_{50}$ dose of WSN virus by inhalation. Three days after virus infection (day 12), four of eight mice per group were euthanized, and the blood, spleen and lungs were collected for assays. Histological sections were stained with anti-matrix protein 1 (M1, red) and anti-nucleoprotein (NP, green) antibodies for analysis of WSN deposits in the lungs by fluorescence microscopy, and plaque titration of the virus was performed. The histological inflammation score was estimated according to the reported scoring criterion described in the Methods. The remaining mice were continuously monitored for body weight changes at one week after infection. $\mathbf{a}, \mathbf{b}$, The outcomes of mice that were pretreated with IL-2 versus dual31/51-20K against WSN virus. Mice that were pretreated with dual-31/51-20K showed a lower viral load and decreased lymphocyte infiltration (a), as well as milder weight loss and a lower death rate (b). Scale bars, $200 \mu \mathrm{m}$ (middle and bottom row) and $50 \mu \mathrm{m}$ (bottom row insets). c, The effects of IL-2 versus dual-31/51-20K on the percentage and number of certain types of pulmonary lymphocytes on day 12 . For a-c, data are mean \pm s.e.m. $n=4$ biologically independent mice per group. Statistical analysis was performed using one-way ANOVA with Dunnett's multiple-comparison test compared with the virus + PBS-treated group (a, c and $\mathbf{b}$ (left)) and two-tailed log-rank (Mantel-Cox) test for the survival analysis (b (right)). The experiment was repeated three times with similar results, and results from one of the three representative experiments are shown (Extended Data Fig. 4 and Supplementary Fig. 18). 
For decades, PEGylation has served as the gold standard for ameliorating the pharmacokinetic properties and immunogenicity of proteins, but PEG itself has been considered to be immunogenic when conjugated to carriers and functions similarly to hapten ${ }^{53}$. The haptogenic character of PEG depends on several factors, such as the length of PEG, the nature of the anchoring protein and the types a
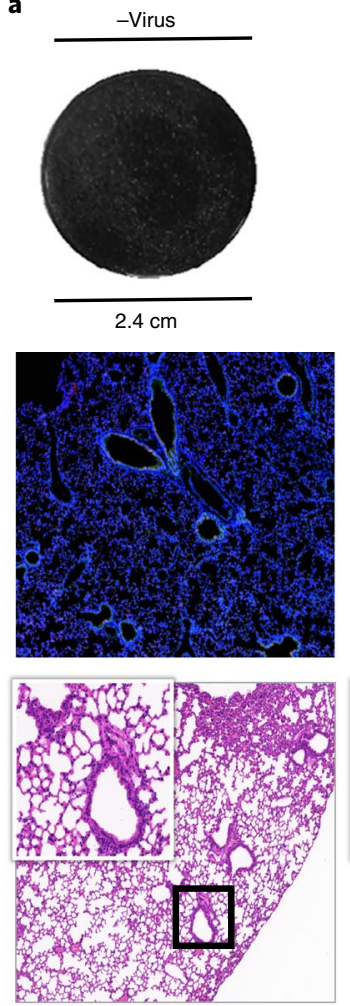
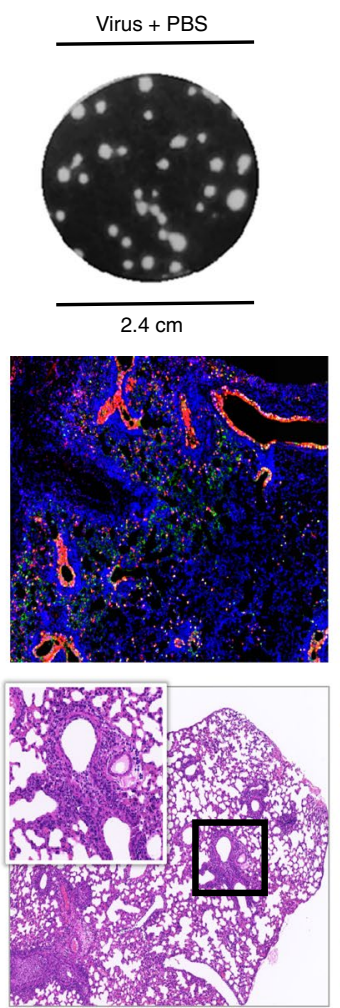
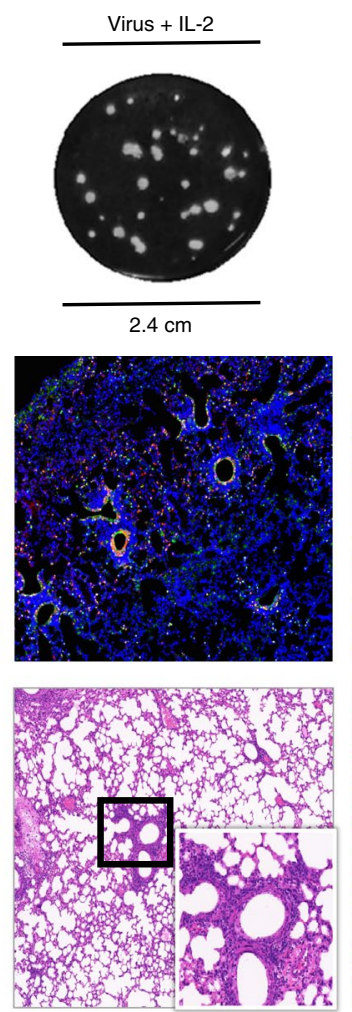
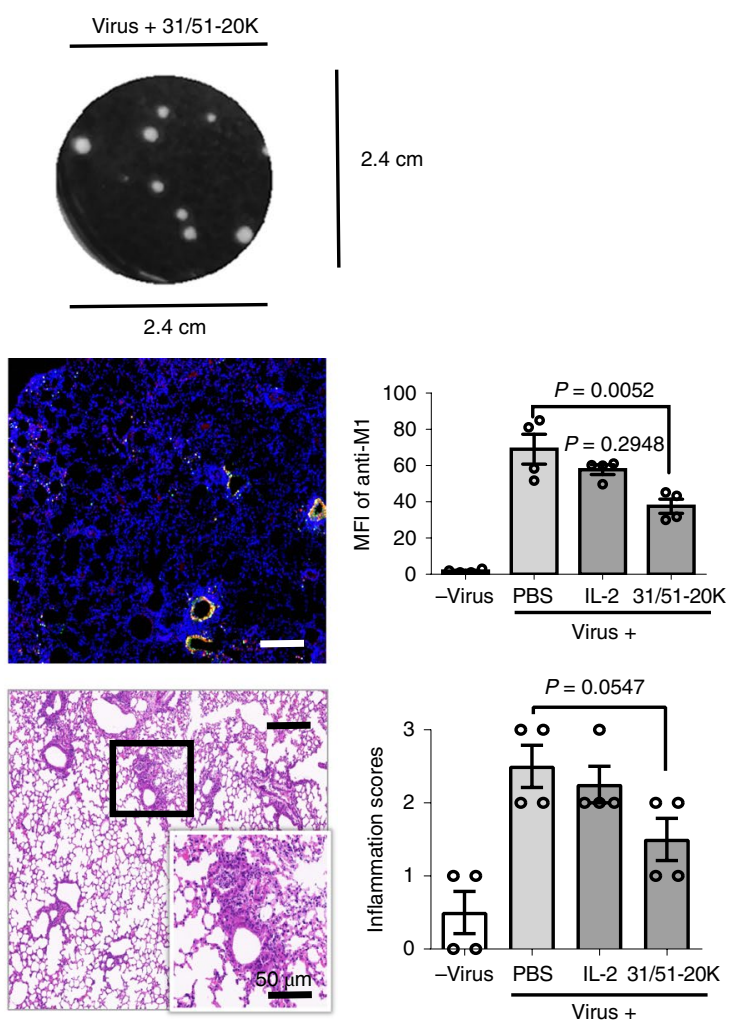
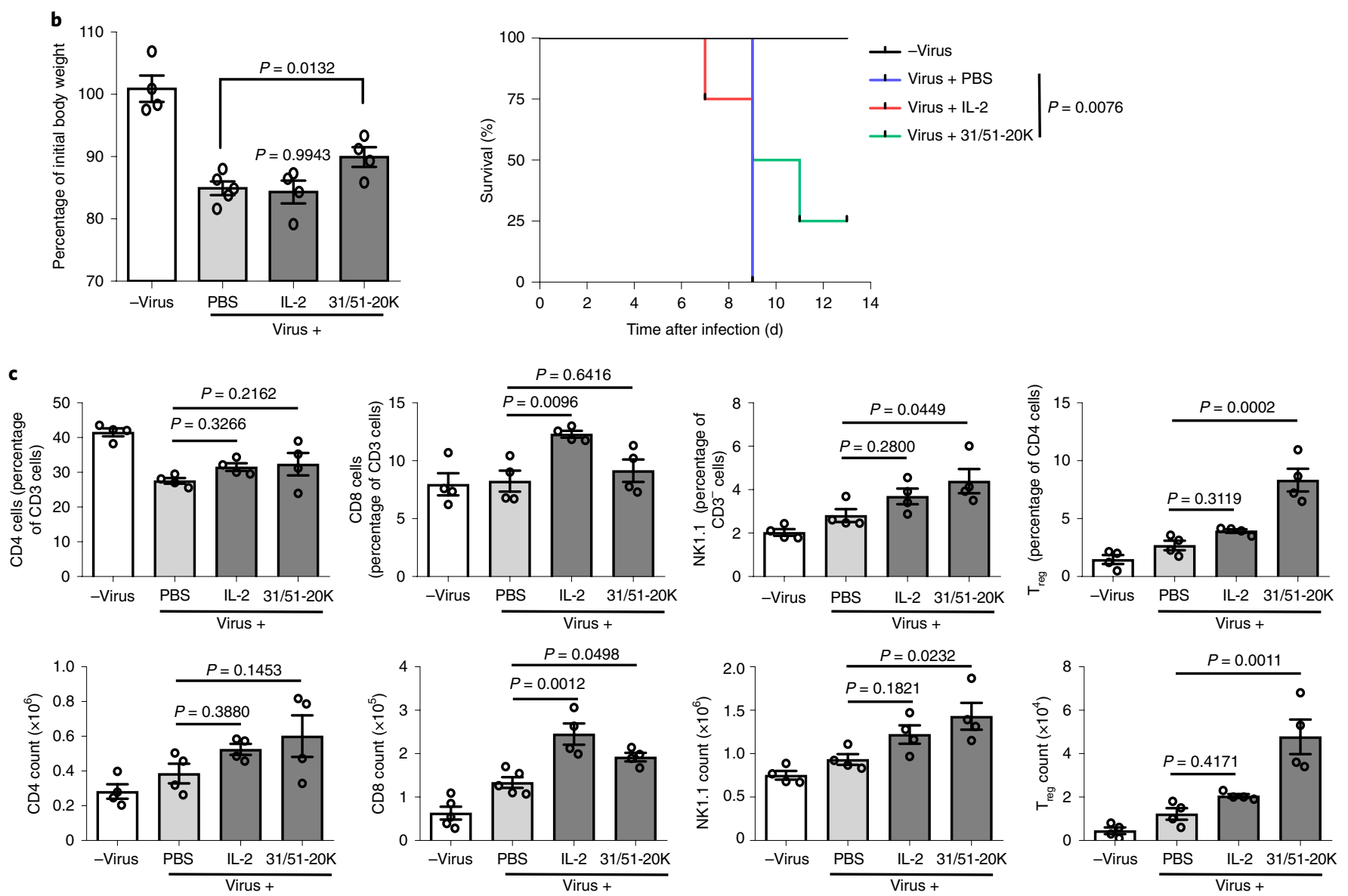
of terminal groups. An evaluation of the potential immunogenicity of dual-31/51-20K after its long-term administration in a mouse model revealed that no significant level of antibodies against either the IL-2 or PEG moiety were elicited by dual-31/51-20K compared with that induced by IL-2, indicating that the incorporation of NAEK and the subsequent PEGylation of IL-2, at least at these two sites, does not create an additional immunogenic epitope and does not introduce immunogenicity. Nevertheless, optimizing the treatment regimens, including the dose and interval of administration, remains an important issue to minimize the potential occurrence of immunogenicity. Furthermore, anti-PEG prescreening before obtaining a PEGylated compound may be needed because of the high prevalence of PEG antibodies found in healthy donors ${ }^{54}$.

One major limitation of this study is that all in vivo experiments were performed in $\mathrm{AD}$ disease models; whether the therapeutic and prophylactic effects of dual-31/51-20K that we observed are repeatable in human patients is therefore worth investigating. On the basis of the features of product consistency and quality control needed for modern drug production and regulatory approval, precision PEGylates offer clear advantages over non-site-specific conjugates because a single, well-defined homogenous product can be produced; therefore, batch-to-batch reproducibility is readily achievable. Endeavours are actively underway to advance these constructs to clinical trials.

In conclusion, we have constructed precision IL-2 PEGylates in a single-molecule form that exhibited notable pharmacokinetic improvements and an extended half-life in the body. These receptor-biased agonists, as exemplified by dual-31/51-20K, preferentially activated and expanded $\mathrm{T}_{\text {reg }}$ cells over effector cells across a wide range of doses and demonstrated sustainable and consistent therapeutic efficacy in mouse models of GvHD, SLE and RA. By addressing the clinical shortcomings of IL-2, that is, its pleiotropic effects and requirement for a daily injection due to its short half-life and narrow therapeutic dose window, this site-specific PEGylation strategy is a promising treatment strategy for ADs. More importantly, this approach presents opportunities for applying site-specific PEGylation to engineer other pivotal inflammatory cytokines for precision immunotherapy for ADs and other diseases.

\section{Methods}

General materials. The DH5 $\alpha$ strain was used to clone and propagate plasmid DNA. Miniprep and Maxiprep Kits (Axygen) were used to collect and purify plasmid DNA. The GoTag GreenMaster Mix (Promega) and a Polymerase Chain Reaction (PCR) Clean-up System (Promega) were used to perform PCR and DNA fragment purification. The QuikChange Lightning Site-Directed Mutagenesis Kit (Agilent) was used to generate site-directed mutations. The azido-bearing unnatural amino acid NAEK and DIBO-PEGs were synthesized as previously reported ${ }^{37,38}$. Commercial IL-2 (Thermo Fisher Scientific) was used to verify the in vitro activity of the IL-2 prepared in house.

Production of the wild-type and NEAK-containing IL-2-His $\times 6$ variants. The cDNAs encoding human IL-2 were cloned into the $\mathrm{pET}-2 \mathrm{la}(+)$ expression vector (Novagen) containing the T7 promoter, a His $\times 6$ tag at the $\mathrm{C}$ terminus and ampR. To generate NEAK-containing IL-2 variants at the selected positions, the amber stop codon TAG was introduced into pET21-IL-2 by site-directed PCR mutagenesis. The obtained plasmids were transformed into the OrigamiB(DE3) strain either with or without pSURAR-YAV, which contained the expanded genetic code system for an amber codon-suppressing tRNA Pyl under the control of the proK promoter and NEAK-specific aminoacyl-tRNA synthetase under the control of the $\operatorname{araB}$ promoter $^{38}$. For mutated IL-2, in brief, transformed OrigamiB(DE3)

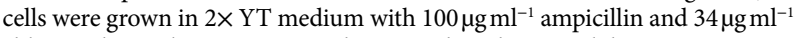
chloramphenicol at 220 r.p.m. and $37^{\circ} \mathrm{C}$. When the optical density at $600 \mathrm{~nm}$ reached approximately 0.8 to 1.0 , NEAK, IPTG and arabinose were added simultaneously to final concentrations of $1 \mathrm{mM}, 0.5 \mathrm{mM}$ and $0.01 \%$, respectively. IL-2 expression was performed as a regular process of protein expression. After overnight induction at $22^{\circ} \mathrm{C}$, all of the cell samples were collected by centrifugation and resuspended in His-binding buffer (20 mM Tris- $\mathrm{HCl}, \mathrm{pH} 8.0,250 \mathrm{mM} \mathrm{NaCl}, 5 \mathrm{mM}$ imidazole). Protein extraction was performed by passing cells through a microfluidizer twice at 1,200 bar with cooling, and the supernatant was collected by centrifugation.

Protein purification and PEGylation. For the production of PEGylated IL-2 analogues, the His-tagged IL-2 protein in the supernatant was first enriched at approximately $1 \mathrm{mg} \mathrm{ml}^{-1}$ using Ni-NTA His-Bind Resin (Novagen), and synthesized DIBO-PEG was then added to the eluent buffer $(20 \mathrm{mM}$ Tris- $\mathrm{HCl}$, $\mathrm{pH} 7.8,250 \mathrm{mM} \mathrm{NaCl}, 250 \mathrm{mM}$ imidazole) at a final concentration of $2 \mathrm{mM}$. Next, the reacted sample was diluted to an appropriate concentration with the $\mathrm{pH}$ adjusted to 4.5 by glacial acetic acid and then loaded onto a SOURCE $15 \mathrm{~S}$ (GE Healthcare) column equilibrated in $20 \mathrm{mM}$ sodium acetate, $\mathrm{pH} 4.5$. PEGylated human IL-2 was eluted with a 4-35\% linear gradient in 20 column volumes of elution buffer ( $20 \mathrm{mM}$ sodium acetate, $2 \mathrm{M} \mathrm{NaCl}, \mathrm{pH} 4.5)$. The main elution peak was pooled, concentrated and buffer-exchanged into D-PBS using ultrafiltration (Millipore) at least three times. The eluted PEGylated IL-2 was further purified by running over a Superdex 200 increase (GE Healthcare) with $20 \mathrm{mM}$ Tris-HCl, $500 \mathrm{mM} \mathrm{NaCl}, \mathrm{pH} 8.0$ as the running buffer. The main elution peak was collected, concentrated and frozen at $-80^{\circ} \mathrm{C}$ until use. PEGylated IL-2 was confirmed by SDS-PAGE stained with Coomassie blue dye and matrix-assisted laser desorption ionization mass spectrometry. The purity of the PEGylated IL-2 protein obtained in this way was usually greater than $95 \%$.

Binding affinity analysis. The binding affinities of IL-2 and PEGylated IL-2 towards IL-2R $\alpha$ and IL-2R $\beta$, respectively, were measured by BLI using an Octet RED96 instrument (FortéBio, Pall Life Sciences). All assays were performed in D-PBS with $0.2 \%$ BSA and $0.05 \%$ Tween-20 (assay buffer). The final volume for all the solutions was $200 \mu \mathrm{l}$ per well. Assays were performed at $25^{\circ} \mathrm{C}$ in solid black 96-well plates (Geiger Bio-One). His-tagged CD25 (IL-2R $\alpha$ ) in capture buffer $\left(20 \mu \mathrm{g} \mathrm{ml}^{-1}\right.$, acetic acid-sodium acetate, $\left.\mathrm{pH} 4.0\right)$ was chemically immobilized by amine coupling on an AR2G biosensor according to the manufacturer's directions. $\mathrm{CD} 122-\mathrm{Fc}(\mathrm{IL}-2 \mathrm{R} \beta)$ in assay buffer $\left(20 \mathrm{\mu g} \mathrm{m}^{-1}\right)$ was loaded onto the surface of protein A Capture Biosensors for $300 \mathrm{~s}$. A threefold dilution series (6.1-500 nM) of IL-2 and PEGylated IL-2 variants was used in a titration series of five. The dissociation of the interaction was followed for $300 \mathrm{~s}$. Between the measurements, no regeneration was needed because the dissociation was completed within $10 \mathrm{~min}$. Data were analysed using FortéBio data acquisition software v.8.1 and were fitted using a global fit 1:1 model to determine the $K_{\mathrm{D}}$ values and other kinetic parameters.

The binding of IL-2 and PEGylated IL-2 to trimeric IL-2R, composed of IL-2R $\alpha$, IL-2R $\beta$ and IL-2R $\gamma$, or to dimeric IL-2R, containing IL-2R $\beta$ and IL-2R $\gamma$, was measured by surface plasmon resonance using a Biacore $8 \mathrm{~K}$ (GE Healthcare) at $25^{\circ} \mathrm{C}$. In brief, trimeric IL-2R containing equimolar amounts of Fc-tagged IL-2R $\alpha$, IL-2R $\beta$ and IL-2R $\gamma$ or dimeric IL-2R containing equimolar amounts of Fc-tagged IL-2R $\beta$ and IL-2R $\gamma$ was immobilized on a CM5 chip with approximately $800-1,000$ RUs using a standard amine coupling procedure (Biacore; GE Healthcare BioSciences). This level of receptor immobilization was sufficient to produce a maximal specific IL-2-binding response. The reference channel underwent the same amine coupling procedures without any protein immobilization to serve as a blank surface. For the surface equilibrium binding assay, a threefold dilution series (0.01-30 nM for trimeric IL-2R and 4.8-300 nM for dimeric IL-2R) of IL-2 and PEGylated IL-2 variants was used in a titration series of seven were injected over the complex of the IL-2R surface at a flow rate of $30 \mu \mathrm{min}^{-1}$ for $5 \mathrm{~min}$, and dissociation was monitored for $10 \mathrm{~min}$ after injection. After every cycle, the IL-2R surfaces were regenerated by $10 \mathrm{mmol}$ glycine- $\mathrm{HCl}(\mathrm{pH} 4.0)$ to remove the residual sample to the baseline level. Data were analysed using Biacore 8 Evaluation Software and were fitted using a 1:1 steady affinity model to determine the $K_{\mathrm{D}}$ values and other kinetic parameters. The IL-2 and PEG-IL-2 variant concentrations were measured using the bicinchoninic acid protein assay (Pierce). The concentrations of all of the samples reflect the weight of the IL-2 without the attached PEG.

Pharmacokinetic analysis in mice. The pharmacokinetic properties of IL-2 and PEGylated analogues were determined after subcutaneous administration in groups of three female BALB/c mice (aged 8 to 10 weeks) that received a single subcutaneous injection of a sample at a dose of $5 \mu \mathrm{g}$ per mouse. The dose sample concentrations reflect the weight of the IL-2 protein without the attached PEG. Mice were bled through the retro-orbital method at various time points $(30 \mathrm{~min}$ and $2 \mathrm{~h}, 8 \mathrm{~h}, 24 \mathrm{~h}$, $48 \mathrm{~h}, 72 \mathrm{~h}$ and $96 \mathrm{~h}$ after injection). The blood samples were centrifuged, and the plasma samples were stored at $-80^{\circ} \mathrm{C}$ until analysis. A predose sample $(0 \mathrm{~h})$ was drawn $1 \mathrm{~d}$ before injection of the test samples. Content levels of the test proteins were quantified using a commercial Sandwich ELISA Kit (Alpha Diagnostic International). As each PEGylated IL-2 analogue produced a different concentration-dependent signal in these assays, the concentrations were calculated using a standard curve generated from the corresponding dosed samples. Pharmacokinetic parameters were estimated using the modelling program Kinetica (v.5.1; Thermo Fisher Scientific). NCA Assistant Extravascular (one compartment first order, no lag time, first-order elimination) was used, and concentration data were uniformly weighted.

Protein thermal stability assay. Protein thermal stability was measured by DSF using a Prometheus NT.48 instrument (NanoTemper Technologies). IL-2 and PEGylated IL-2 variants were dialysed into D-PBS before measurement, and $10 \mu \mathrm{l}$ of each sample was loaded in nanoDSF grade high-sensitivity glass capillaries (NanoTemper Technologies) at a heating rate of $1^{\circ} \mathrm{C} \mathrm{min}-1$ in a range from $20^{\circ} \mathrm{C}$ to $95^{\circ} \mathrm{C}$. Temperature-induced protein unfolding was measured by detecting changes in tryptophan fluorescence at emission wavelengths of $330 \mathrm{~nm}$ and $350 \mathrm{~nm}$, and melting points $\left(T_{\mathrm{m}}\right)$ were calculated according to the manufacturer's instructions. 
In vitro pSTAT5 assays in hPBMCs and isolated specific immune cell subsets. The in vitro pSTAT5 assays were performed as previously reported ${ }^{20}$. In brief, hPBMCs were isolated from healthy and patient donors by Ficoll and resuspended in RPMI $0.1 \%$ BSA. Cells were rested at $37^{\circ} \mathrm{C}$ in a T25 tissue flask until the time of assay $(1-2 \mathrm{~h})$. The rested cells were resuspended at $2 \times 10^{6} \mathrm{per} \mathrm{ml}$ in assay medium (RPMI, $0.1 \%$ BSA) and then aliquoted at $50 \mu \mathrm{l}$ per well $\left(1 \times 10^{5}\right)$ into a 96-well V-bottom plate. An equal volume of each protein sample was prepared in assay medium and added to the test wells in serial fivefold dilutions, and the cells were cultured in a $37^{\circ} \mathrm{C}$ incubator for $50 \mathrm{~min}$. Cells were fixed by the addition of $100 \mu \mathrm{l}$ of fixation buffer (BD Biosciences) and incubated at $37^{\circ} \mathrm{C}$ for $15 \mathrm{~min}$. After washing three times with D-PBS, assay plates were centrifuged to pellet the cells, and permeabilization buffer III (BD Biosciences) was used to resuspend the cells, followed by $15 \mathrm{~min}$ incubation on ice. The fixed and permeabilized cells were washed twice with FACS buffer and stained with the following antibodies for flow cytometry analysis: anti-human CD3-APC/Cy7, CD4-PE/Cy7, CD8-FITC, CD25-APC, CD127-PE, CD56/CD16-Brilliant Violet 605 and pSTAT5-Pacific Blue. For pSTAT5 assays in specific subpopulations of hPBMCs, magnetic separation kits (MiltenyiBiotech) were used to isolate purified cell populations according to the manufacturer's directions. To obtain purified $\mathrm{T}_{\text {reg }}$ cells, $\mathrm{CD} 4^{+} \mathrm{T}$ cells were first enriched by negative selection with magnetic-activated cell sorting, and $\mathrm{T}_{\text {reg }}$ cells $\left(\mathrm{CD} 4^{+} \mathrm{CD} 25^{\text {high }} \mathrm{CD} 127^{\text {low }}\right)$ were then sorted on a FACSAria (BD Biosciences). The sorted $\mathrm{T}_{\mathrm{reg}}$ cells were expanded with IL-2 and CD3/CD28 beads ex vivo for $9 \mathrm{~d}$ before the pSTAT5 assay. The purities of isolated and expanded $\mathrm{T}_{\mathrm{reg}}$, native $\mathrm{CD} 4$, memory CD4, native CD8, memory CD8 and NK cells were confirmed using flow cytometry according to the manufacturer's directions (data not shown).

All FACS antibodies were used at a dilution of 1:50. Data were collected using the LSR Fortessa system and analysed using FlowJo software. Data are plotted as background-subtracted MFI, normalized to the maximum signal for each cell type $\left(\mathrm{IL}-2,1 \mu \mathrm{g} \mathrm{ml}^{-1}\right)$. The background is defined as pSTAT5 MFI in non-stimulated cells. $\mathrm{T}_{\text {reg }}$ cells are defined as $\mathrm{CD} 3^{+} \mathrm{CD} 8^{-} \mathrm{CD} 4^{+} \mathrm{CD} 25^{\text {high }} \mathrm{CD} 127^{\text {low }}$; $\mathrm{NK}$ cells are defined as $\mathrm{CD}^{-}{ }^{-} \mathrm{CD} 16^{+} \mathrm{CD} 56^{+}$; and $\mathrm{CD} 8^{+} \mathrm{T}$ cells are defined as $\mathrm{CD} 3^{+} \mathrm{CD} 4^{-} \mathrm{CD} 8^{+}$.

In vitro cell proliferation and IL-2-induced protein expression assay. The IL2-mediated proliferation of specific cell subsets was analysed by flow cytometry. In brief, hPBMCs were isolated from healthy and patient donors by Ficoll and resuspended in complete medium (RPMI 1640,10\% FBS, sodium pyruvate, non-essential amino acid and penicillin-streptomycin). Then, $100 \mu \mathrm{l}$ per well $\left(2 \times 10^{5}\right)$ aliquots of resuspended cells were distributed into a 96-well V-bottom plate, and an equal volume of $2 \times$ IL-2 or PEG-IL- 2 variants was added to the test wells in serial fivefold dilutions. Control wells contained an equal volume of D-PBS (negative control). After incubation for $96 \mathrm{~h}$ at $37^{\circ} \mathrm{C}$, the cultured cells were centrifuged, resuspended in FACS buffer, and stained extracellularly with anti-human CD3-BV510, CD4-PE/Cy7, CD8-FITC, CD25-APC, CD279-BV650, CD185-Alexa Fluor 700 (AF700), CD56-BV605 and CD16-BV605 antibodies. Cells were then washed twice with D-PBS containing 0.2\% BSA and fixed in Foxp3 Transcription Factor Fixation/Permeabilization Buffer (eBioscience) for $30 \mathrm{~min}$ on ice. After two washes in permeabilization buffer (eBioscience), cells were stained intracellularly with anti-human Foxp3-PE antibodies for $1 \mathrm{~h}$ at room temperature. For the analysis of IL-17- and IFN- $\gamma$-producing cells, cultured cells were stimulated with $1 \times$ cell stimulation cocktail (plus protein transport inhibitors) for $4 \mathrm{~h}$ and then stained extracellularly with anti-human CD3 and CD4 antibodies and intracellularly with anti-human IL-17A-PE and IFN- $\gamma$-BV421 antibodies as described above.

The in vitro IL-2-induced protein assays were performed as described above with slight changes ${ }^{20}$. In brief, hPBMCs were resuspended in complete medium and incubated with serial fivefold dilutions of IL-2 or PEGylated IL-2 variants in a $37^{\circ} \mathrm{C}$ incubator for $72 \mathrm{~h}$. The cells were collected and stained for the detection of IL-2-induced protein expression. The FACS antibodies used included anti-CD3-APC/Cy7, anti-CD4-PE/Cy7, anti-CD8-FITC, anti-CD25-APC, anti-Foxp3-Pacific Blue and anti-CD49d-BV605. All FACS antibodies were used at a dilution of 1:50. The stained cell suspensions were filtered through a $70 \mathrm{~mm}$ nylon cell strainer (BD Biosciences), and an equal amount of cells was analysed by flow cytometry to analyse proliferation and protein expression. Data were collected on an LSR Fortessa and analysed using FlowJo.

In vivo cell proliferation and IL-2-induced protein expression assay. To assay the responses of human immune cells to PEGylated IL-2, a humanized NOD-SCID IL-2 receptor gamma null (NSG) mouse expansion model was applied as described previously with slight changes ${ }^{20}$. In brief, hPBMCs were isolated from healthy donors by Ficoll and activated overnight with $12.5 \mathrm{ng} \mathrm{ml}^{-1}$ anti-human $\mathrm{CD} 3$ and $25 \mathrm{ng} \mathrm{ml}^{-1}$ anti-human CD28. After overnight incubation, cells were collected and labelled with Fixable Viability Dye eFluor 450 (FVD 450, Thermo Fisher Scientific) according to the manufacturer's directions, and an equal amount of labelled hPBMCs $\left(5 \times 10^{6}\right)$ was injected intravenously into NSG mice (aged 8-10 weeks). The injected mice (three per group) were then subcutaneously injected with IL-2 daily for five consecutive days or an equal dose of PEGylated IL-2 variants every other day for three times. Mice were euthanized by cervical dislocation $5 \mathrm{~d}$ after the last injection, and splenocytes were collected for flow analysis. Cells were extracellularly stained with anti-human CD3-APC/Cy7, CD4-PE/Cy7, CD8-FITC and CD25-APC antibodies and intracellularly with anti-human Foxp3-Pacific
Blue antibodies using the Foxp3 Buffer Kit (eBioscience) as described above. Dead cell exclusion was performed using FVD 450. For the xeno-GvHD assay, hPBMCs were isolated and activated overnight with anti-CD3/CD28 beads according to the manufacturer's directions (Thermo Fisher Scientific). After overnight incubation, mice received an intravenous injection of $3 \times 10^{7}$ activated hPBMCs and a subcutaneous injection of IL-2 daily for five consecutive days or an equal dose of PEGylated IL-2 variants every other day for three times and repeated twice (ten and six injections total for IL-2 and dual-31/51-20K, respectively). PBS-treated mice were used as a negative control. Mice were monitored for weight loss and survival for $60 \mathrm{~d}$, and a loss in body weight of greater than $25 \%$ of the initial weight was considered to correspond to death and mice were euthanized at this point.

To assay the effects of human IL-2 on mouse immune cells in vivo, C57BL/6 mice (aged 8-10 weeks, three per group) were subcutaneously injected with PEGylated IL-2 variants, IL-2 and PBS as described above. The treated mice were euthanized $3 \mathrm{~d}$ later after the last injection, and splenocytes were collected for flow analysis. The FACS antibodies used included anti-CD3-APC/Cy7, anti-CD4-PE/ Cy7, anti-CD8-FITC, anti-CD25-APC, anti-CTLA4-BV605 and anti-Foxp3-Pacific Blue. The data were analysed using FlowJo software, and the ratios of the absolute number of $\mathrm{T}_{\text {reg }}$ cells $\left(\mathrm{CD} 4^{+} \mathrm{CD} 25^{+} \mathrm{Foxp}^{+}\right)$to either total $\mathrm{CD} 8^{+} \mathrm{T}\left(\mathrm{CD}^{+} \mathrm{CD} 8^{+}\right)$or $\mathrm{T}_{\text {conv }}\left(\mathrm{CD} 4^{+} \mathrm{T}\right.$ except for $\mathrm{T}_{\text {reg }}$ cells) cells were calculated. The Animal Use Protocol was reviewed and approved annually by the Ethics Review Board of PUMC

Hospital, Chinese Academy of Medical Science (CAMS).

Assay of the therapeutic effects of PEGylated IL-2 in MRL/lpr mice. For analysing the therapeutic potential of IL-2 PEGylates in SLE, a spontaneous SLE animal model was applied using MRL/lpr mice. Female MRL/lpr mice (aged four weeks) were purchased from the SLAC Laboratory. At nine weeks of age, $\mathrm{MRL} / \mathrm{lpr}$ mice were subcutaneously injected with $0.1 \mu \mathrm{g}$ or $0.5 \mu \mathrm{g}$ of unmodified IL-2 daily for five consecutive days or with an equal dose of dual-31/51-20K once every other day for a total of three times, and this regimen was repeated the following week (ten and six injections in total for IL-2 and dual-31/51-20K, respectively). Mice were bled and placed into individual metabolic cages for urine collection every week beginning at week 10 . The detection of anti-double-stranded DNA antibodies and ANA was performed using ELISA Kits (Alpha Diagnostic International) according to the manufacturer's instructions, and proteinuria levels were determined using the Bradford (Takara) method for protein quantitation. Baseline levels of anti-double-stranded DNA antibodies, ANA and proteinuria were determined using samples from female mice (aged 6 weeks) before the onset of signs of SLE. After one week of treatment, four out of eight mice that were treated with a $0.5 \mu \mathrm{g}$ dose from the treated groups were euthanized, and the spleen was removed for flow analysis. At the end of the experiment, all of the mice were euthanized by cervical dislocation, and the kidneys were removed for histopathological and immunofluorescence examinations. For pathological study of kidneys, in brief, one kidney was fixed in buffered $10 \%$ formalin and embedded in a paraffin block. Approximately 5 - $\mu$ m-thick sections were cut and stained with H\&E. Sections were graded by a single renal pathologist without knowledge of the treatment modality for glomerular, interstitial and vascular lesions according to a semiquantitative grading scheme as previously reported ${ }^{55}$. For the determination of IgG and C3 deposition, the other kidney was snap-frozen and cut into sections (thickness, $5 \mu \mathrm{m}$ ). Kidney cryosections were stained with anti-mouse IgG-Fc-AF647 for the determination of IgG deposition, and stained with rat anti-C3 antibodies, followed by goat anti-rat-IgG-H\&L-AF488 (Abcam) for the determination of $\mathrm{C} 3$ deposition. The slides were visualized by confocal microscopy, and the deposition of antibody and C3 was quantified by MFI using Image (v.1.52t). The Animal Use Protocol was reviewed and approved annually by the Ethics Review Board of PUMC Hospital, CAMS.

Assay of therapeutic effects of PEGylated IL-2 using a CIA model. The CIA model was established as described previously ${ }^{45}$. In brief, female DBA/1 mice (aged 6-8 weeks) were immunized intradermally with bovine COII emulsified in an equal volume of complete Freund's adjuvant (CFA, Chondrex). The mice were rechallenged with COII in IFA (Chondrex) $21 \mathrm{~d}$ later. In one experiment, starting on the first day after the rechallenge with COII (on day 22), mice were given $0.5 \mu \mathrm{g}$ of IL-2 every other day for three times or a total dose $(1.5 \mu \mathrm{g})$ of dual-31/51-20K for single dose. In the other experiment, starting one week before the rechallenge with COII (on day 14), mice were given $0.5 \mu \mathrm{g}$ and $0.1 \mu \mathrm{g}$ IL-2 every other day for three times or an equal dose of dual-31/51-20K as a single dose. The mice treated with PBS were used as a negative control for all of the experiments. The mice were examined daily after rechallenge with COII for signs of joint inflammation and scored as previously reported ${ }^{56}: 0$, normal; 1 , erythema and mild swelling confined to the ankle joint; 2 , erythema and mild swelling extending from the ankle to metatarsal or metacarpal joints; 3 , erythema and moderate swelling extending from the ankle to the metatarsophalangeal or metacarpophalangeal joints; 4 , erythema and severe swelling extending from the ankle to the digits. Scores from 0 to 4 were assigned for each paw and then added together to yield a final disease score. In the first experiment, half of the eight mice from each group were euthanized on day 8 after rechallenge with COII, and splenocytes were collected. Some splenocytes were stained extracellularly with anti-mouse CD3-APC/Cy7, CD4-PE/Cy7, CD8-FITC and CD25-APC antibodies and intracellularly with anti-mouse Foxp3-Pacific Blue 
antibodies as described above; the rest were stimulated with $1 \times$ Cell Stimulation Cocktail Plus Transport Inhibitors (Thermo Fisher Scientific) overnight and stained extracellularly with anti-mouse CD3-APC/Cy7 and CD4-PE/Cy7 antibodies, followed by intracellularly with anti-IL-17A-PE antibodies. Stained single-cell suspensions were analysed using the Fortessa flow cytometer, and data were analysed and presented with FlowJo software. For histopathological analysis, all of the mice were killed at the end of the experiment, and the fore- and hindpaws were dissected and fixed in $10 \%$ buffered formalin. Fixed tissues were decalcified for $10 \mathrm{~d}$ in $14 \%$ ethylene diamine tetraacetic acid, followed by dehydration and paraffin embedding. Joint sections (approximate thickness, $5 \mu \mathrm{m}$ ) were prepared and stained with H\&E and toluidine blue. Sections of arthritic paws were graded by an individual who did not know which treatments the animals had received. A lesion severity score of $0-4$ was assigned to each paw according to a previously reported scoring system ${ }^{57}$ and then added together to yield a final histology severity score. The Animal Use Protocol was reviewed and approved annually by the Ethics Review Board of PUMC Hospital, CAMS.

Assay of the antiviral effects of PEGylated IL-2 treatment. To study whether the risk of infection could be increased by the injection of PEGylated IL-2 during the course of treatment, an influenza virus infection model was constructed and applied. In brief, C57BL/ 6 mice (aged 8 weeks) were treated with $0.5 \mu$ g of IL- 2 daily for five consecutive days or an equal dose of dual-31/51-20K every other day three times. Control mice received injections of D-PBS. On the day 9 , the treated mice were infected with approximately $20 \times \mathrm{LD}_{50}$ of the influenza $\mathrm{A}$ virus $(\mathrm{A} / \mathrm{WS} / 1933$ H1N1, WSN) by intranasal delivery. Three days after virus infection (day 12), four out of eight mice per group were euthanized, and the blood, spleen and lungs were collected for assays. Mice were monitored for weight loss and survival for two weeks starting on the day of virus infection, and body weight loss higher than $25 \%$ of the initial weight was regarded as death. For flow analysis, blood and lung cells were resuspended in $1 \times$ red blood cell lysis buffer (BioLegend) for $10 \mathrm{~min}$ to lyse red blood cells. After washing, cell suspensions of blood cells, lung cells and isolated splenocytes were stained extracellularly with anti-mouse CD3-BV510, CD4-PE/Cy7, CD8a-FITC, CD25-BV650, NK1.1-PE, CD69-APC/Cy7, CD314 (NKG2D)-APC and CD335 (NKp46)-BV605 antibodies and intracellularly with anti-CD335 (NKp46)-BV605 and anti-Foxp3-BV421 antibodies. Stained cells were filtered through a $70 \mathrm{~mm}$ nylon cell strainer and analysed by flow cytometry (CytoFLEX, Beckman Coulter) and CytExpert (v.2.3). For the determination of virus-mediated lung lesions and viral titres in the lungs, the lungs were removed for histopathological and immunofluorescence examinations on day 12. For pathological analysis, in brief, parts of the lungs were fixed with $10 \%$ formalin, embedded in paraffin, sectioned and stained with H\&E. Sections were semiquantitatively scored by a single pathologist without knowledge of the treatment modality according to a previously reported scheme $e^{58}$. For immunofluorescence examinations, parts of the lungs were snap-frozen and cut into sections (thickness, $5 \mu \mathrm{m}$ ). The lung cryosections were stained with mouse anti-influenza A virus nucleoprotein and matrix protein (M1) antibodies (GeneTex), followed by FITC- and APC-conjugated secondary antibodies. The slides were visualized with a confocal microscope, and quantities of virus were determined on the basis of the MFI of M1 using ImageJ. The titres of WSN in the lungs were also determined by a plaque formation assay. In brief, MDCK (ATCC No. CCL-34) cells were grown in a 12 -well cell culture plate to produce a confluent monolayer. After the cells were washed with PBS, influenza virus extracted from an equal weight of lung tissue was added to the test wells in serial tenfold dilutions, and the cells were incubated at $37^{\circ} \mathrm{C}$ for $1 \mathrm{~h}$ for viral absorption. Unabsorbed virus was removed by washing the cells with PBS, and then $1 \mathrm{ml}$ of DMEM supplemented with $2 \mu \mathrm{g} \mathrm{ml}^{-1}$ TPCK-treated trypsin and $1.5 \%$ agarose was added to each well. After continued incubation for $4 \mathrm{~d}$ at $37^{\circ} \mathrm{C}$, the cells were fixed with $4 \%$ paraformaldehyde and then stained with crystal violet (Sigma-Aldrich). Viral titres were determined according to the visible plaques presented.

Immunogenicity evaluation. To study whether NAEK-mediated site-specific PEGylation induced enhanced immunogenicity, C57BL/6 mice (aged 8-10 weeks) were injected subcutaneously with $0.5 \mu \mathrm{g}$ of unmodified IL-2 daily for five consecutive days or with dual-31/51-20K every other day each week for 4 weeks (for a total of 20 and 12 injections of IL-2 and dual-31/51-20K, respectively). PBS-treated mice were used as negative controls. The mice were bled through the retro-orbital method at the end of weeks 2 and 4 . The blood samples were centrifuged, and the plasma samples were stored at $-80^{\circ} \mathrm{C}$ until analysis. Plasma antibodies against both the IL- 2 and PEG moieties were detected by ELISA. In brief, to assay antibodies against IL-2, the ELISA plate was coated with IL-2 without a His tag (Thermo Fisher Scientific) and blocked with PBS with 3\% BSA. Plasma samples diluted 1:100 were incubated on the plates for $1 \mathrm{~h}$ at room temperature and then with HRP-conjugated anti-human IgG or IgG1 antibodies (Thermo Fisher Scientific) at a 3,000-fold dilution at $37^{\circ} \mathrm{C}$ for $1 \mathrm{~h}$. For the analysis of antibodies against the PEG moiety, $1 \mathrm{mM}$ biotin- $\mathrm{PEG}_{4}-\mathrm{N}_{3}$ was immobilized on ELISA plates precoated with streptavidin (Thermo Fisher Scientific), and the plates were then incubated with a twentyfold $(20 \mathrm{mM})$ excess of $20 \mathrm{kDa}$ DIBO-PEG overnight at $4^{\circ} \mathrm{C}$. An isotype monoclonal antibody $\left(10 \mathrm{ng} \mathrm{ml}^{-1}\right)$ against the IL-2 or PEG moiety (Abcam) was used as a positive control. The plates were rinsed three times with PBS-Tween-20 between each step.
Assay of endocytosis of PEGylated IL-2 after binding with its receptor. A cell model with CD25-engineered YT cells and pHrodo Red-labelled samples was used to examine the endocytosis of PEGylated IL-2 after binding with its receptor. The labelling with pHrodo-Red dye (Thermo Fisher Scientific) was conducted according to the manufacturer's directions. In brief, PEGylated IL-2 and IL-2 were buffer-exchanged in $100 \mathrm{mM} \mathrm{NaHCO}_{3}$ buffer ( $\mathrm{pH} 9.0$ ) at a final concentration of approximately $10 \mathrm{mg} \mathrm{ml}^{-1}$. The samples were then incubated with pHrodo Red at $37^{\circ} \mathrm{C}$ for $2 \mathrm{~h}$ at molar ratios of 1:20, and this step was followed by desalination of unconjugated dye using a $3 \mathrm{kDa}$ centrifugal filter unit (Millipore) and exchange with PBS buffer. For the endocytosis experiments, $1-2 \times 10^{6}$ cells were incubated in $200 \mu \mathrm{l}$ of RPMI and $10 \% \mathrm{FBS}$ with $1 \mu \mathrm{g} \mathrm{ml}^{-1}$ labelled samples at $37^{\circ} \mathrm{C}$ for various durations. After washing the incubated cells at the indicated time, the live cells were washed and stained directly with AF647-labelled anti-His-tag antibodies (BioLegend) for flow analysis. The background was defined as the MFI of anti-His-AF647 antibodies or pHrodo-Red in non-IL-2-treated but stained cells, and the data are plotted as the background substrate MFI.

For localization analysis of the PEGylated IL-2 and IL-2 after binding to its receptor, the pHrodo-Red-labelled samples were incubated with $1-2 \times 10^{6}$ YT-CD 25 cells overnight at $37^{\circ} \mathrm{C}$. The surface and endocytic localizations of the samples were then revealed by incubating the cells with anti-His antibodies and then with AF647-labelled anti-mouse IgG (BioLegend) and LysoTracker Blue BND-22 (Thermo Fisher Scientific) at a 1:5,000 dilution for $30 \mathrm{~min}$ in the dark. The samples were rinsed twice with 3\% FBS in PBS between each step. The cells were then imaged using a confocal laser-scanning microscope (Nikon).

Statistical analysis. All statistical calculations were performed using GraphPad Prism 8.0. Statistical tests and $P$ values are described in the figures and figure legends and all $P$ values are presented in the figures unless $P<0.0001$, which is then indicated in the legend.

Reporting Summary. Further information on research design is available in the Nature Research Reporting Summary linked to this article.

\section{Data availability}

The main data supporting the results in this study are available within the paper and its Supplementary Information. The raw and analysed datasets generated during the study are too large to be publicly shared, yet they are available for research purposes from the corresponding authors on reasonable request. The quaternary structure of IL-2 associated with the trimeric receptor is available from publicly available datasets (http://www1.rcsb.org).

Received: 8 June 2020; Accepted: 23 August 2021;

Published online: 27 September 2021

\section{References}

1. Klatzmann, D. \& Abbas, A. K. The promise of low-dose interleukin-2 therapy for autoimmune and inflammatory diseases. Nat. Rev. Immunol. 15, 283-294 (2015).

2. Abbas, A. K., Trotta, E., Simeonov, R. D., Marson, A. \& Bluestone, J. A. Revisiting IL-2: biology and therapeutic prospects. Sci. Immunol. https://doi. org/10.1126/sciimmunol.aat1482 (2018).

3. Boyman, O. \& Sprent, J. The role of interleukin-2 during homeostasis and activation of the immune system. Nat. Rev. Immunol. 12, 180-190 (2012).

4. He, J. et al. Efficacy and safety of low-dose IL-2 in the treatment of systemic lupus erythematosus: a randomised, double-blind, placebo-controlled trial. Ann. Rheum. Dis. 79, 141-149 (2020).

5. Rosenzwajg, M. et al. Immunological and clinical effects of low-dose interleukin-2 across 11 autoimmune diseases in a single, open clinical trial. Ann. Rheum. Dis. 78, 209-217 (2019).

6. Mizui, M. \& Tsokos, G. C. Low-dose IL-2 in the treatment of lupus. Curr. Rheumatol. Rep. 18, 68 (2016).

7. Kim, N. et al. Therapeutic potential of low-dose IL-2 in a chronic GVHD patient by in vivo expansion of regulatory T cells. Cytokine 78, 22-26 (2016).

8. He, J. et al. Low-dose interleukin-2 treatment selectively modulates CD4 ${ }^{+}$ T cell subsets in patients with systemic lupus erythematosus. Nat. Med. 22, 991-993 (2016)

9. Dwyer, C. J., Ward, N. C., Pugliese, A. \& Malek, T. R. Promoting immune regulation in type 1 diabetes using low-dose interleukin-2. Curr. Diab. Rep. 16, 46 (2016).

10. Koreth, J. et al. Interleukin-2 and regulatory $\mathrm{T}$ cells in graft-versus-host disease. N. Engl. J. Med. 365, 2055-2066 (2011).

11. Saadoun, D. et al. Regulatory T-cell responses to low-dose interleukin-2 in HCV-induced vasculitis. N. Engl. J. Med. 365, 2067-2077 (2011).

12. Pol, J. G., Caudana, P., Paillet, J., Piaggio, E. \& Kroemer, G. Effects of interleukin-2 in immunostimulation and immunosuppression. J. Exp. Med. https://doi.org/10.1084/jem.20191247 (2020).

13. Lotze, M. T. et al. In vivo administration of purified human interleukin 2. II. Half life, immunologic effects, and expansion of peripheral lymphoid cells in vivo with recombinant IL 2. J. Immunol. 135, 2865-2875 (1985). 
14. Boyman, O., Kovar, M., Rubinstein, M. P., Surh, C. D. \& Sprent, J. Selective stimulation of $\mathrm{T}$ cell subsets with antibody-cytokine immune complexes. Science 311, 1924-1927 (2006).

15. Levin, A. M. et al. Exploiting a natural conformational switch to engineer an interleukin-2 'superkine'. Nature 484, 529-533 (2012).

16. Mitra, S. et al. Interleukin-2 activity can be fine tuned with engineered receptor signaling clamps. Immunity 42, 826-838 (2015).

17. Ward, N. C. et al. IL-2/CD25: a long-acting fusion protein that promotes immune tolerance by selectively targeting the IL-2 receptor on regulatory T cells. J. Immunol. 201, 2579-2592 (2018).

18. Sockolosky, J. T. et al. Selective targeting of engineered T cells using orthogonal IL-2 cytokine-receptor complexes. Science 359, 1037-1042 (2018).

19. Spangler, J. B. et al. Engineering a single-agent cytokine/antibody fusion that selectively expands regulatory $\mathrm{T}$ cells for autoimmune disease therapy. J. Immunol. 201, 2094-2106 (2018).

20. Trotta, E. et al. A human anti-IL-2 antibody that potentiates regulatory T cells by a structure-based mechanism. Nat. Med. 24, 1005-1014 (2018).

21. Rao, B. M., Girvin, A. T., Ciardelli, T., Lauffenburger, D. A. \& Wittrup, K. D. Interleukin-2 mutants with enhanced alpha-receptor subunit binding affinity. Protein Eng. 16, 1081-1087 (2003).

22. Carmenate, T. et al. Human IL-2 mutein with higher antitumor efficacy than wild type IL-2. J. Immunol. 190, 6230-6238 (2013).

23. Liu, D. V., Maier, L. M., Hafler, D. A. \& Wittrup, K. D. Engineered interleukin-2 antagonists for the inhibition of regulatory $\mathrm{T}$ cells. J. Immunother. 32, 887-894 (2009).

24. Carmenate, T. et al. Blocking IL-2 signal in vivo with an IL-2 antagonist reduces tumor growth through the control of regulatory T cells. J. Immunol. 200, 3475-3484 (2018)

25. Karakus, U. et al. Receptor-gated IL-2 delivery by an anti-human IL-2 antibody activates regulatory $\mathrm{T}$ cells in three different species. Sci. Transl. Med. https://doi.org/10.1126/scitranslmed.abb9283 (2020)

26. Lee, J. Y. et al. TCB2, a new anti-human interleukin-2 antibody, facilitates heterodimeric IL-2 receptor signaling and improves anti-tumor immunity Oncoimmunology 9, 1681869 (2020).

27. Arenas-Ramirez, N. et al. Improved cancer immunotherapy by a CD25-mimobody conferring selectivity to human interleukin-2. Sci. Transl. Med. 8, 367ra166 (2016).

28. Spangler, J. B. et al. Antibodies to interleukin-2 elicit selective T cell subset potentiation through distinct conformational mechanisms. Immunity 42, 815-825 (2015).

29. Sahin, D. et al. An IL-2-grafted antibody immunotherapy with potent efficacy against metastatic cancer. Nat. Commun. 11, 6440 (2020).

30. Peterson, L. B. et al. A long-lived IL-2 mutein that selectively activates and expands regulatory $\mathrm{T}$ cells as a therapy for autoimmune disease. J. Autoimmun. 95, 1-14 (2018).

31. Pasut, G. \& Veronese, F. M. State of the art in PEGylation: the great versatility achieved after forty years of research. J. Control. Release 161, 461-472 (2012).

32. Charych, D. H. et al. NKTR-214, an engineered cytokine with biased IL2 receptor binding, increased tumor exposure, and marked efficacy in mouse tumor models. Clin. Cancer Res. 22, 680-690 (2016).

33. Tian, F. et al. A general approach to site-specific antibody drug conjugates. Proc. Natl Acad. Sci. USA 111, 1766-1771 (2014).

34. Cho, H. et al. Optimized clinical performance of growth hormone with an expanded genetic code. Proc. Natl Acad. Sci. USA 108, 9060-9065 (2011).

35. Zhang, B. et al. Development of next generation of therapeutic IFN- $\alpha 2 b$ via genetic code expansion. Acta Biomater. 19, 100-111 (2015).

36. Wu, L. et al. Precise and combinatorial PEGylation generates a low-immunogenic and stable form of human growth hormone. J. Control. Release 249, 84-93 (2017).

37. Mbua, N. E., Guo, J., Wolfert, M. A., Steet, R. \& Boons, G. J. Strain-promoted alkyne-azide cycloadditions (SPAAC) reveal new features of glycoconjugate biosynthesis. ChemBioChem 12, 1912-1921 (2011).

38. Nguyen, D. P. et al. Genetic encoding and labeling of aliphatic azides and alkynes in recombinant proteins via a pyrrolysyl-tRNA synthetase/tRNA ${ }^{\mathrm{CUA}}$ pair and click chemistry. J. Am. Chem. Soc. 131, 8720-8721 (2009).

39. Stauber, D. J., Debler, E. W., Horton, P. A., Smith, K. A. \& Wilson, I. A. Crystal structure of the IL-2 signaling complex: paradigm for a heterotrimeric cytokine receptor. Proc. Natl Acad. Sci. USA 103, 2788-2793 (2006).

40. Wang, X., Rickert, M. \& Garcia, K. C. Structure of the quaternary complex of interleukin-2 with its $\alpha, \beta$, and $\gamma_{c}$ receptors. Science 310, 1159-1163 (2005).

41. Yu, A. et al. Selective IL-2 responsiveness of regulatory T cells through multiple intrinsic mechanisms supports the use of low-dose IL-2 therapy in type 1 diabetes. Diabetes 64, 2172-2183 (2015).

42. Miksa, M., Komura, H., Wu, R., Shah, K. G. \& Wang, P. A novel method to determine the engulfment of apoptotic cells by macrophages using pHrodo succinimidyl ester. J. Immunol. Methods 342, 71-77 (2009).

43. Rao, B. M., Driver, I., Lauffenburger, D. A. \& Wittrup, K. D. High-affinity CD25-binding IL-2 mutants potently stimulate persistent T cell growth. Biochemistry 44, 10696-10701 (2005).
44. Dominguez-Villar, M. \& Hafler, D. A. Regulatory T cells in autoimmune disease. Nat. Immunol. 19, 665-673 (2018).

45. Brand, D. D., Latham, K. A. \& Rosloniec, E. F. Collagen-induced arthritis. Nat. Protoc. 2, 1269-1275 (2007).

46. Krieg, C., Letourneau, S., Pantaleo, G. \& Boyman, O. Improved IL-2 immunotherapy by selective stimulation of IL-2 receptors on lymphocytes and endothelial cells. Proc. Natl Acad. Sci. USA 107, 11906-11911 (2010).

47. Ito, T. et al. Two functional subsets of $\mathrm{FOXP}^{+}$regulatory $\mathrm{T}$ cells in human thymus and periphery. Immunity 28, 870-880 (2008).

48. Gesbert, F., Sauvonnet, N. \& Dautry-Varsat, A. Clathrin-independent endocytosis and signalling of interleukin 2 receptors IL-2R endocytosis and signalling. Curr. Top. Microbiol. Immunol. 286, 119-148 (2004).

49. Li, Y. et al. Regulatory T cells control toxicity in a humanized model of IL-2 therapy. Nat. Commun. 8, 1762 (2017).

50. Arce Vargas, F. et al. Fc-optimized anti-CD25 depletes tumor-infiltrating regulatory $\mathrm{T}$ cells and synergizes with $\mathrm{PD}-1$ blockade to eradicate established tumors. Immunity 46, 577-586 (2017)

51. Hofmann, K., Clauder, A. K. \& Manz, R. A. Targeting B cells and plasma cells in autoimmune diseases. Front. Immunol. 9, 835 (2018).

52. Mizui, M. Natural and modified IL-2 for the treatment of cancer and autoimmune diseases. Clin. Immunol. 206, 63-70 (2019).

53. Verhoef, J. J., Carpenter, J. F., Anchordoquy, T. J. \& Schellekens, H. Potential induction of anti-PEG antibodies and complement activation toward PEGylated therapeutics. Drug Discov. Today 19, 1945-1952 (2014).

54. Garay, R. P., El-Gewely, R., Armstrong, J. K., Garratty, G. \& Richette, P. Antibodies against polyethylene glycol in healthy subjects and in patients treated with PEG-conjugated agents. Expert Opin. Drug Deliv. 9, 1319-1323 (2012).

55. Tao, X., Fan, F., Hoffmann, V., Longo, N. S. \& Lipsky, P. E. Therapeutic impact of the ethyl acetate extract of Tripterygium wilfordii Hook F on nephritis in NZB/W F1 mice. Arthritis Res. Ther. 8, R24 (2006).

56. Wang, $\mathrm{H}$. et al. TACI-ligand interactions are required for $\mathrm{T}$ cell activation and collagen-induced arthritis in mice. Nat. Immunol. 2, 632-637 (2001).

57. Deng, G. M., Zheng, L., Chan, F. K. \& Lenardo, M. Amelioration of inflammatory arthritis by targeting the pre-ligand assembly domain of tumor necrosis factor receptors. Nat. Med. 11, 1066-1072 (2005).

58. Wang, J. et al. Klebsiella pneumoniae alleviates influenza-induced acute lung injury via limiting NK cell expansion. J. Immunol. 193, 1133-1141 (2014).

\section{Acknowledgements}

We thank Z. Tian (University of Science and Technology of China, Hefei) for gifting the YT cell line; Y. Hou for her support with flow cytometry technology and D. Liu (Peking University) for her participation in mass spectrometry experiments; $\mathrm{X}$. Wu from the X.Z. laboratory and H. Li from the Tsokos laboratory for their discussions; and all of the donors who participated in the study. This study was supported by grants from the National Key Research and Development Program of China (no. 2019ZX09739), National Natural Science Foundation of China (nos 81788101, 81803419, 81630044, $81802121,21805311)$, Chinese Academy of Medical Science Innovation Fund for Medical Sciences (nos CIFMS2016-12M-1-003, 2017-12M-1-008, 2017-I2M-3-011, 2016-12M-1008) and Capital's Funds for Health Improvement and Research (no. 2020-2-4019).

\section{Author contributions}

B.Z., Y.W., J.S., D.Z. and X.Z. designed the study. B.Z., Y.W., J.S., Y.H., J.H., Y.Y. and Y.S. performed the experiments in vitro and in vivo and analysed the data. D.J. and F.Y. performed experiments of chemical synthesis. S.L. contributed to the crystal structure analysis and site selection. W.M. and B.C. performed experiments with influenza virus. P.L., L.W., W.S., M.W. and X.L. contributed to the collection and assembly of data and polished the language. L. Zhao, H.C., Y.F., H.L., L. Zhang and G.C.T. provided comments. B.Z., D.Z., G.C.T. and Z.X. wrote and reviewed the manuscript. All of the authors reviewed the manuscript.

\section{Competing interests}

The authors declare no competing interests.

\section{Additional information}

Extended data is available for this paper at https://doi.org/10.1038/s41551-021-00797-8.

Supplementary information The online version contains supplementary material available at https://doi.org/10.1038/s41551-021-00797-8.

Correspondence and requests for materials should be addressed to George C. Tsokos, Demin Zhou or Xuan Zhang.

Peer review information Nature Biomedical Engineering thanks Onur Boyman, David Klatzmann and the other, anonymous, reviewer(s) for their contribution to the peer review of this work. Peer reviewer reports are available.

Reprints and permissions information is available at www.nature.com/reprints. Publisher's note Springer Nature remains neutral with regard to jurisdictional claims in published maps and institutional affiliations.

(c) The Author(s), under exclusive licence to Springer Nature Limited 2021 

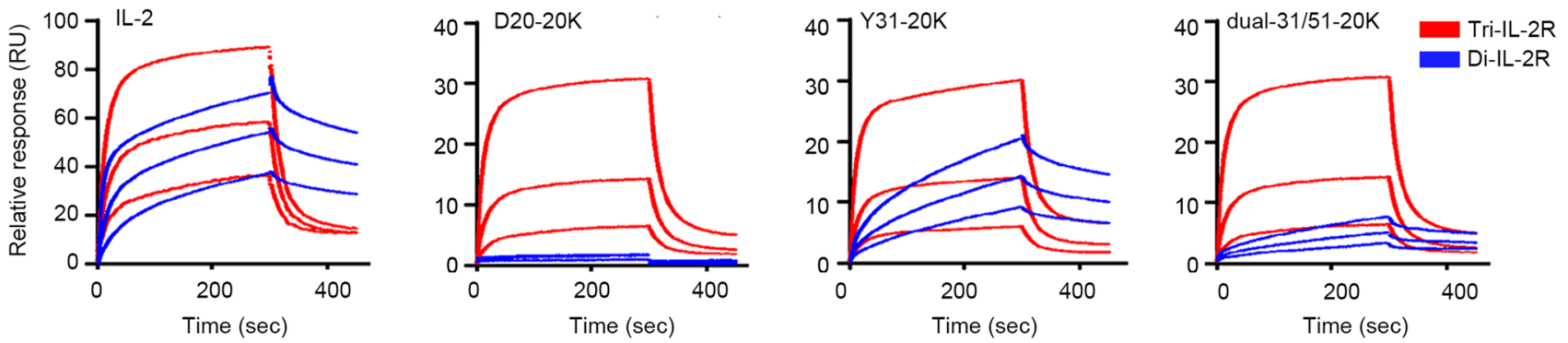

Extended Data Fig. 1 | Characterization of the binding of representative PEGylated variants to dimeric or trimeric IL-2Rs, assessed by surface plasmon resonance (SPR), for identification of IL-2 PEGylates showing the highest level of selectivity towards trimeric IL-2Rs. Fc-tagged extracellular domains of the IL-2R subunits were immobilized on a CM5 chip at an equimolar ratio. Three representative concentrations of each sample in a series of 3-fold dilutions for trimeric $(3.3,10$ and $30 \mathrm{nM})$ or dimeric $(33.3,100$ and $300 \mathrm{nM}) \mathrm{IL}-2 \mathrm{R}$ complexes are presented. All kinetic parameters are provided in $\mathrm{S}$ Table 2. Representative results from one of two independent experiments are shown. See also Fig. 1. 

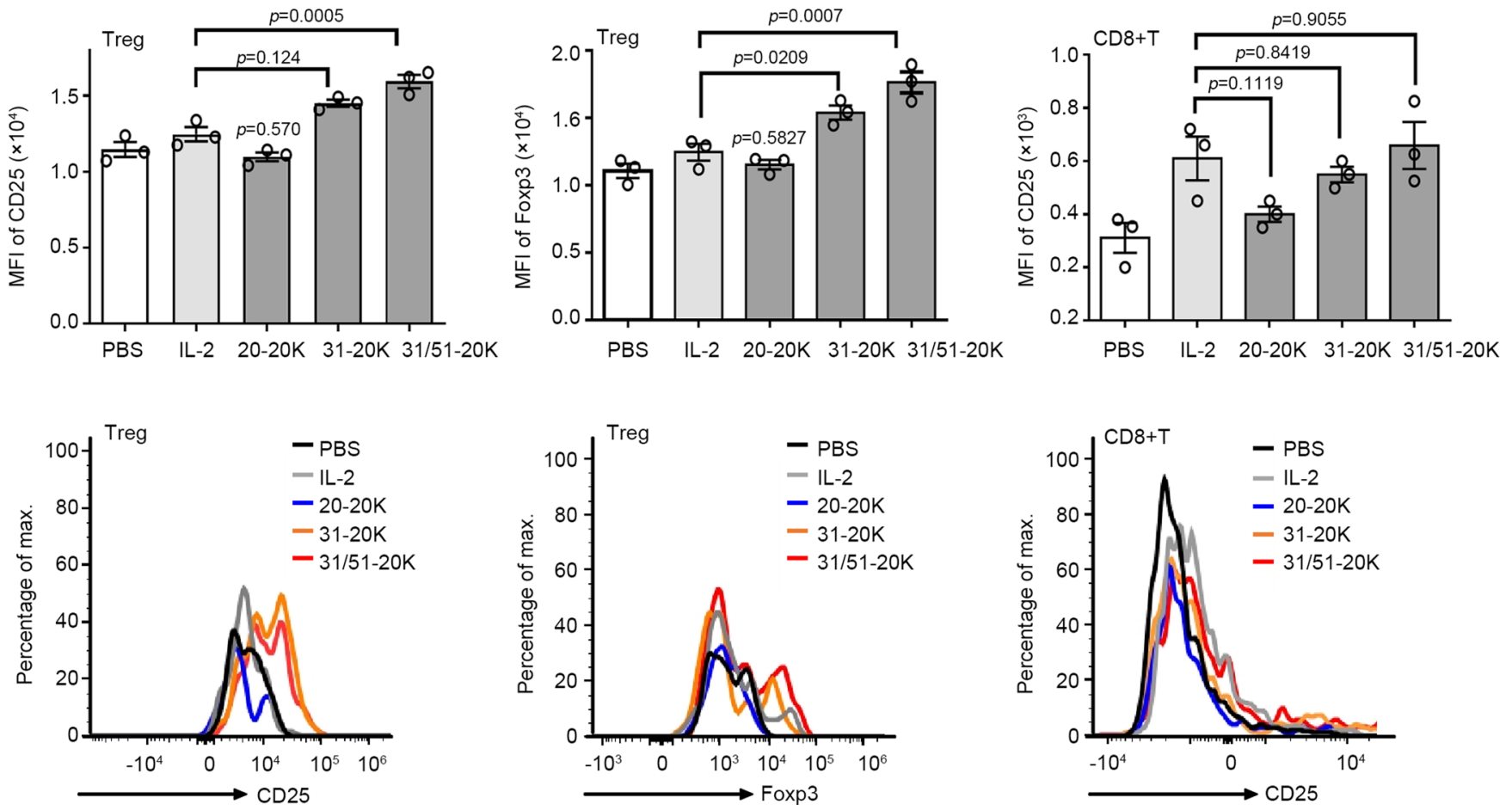

Extended Data Fig. 2 | Validation of Treg-selective activation, as reflected by increased expression of CD25 and FoxP3 by PEGylated IL-2s in a xeno-GvHD mouse model. The MFI bars graphs (top) and flow cytometry histograms (bottom) of induced CD25 and Foxp3 on Tregs and CD8 + T cells in response to IL-2 and its PEGylated variants at a dose of $2 \mu \mathrm{g}$, with PBS as the background. The data are presented as the mean \pm SEM, $n=3$ biologically independent mice per group. Statistical analysis was performed using one-way ANOVA (Dunnett's multiple-comparison test compared with IL-2 treated group). Representative results from one of three independent experiments are shown. See also Fig. $4 a$, b. 

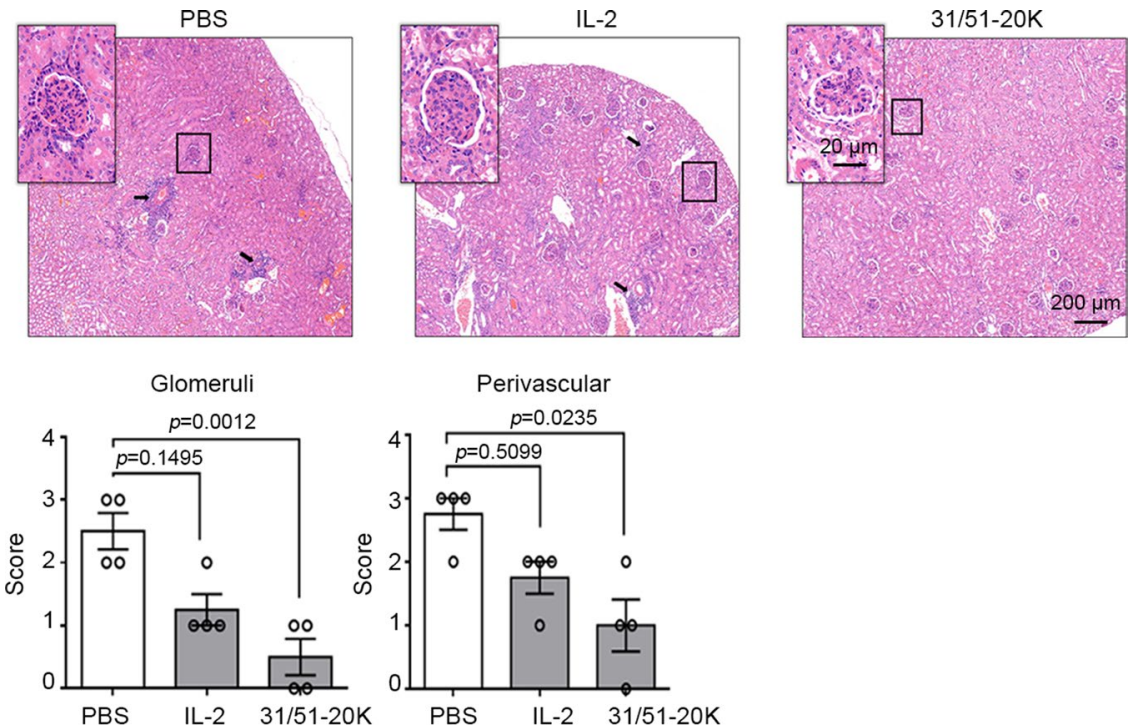

Extended Data Fig. 3 | Dual-31/51-20K-mediated mitigation of kidney lesions in MRL/lpr mice. The ability of dual-31/51-20 K to reduce kidney lesions, as reflected by $H \& E$ staining of the $0.5 \mu \mathrm{g}$ treatment groups, with the mononuclear cells infiltrating into the cortical tubulointerstitial/perivascular areas and the scores of glomerular and perivascular lesions shown by arrows and bar graphs, respectively. The data are presented as the mean \pm SEM, $n=4$ biologically independent mice per group. Statistical analysis was performed using one-way ANOVA (Dunnett's multiple-comparison test compared with PBS treated group). Representative results from one of two experiments are shown. See also Fig. 5b, c. 

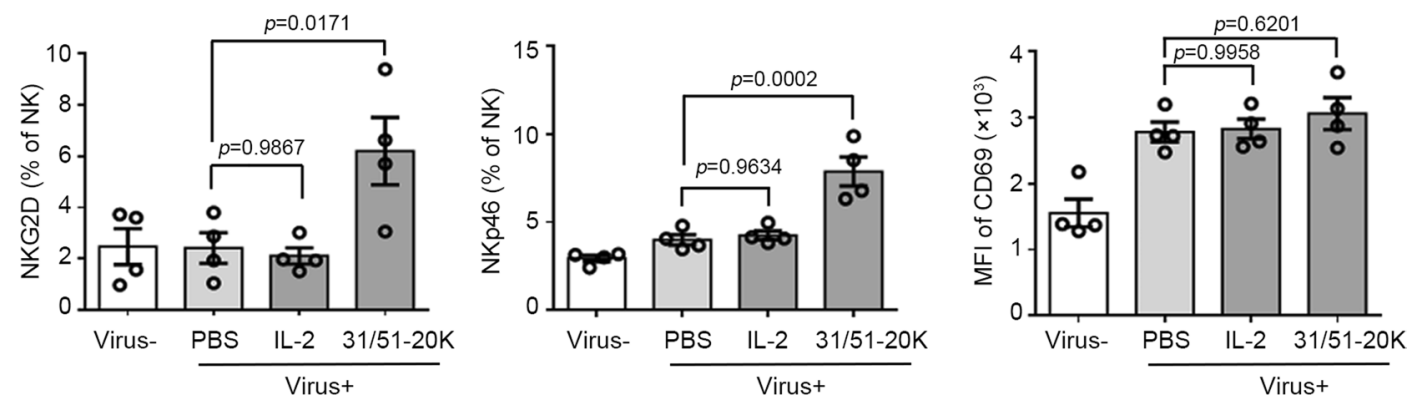

Extended Data Fig. 4 | The effects of IL-2 versus dual-31/51-20 K on activation of pulmonary NK cells. Bar graphs show the expression of activated markers, including NKG2D, NKp46, and CD69, on pulmonary NK cells of mice with indicated treatment. Data are presented as the mean $\pm S E M, n=4$ biologically independent mice per group. Statistical analysis was performed using one-way ANOVA (Dunnett's multiple-comparison test compared with + virus/ PBS-treated group). The experiment was repeated three times with similar results, and one of three representative results is shown. See also Fig. $7 c$. 


\section{natureresearch}

Corresponding author(s): Tsokos

Xuan Zhang, Demin Zhou and George C.

Last updated by author(s): Aug 16, 2021

\section{Reporting Summary}

Nature Research wishes to improve the reproducibility of the work that we publish. This form provides structure for consistency and transparency in reporting. For further information on Nature Research policies, see Authors \& Referees and the Editorial Policy Checklist.

\section{Statistics}

For all statistical analyses, confirm that the following items are present in the figure legend, table legend, main text, or Methods section.

n/a Confirmed

$\bigotimes$ The exact sample size $(n)$ for each experimental group/condition, given as a discrete number and unit of measurement

$\bigotimes$ A statement on whether measurements were taken from distinct samples or whether the same sample was measured repeatedly

The statistical test(s) used AND whether they are one- or two-sided

Only common tests should be described solely by name; describe more complex techniques in the Methods section.

Х $\square$ A description of all covariates tested

Х $\square$ A description of any assumptions or corrections, such as tests of normality and adjustment for multiple comparisons

A full description of the statistical parameters including central tendency (e.g. means) or other basic estimates (e.g. regression coefficient)

AND variation (e.g. standard deviation) or associated estimates of uncertainty (e.g. confidence intervals)

For null hypothesis testing, the test statistic (e.g. $F, t, r$ ) with confidence intervals, effect sizes, degrees of freedom and $P$ value noted

Give $P$ values as exact values whenever suitable.

Х $\square$ For Bayesian analysis, information on the choice of priors and Markov chain Monte Carlo settings

Х $\square$ For hierarchical and complex designs, identification of the appropriate level for tests and full reporting of outcomes

Х $\square$ Estimates of effect sizes (e.g. Cohen's $d$, Pearson's $r$ ), indicating how they were calculated

Our web collection on statistics for biologists contains articles on many of the points above.

\section{Software and code}

\section{Policy information about availability of computer code}

Data collection

Flow-cytometry data collection was performed using LSR Fortessa (BD Biosciences, CA) or CytoFLEX (Beckman Counter, USA) CytExpert v2.4. software. Binding kinetics data were collected using Octet RED96 (FortéBio) or Biacore 8K (GE) system. All ELISA data were collected using Infinite M200 pro I-control v1.1 (TECAN).

Data analysis

Flow-cytometry data were analysed using FlowJo V10 and CytExpert v2.4. Binding kinetic data were analysed using FortéBio data acquisition software v.8.1 and Biacore 8K Insight Evaluation 2.0.15. Pharmacokinetic parameters were analysed using Kinetica v5.1. Mean fluorescence intensity of sections were analysed using ImageJ v1.52t. All statistical calculations were performed using GraphPad Prism v8. All software used in this study for data analysis are either commercially available or open-source, and referenced were applicable. Details of all data analyses are included in Methods.

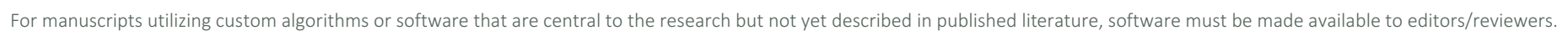
We strongly encourage code deposition in a community repository (e.g. GitHub). See the Nature Research guidelines for submitting code \& software for further information.

\section{Data}

Policy information about availability of data

All manuscripts must include a data availability statement. This statement should provide the following information, where applicable:

- Accession codes, unique identifiers, or web links for publicly available datasets

- A list of figures that have associated raw data

- A description of any restrictions on data availability

The main data supporting the results in this study are available within the paper and its Supplementary Information. The raw and analysed datasets generated during the study are too large to be publicly shared, yet they are available for research purposes from the corresponding authors on reasonable request. The quaternary structure of IL-2 assembled to the trimeric receptor is available from publicly available datasets (http://www1.rcsb.org). 
Please select the one below that is the best fit for your research. If you are not sure, read the appropriate sections before making your selection. \Life sciences Behavioural \& social sciences Ecological, evolutionary \& environmental sciences

For a reference copy of the document with all sections, see nature.com/documents/nr-reporting-summary-flat.pdf

\section{Life sciences study design}

All studies must disclose on these points even when the disclosure is negative.

Sample size No statistical methods were used to determine sample sizes. For in vitro studies, $n=3$ or $n=4$ biologically independent replicates derived from different donors were used. This sample size is often reported in previous publications to be sufficient for a confident data analysis (Trotta, E. et al. Nat Med 24, 1005-1014, doi:10.1038/s41591-018-0070-2, 2018). The numbers of animals per group are based on the need for proper statistical evaluation, which is based on our experience and that of other investigators.

Data exclusions No data were excluded.

Replication All attempts at replication were successful.

Randomization For in vitro cell-based analyses, including PSTAT5, YT-based cell analysis, and cell phenotypic assay, all cells under well-controlled conditions were analysed equally, and therefore no randomization was necessary. For the animal study, mice were assigned to different experimental treatments randomly.

Blinding In all cell-based and mice-based experiments, data collection and analysis were performed in a blinded manner because each sample was only identified with a number that didn't show any information about the treatment administrated. The pathological scores demonstrated in SEL, $\mathrm{CIA}$ and virus studies were graded by a pathologist without knowledge of the treatment, to avoid any biased scoring of disease progression.

\section{Reporting for specific materials, systems and methods}

We require information from authors about some types of materials, experimental systems and methods used in many studies. Here, indicate whether each material, system or method listed is relevant to your study. If you are not sure if a list item applies to your research, read the appropriate section before selecting a response.

\begin{tabular}{l|l}
\multicolumn{3}{c}{ Materials \& experimental syster } \\
\hline $\mathrm{n} / \mathrm{a}$ & Involved in the study \\
\hline & $\bigotimes$ Antibodies \\
$\square$ & $\bigotimes$ Eukaryotic cell lines \\
$\square$ & $\square$ Palaeontology \\
$\square$ & $\bigotimes$ Animals and other organisms \\
& $\square$ Clinical data
\end{tabular}

\section{Antibodies}

Antibodies used \begin{tabular}{l|l}
\multicolumn{2}{l}{ Methods } \\
\hline n/a & Involved in the study \\
$\square$ & $\square$ ChIP-seq \\
$\square$ & F Flow cytometry \\
$\searrow$ & $\square$ MRI-based neuroimaging
\end{tabular} The following antibodies were used to stain human cells: CD3 APC/Cyanine7 (clone UCHT1, Biolegend, no. 300426), CD3 Brilliant Violet 510 (clone UCHT1, Biolegend, no. 300448), CD3 APC/Cyanine7 (clone SK7, Biolegend, no. 344818), CD4 PE/Cyanine7 (clone RPA-T4, Biolegend, no. 300512), CD8 FITC (clone SK1, Biolegend, no. 344704), CD25 APC (clone BC96, Biolegend, no. 302610), CD25 Brilliant Violet 605 (clone BC96, Biolegend, no. 302632), CD45 RA APC (clone HI100, Biolegend, no. 304111), CD45RO APC/Cyanine7 (clone UCHL1, Biolegend, no. 304228), CD45 APC/Cyanine7 (clone HI30, Biolegend, no. 304014), CD197 (CCR7) PE/Cy7 (clone G043H7, Biolegend, no. 353225), CD49d Brilliant Violet 605 (clone 9F10, Biolegend, no. 304324), Foxp3 Pacific Blue (clone 206D, Biolegend, no. 320116), Foxp3 PE (clone 206D, Biolegend, no. 320108), CD127 PE (clone A019D5, Biolegend, no. 351304), CD16 PerCP/Cy5.5 (clone 3G8, Biolegend, no. 302028), CD16 Brilliant Violet 605 (clone 3G8, Biolegend, no. 302040), CD56 Brilliant Violet 605 (clone HCD56, Biolegend, no. 318334), IL-17A PE (clone BL168, Biolegend, no. 512306), IFN- $\gamma$ Brilliant Violet 421 (clone 4S.B3, Biolegend, no. 502532), CD279 (PD-1) Brilliant Violet 650 (clone EH12.2H7, Biolegend, no. 329950), CD185 (CXCR5) Alexa Fluor 700 (clone J252D4, Biolegend, no. 356916), pSTAT5 Pacific Blue (clone 47/Stat5(pY694), BD Biosciences, no. 560311), anti-human IL-2 APC (clone MQ1-17H12, Biolegend, no. 500310), anti-HHHHHH APC (clone J095G46, Biolegend, no. 362605), anti-HHHHHH Alexa Fluor ${ }^{\circledR} 647$ (clone J095G46, Biolegend, no. 362611). The following antibodies were used to stain mouse cells: CD3 APC/Cyanine7 (clone 17A2, Biolegend, no. 100222), CD3 Brilliant Violet 510 (clone 17A2, Biolegend, no. 100234), CD3 FITC (clone 17A2, Biolegend, no. 100203), CD4 PE/Cy7 (clone RM4-5, Biolegend, no. 100528), CD8a FITC (clone 53-6.7, Biolegend, no. 100706), CD25 APC (clone PC61, Biolegend, no. 102012), CD25 Brilliant Violet 650 (clone PC61, Biolegend, no. 102038), CD62L FITC (clone MEL-14, Biolegend, no. 104406), CD127 PE (clone A7R34, Biolegend, no. 135010), Foxp3 Pacific Blue (clone MF-14, Biolegend, no. 126410), Foxp3 Brilliant Violet 421 (clone MF-14, Biolegend, no. 126419), CD103 PerCP/Cy5.5 (clone 2E7, Biolegend, no. 121416), CTLA4 Brilliant Violet 605 (clone UC10-4B9, Biolegend, no. 106323), CD49b 
(pan-NK cells) PE (clone DX5, Biolegend, no. 108908), NK-1.1 FITC (clone PK136, Biolegend, no. 108706), CD69 APC/Cyanine7 (clone H1.2F3, Biolegend, no. 104526), CD314 (NKG2D) APC (clone CX5, Biolegend, no. 130212), CD335 (NKp46) Brilliant Violet 605 (clone 29A1.4, Biolegend, no. 137619), CD279 (PD-1) PE (clone RMP1-30, Biolegend, no. 109104), IL-17A PE (clone TC11-18H10.1, Biolegend, no. 506904), CD45.2 (Ly5.2) FITC (clone 104, Biolegend, no. 109806), CD11b FITC (clone M1/70, Biolegend, no. 101206), CD11c FITC (clone N418, Biolegend, no. 117305), CD45R/B220 FITC (clone RA3-6B2, Biolegend, no. 103205), CD31 APC (clone 390, Biolegend, no. 102410).

All FACs antibodies were used at a 1:50 dilution.

Validation

Validation of each antibody was carried out according to the standard information provided by the manufacturers' websites.

\section{Eukaryotic cell lines}

Policy information about cell lines

Cell line source(s)

The NK-derived YT cell line was kindly provided by Zhigang Tian, and was obtained via the National cancer institute ( $\mathrm{NCl}$, USA). The MDCK cell line was purchased from ATCC (ATCC No. CCL-34).

Authentication

CD25 expression of the YT cell line was analysed by flow cytometry. All lines authenticated with STR profiling.

Mycoplasma contamination All cells tested negative for mycoplasma.

Commonly misidentified lines (See ICLAC register)

No commonly misidentified cell lines were used.

\section{Animals and other organisms}

Policy information about studies involving animals; ARRIVE guidelines recommended for reporting animal research

Laboratory animals

BALB/c mice were 8-to-10-week-old females.

C57BL/6J (B6) mice were 8-to-10-week-old females.

NOD-SCID IL-2 receptor gamma null (NSG) mice were 8-to-10 week-old females.

$\mathrm{MRL} / \mathrm{lpr}$ mice were 4-week-old females.

DBA/1JNCrlj (DBA/1) mice were 8-to-10 week-old females.

The animals were housed at temperatures of $18-23^{\circ} \mathrm{C}, 40-60 \%$ humidity, 12 -hour-light/12-hour-dark cycles, and were allowed food and water ad libitum.

Wild animals

The study did not involve wild animals.

Field-collected samples

The study did not involve samples collected from the field.

Ethics oversight

The animal use protocol was reviewed and approved annually by the Ethics Review Board of PUMC Hospital, Chinese Academy of Medical Science (CAMS).

Note that full information on the approval of the study protocol must also be provided in the manuscript

\section{Human research participants}

Policy information about studies involving human research participants

Population characteristics Peripheral blood mononuclear cells were obtained from healthy donors and patient donors. Population characteristics were not available to the researchers.

Recruitment

Healthy and patient donors were recruited by advertising, and human blood samples from 20-to-50-year-old women were provided by our institution. There was no self-selection or any other bias.

Ethics oversight

All studies were approved by the Ethics Review Board of PUMC Hospital, Chinese Academy of Medical Science (CAMS).

Note that full information on the approval of the study protocol must also be provided in the manuscript.

\section{Flow Cytometry}

Plots

Confirm that:

Х The axis labels state the marker and fluorochrome used (e.g. CD4-FITC).

Х The axis scales are clearly visible. Include numbers along axes only for bottom left plot of group (a 'group' is an analysis of identical markers).

Х All plots are contour plots with outliers or pseudocolor plots.

Х A numerical value for number of cells or percentage (with statistics) is provided. 
For the in vitro PSTAT5 assay, hPBMCs were isolated from healthy and patient donors by Ficoll, and resuspended in RPMI $0.1 \%$ BSA. Cells were rested at $37^{\circ} \mathrm{C}$ in a T25 tissue flask until the time of assay (1-2 h). The rested cells were resuspended at $2 \times 10^{\wedge} 6 /$ $\mathrm{ml}$ in assay medium (RPMI, $0.1 \% \mathrm{BSA})$ and then aliquoted at $50 \mu \mathrm{l} /$ well $\left(1 \times 10^{\wedge} 5\right)$ into a 96 -well V-bottom plate. An equal volume of each protein sample was prepared in assay medium and added to the test wells in serial 5 -fold dilutions, and the cells were cultured in a $37^{\circ} \mathrm{C}$ incubator for $30 \mathrm{~min}$. Cells were fixed by the addition of $100 \mu \mathrm{l}$ of fixation buffer (BD Biosciences) and incubated at $37^{\circ} \mathrm{C}$ for $15 \mathrm{~min}$. After washing three times with D-PBS, assay plates were centrifuged to pellet the cells, and permeabilization buffer III (BD Biosciences) was used to resuspend the cells, followed by 15 min incubation on ice. The fixed and permeabilized cells were washed twice with FACS buffer and stained for flow cytometry.

For other in vitro and in vivo experiments, extracellular staining was performed in FACS buffer for 1 hour on ice followed by fixation using FoxP3 buffer kit (eBioscience) for $30 \mathrm{~min}$ on ice. Intracellular staining performed in permeabilization buffer provided in the FoxP3 buffer kit for 1 hour on ice.

Human blood samples were collected in purple-top tubes (BD Biosciences). Equal amount of cells was analysed for the majority of experiments performed. All FACS antibodies were used at 1:50 dilution. The stained cell suspensions were filtered through a 70-mm nylon cell strainer (BD Biosciences) before analysis.

Instrument

Software

Cell population abundance

Gating strategy
Data acquisitions were performed on LSR Fortessa (BD) and CytoFLEX (Beckman Coulter) as indicated in Methods. The comparative test between the two instruments has been carried out using a PSTAT5 assay, and no obvious systematic error was found.

Flow-cytometry data were analysed using FlowJo V10 and CytExpert (version 2.4), as indicated in Methods.

The purities of the sorted populations were generally greater than $90 \%$.

For experiments in pSTAT5 assay using purified subsets of immune cells, the purities of naïve CD4+, naïve CD8+, memory CD4+, memory CD8+ and NK cells were greater than 95\%, and the purity of expanded Treg cells was greater than 70\%.

For experiments in PSTAT5 assay, cells were gated on FSC/SSC according to cell size and granularity. Regulatory T cells were gated as CD3+CD4+CD25highCD127low, CD8 T cells were gated as CD3+CD4-CD8+, NK cells were gated as CD3-CD16+CD56+.

In the NSG expansion model, cells were gated on FSC/SSC according to cell size and granularity, then subsequently gated on hCD3+ viable cells to identify adoptively transferred PBMCs. Regulatory T cells were gated as anti-human CD3+CD4 + CD25highFoxp+, and the remaining cells were classified as conventional CD4+ T cells. CD8 T cells were gated as anti-human CD3 + CD4-CD8+.

For experiments in C57BL/6, CIA, MRL/Ipr, cells were gated on FSC/SSC according to cell size and granularity. Regulatory T cells were gated as anti mouse $C D 3+C D 4+C D 25$ highFoxp+, and the remaining cells were classified as conventional CD4+ T cells. CD8 T cells were gated as $\mathrm{CD} 3+\mathrm{CD} 8+$. IL-17 secreting CD4 T cells were gate as CD3+CD4+IL17A+. Follicular helper T cells were gate as CD3+CD4+CXCR5highPD-1high. NK cells were gated as CD45+CD3-NK1.1+. Pulmonary endothelial cells were gate as Ly5.2-B220CD3-NK1.1-CD11b-CD11c-CD31+.

For all FACS experiments, SSC-A/SSC-H plots were used to determine single population gates. Isotype controls were used to indicate the boundaries between positive and negative population.

$\bigotimes$ Tick this box to confirm that a figure exemplifying the gating strategy is provided in the Supplementary Information. 